\title{
Analysis of Unit-Level Changes in Operations with Increased SPP Wind from EPRI/LCG Balancing Study
}

November 2011

Prepared by

Stanton W. Hadley - ORNL 


\title{
DOCUMENT AVAILABILITY
}

Reports produced after January 1, 1996, are generally available free via the U.S. Department of Energy (DOE) Information Bridge:

Web site: http://www.osti.gov/bridge

Reports produced before January 1, 1996, may be purchased by members of the public from the following source:

National Technical Information Service

5285 Port Royal Road

Springfield, VA 22161

Telephone: 703-605-6000 (1-800-553-6847)

TDD: $703-487-4639$

Fax: 703-605-6900

E-mail: info@ntis.fedworld.gov

Web site: http://www.ntis.gov/support/ordernowabout.htm

Reports are available to DOE employees, DOE contractors, Energy Technology Data Exchange (ETDE) representatives, and International Nuclear Information System (INIS) representatives from the following source:

Office of Scientific and Technical Information

P.O. Box 62

Oak Ridge, TN 37831

Telephone: 865-576-8401

Fax: 865-576-5728

E-mail: reports@adonis.osti.gov

Web site: http://www.osti.gov/contact.html

\begin{abstract}
This report was prepared as an account of work sponsored by an agency of the United States Government. Neither the United States government nor any agency thereof, nor any of their employees, makes any warranty, express or implied, or assumes any legal liability or responsibility for the accuracy, completeness, or usefulness of any information, apparatus, product, or process disclosed, or represents that its use would not infringe privately owned rights. Reference herein to any specific commercial product, process, or service by trade name, trademark, manufacturer, or otherwise, does not necessarily constitute or imply its endorsement, recommendation, or favoring by the United States Government or any agency thereof. The views and opinions of authors expressed herein do not necessarily state or reflect those of the United States Government or any agency thereof.
\end{abstract}




\section{Analysis of Unit-Level Changes in Operations with Increased SPP Wind from EPRI/LCG Balancing Study}

Stanton W. Hadley - ORNL

November 2011

OAK RIDGE NATIONAL LABORATORY

Oak Ridge, Tennessee 37831 managed by

UT-BATTELLE, LLC

for the

U.S. DEPARTMENT OF ENERGY

under contract No. DE-AC05-00OR22725 



\section{CONTENTS}

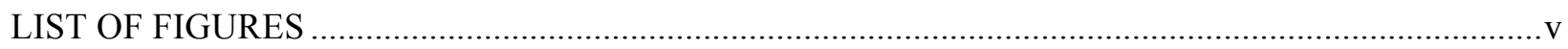

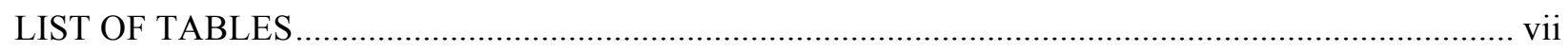

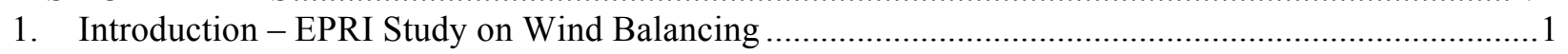

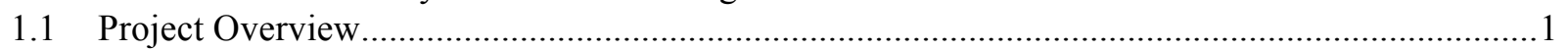

1.2 Report Structure and Relation to Previous Project Reports ..................................................

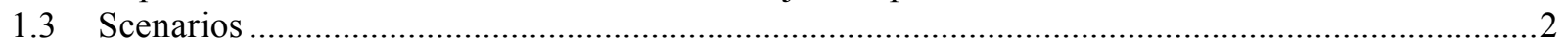

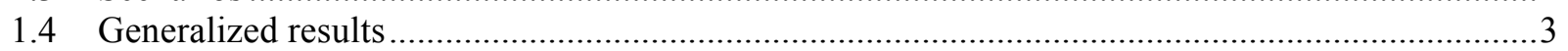

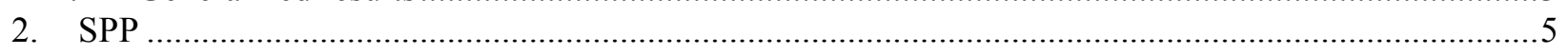

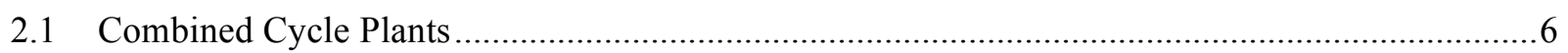

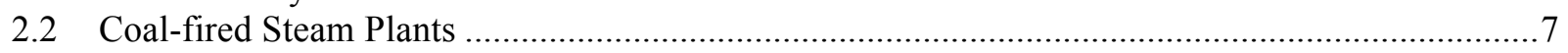

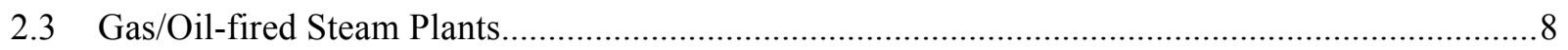

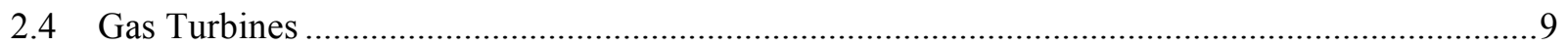

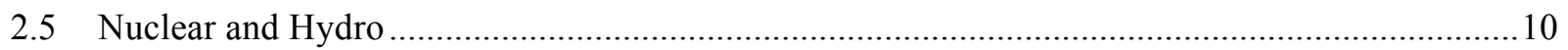

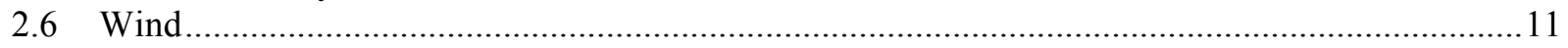

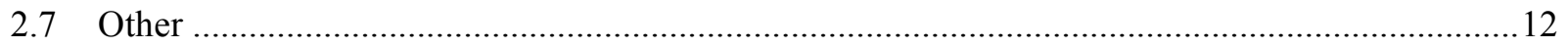

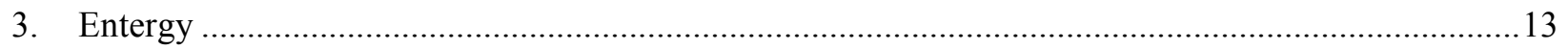

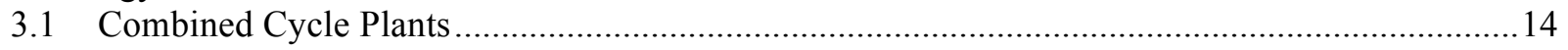

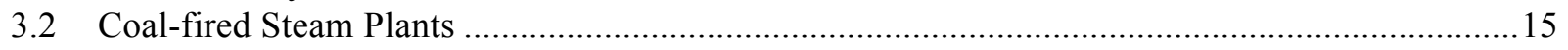

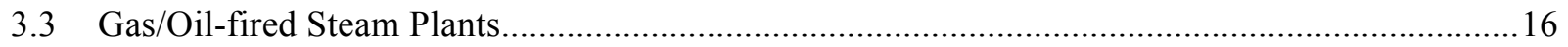

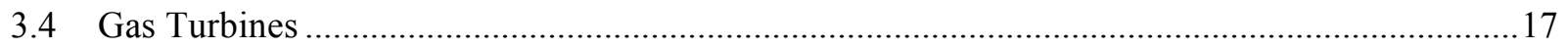

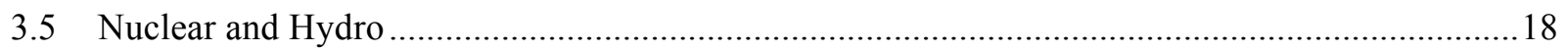

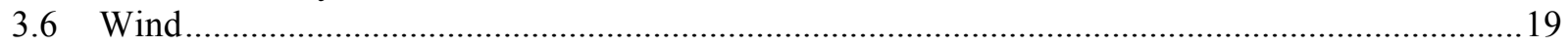

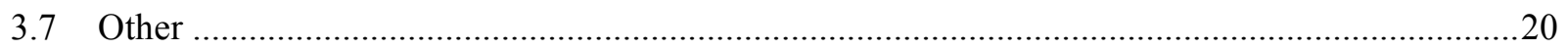

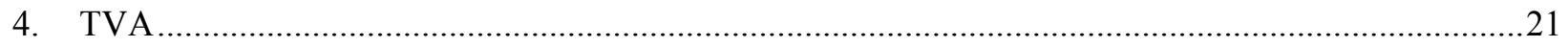

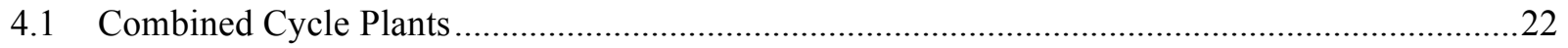

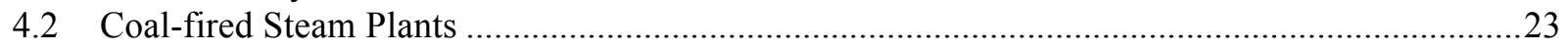

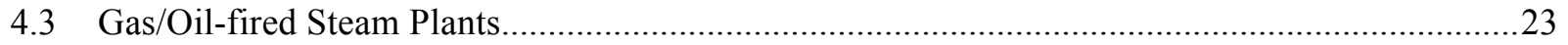

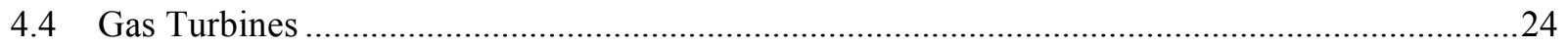

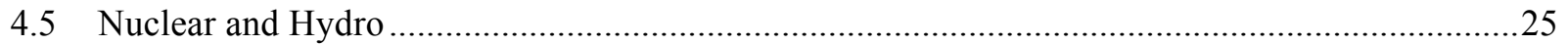

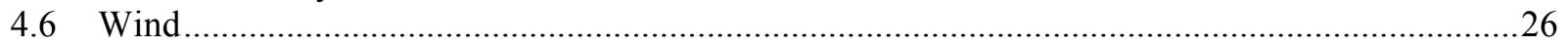

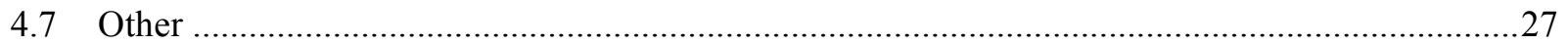

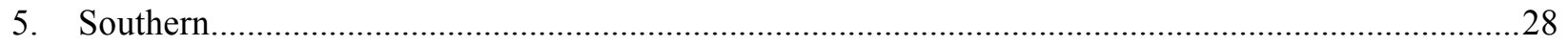

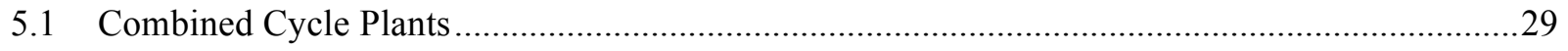

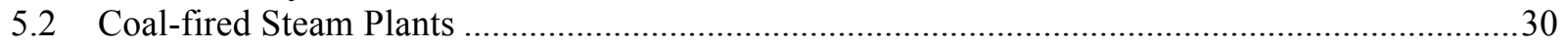

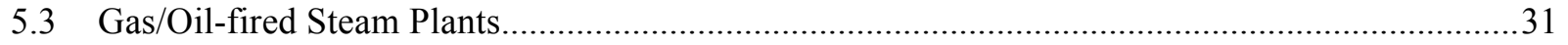

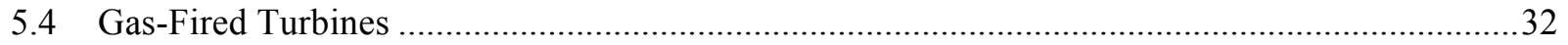

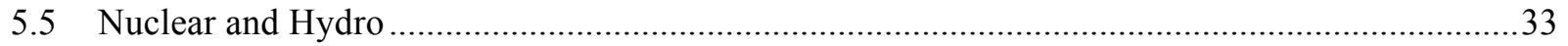

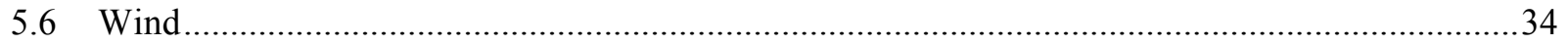

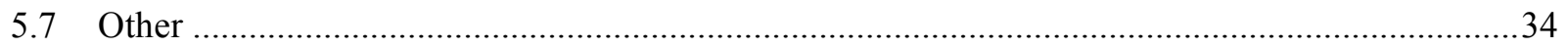

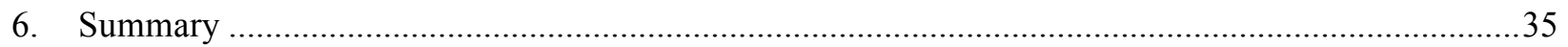

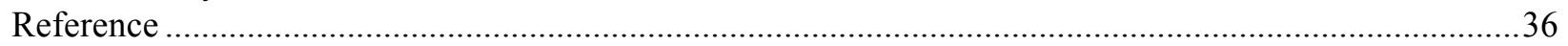





\section{LIST OF FIGURES}

Figure 1. Entergy Gas/Oil-fired Steam Plant Capacity Factors 3

Figure 2. SPP Combined Cycle Capacity Factors 6

Figure 3. SPP Combined Cycle \# of Start-Ups 6

Figure 4. SPP Coal-fired Steam Plant Capacity Factors 7

Figure 5. SPP Coal-fired Steam Plant \# of Start-Ups 7

Figure 6. SPP Gas/Oil-fired Steam Plant Capacity Factors 8

Figure 7. SPP Gas/Oil-fired Steam Plant \# of Start-Ups 8

Figure 8. SPP Gas Turbine Capacity Factors 9

Figure 9. SPP Gas Turbine \# of Start-Ups 9

Figure 10. SPP Nuclear and Hydro Capacity Factors 10

Figure 11. SPP Nuclear and Hydro \# of Start-Ups 10

Figure 12. SPP Wind Capacity Factors

Figure 13. SPP Wind \# of Start-Ups 11

Figure 14. SPP Other Capacity Factors 12

Figure 15. SPP Other \# of Start-Ups 12

Figure 16. Entergy Combined Cycle Capacity Factors 14

Figure 17. Entergy Combined Cycle \# of Start-Ups 14

Figure 18. Entergy Coal-fired Steam Plant Capacity Factors 15

Figure 19. Entergy Coal-fired Steam Plant \# of Start-Ups 15

Figure 20. Entergy Gas/Oil-fired Steam Plant Capacity Factors 16

Figure 21. Entergy Gas/Oil-fired Steam Plant \# of Start-Ups 16

Figure 22. Entergy Gas Turbine Capacity Factors 17

Figure 23. Entergy Gas Turbine \# of Start-Ups 17

Figure 24. Entergy Nuclear and Hydro Capacity Factors 18

Figure 25. Entergy Nuclear and Hydro \# of Start-Ups 18

Figure 26. Entergy Wind Capacity Factors 19

Figure 27. Entergy Wind \# of Start-Ups 19

Figure 28. Entergy Other Capacity Factors 20

$\begin{array}{ll}\text { Figure 29. Entergy Other \# of Start-Ups } & 20\end{array}$

Figure 30. TVA Combined Cycle Capacity Factors 22

Figure 31. TVA Combined Cycle \# of Start-Ups 22

Figure 32. TVA Coal-fired Steam Plant Capacity Factors 23 
Figure 33. TVA Coal-fired Steam Plant \# of Start-Ups

Figure 34. TVA Gas Turbine Capacity Factors

Figure 35. TVA Gas Turbine \# of Start-Ups

Figure 36. TVA Nuclear and Hydro Capacity Factors

Figure 37. TVA Nuclear and Hydro \# of Start-Ups

Figure 38. TVA Wind Capacity Factors

Figure 39. TVA Wind \# of Start-Ups

Figure 40. TVA Other Capacity Factors

Figure 41. TVA Other \# of Start-Ups

Figure 42. Southern Combined Cycle Capacity Factors

Figure 43. Southern Combined Cycle \# of Start-Ups

Figure 44. Southern Coal-fired Steam Plant Capacity Factors 30

Figure 45. Southern Coal-fired Steam Plant \# of Start-Ups 30

Figure 46. Southern Gas/Oil-fired Steam Plant Capacity Factors

Figure 47. Southern Gas/Oil-fired Steam Plant \# of Start-Ups

Figure 48. Southern Gas Turbine Capacity Factors

Figure 49. Southern Gas Turbine \# of Start-Ups

Figure 50. Southern Nuclear and Hydro Capacity Factors

Figure 51. Southern Nuclear and Hydro \# of Start-Ups

Figure 52. Southern Other Capacity Factors 34

Figure 53. Southern Other \# of Start-Ups 


\section{LIST OF TABLES}

Table 1. Scenarios parameters used in Study 2

Table 2. Mix of Units in SPP 5

Table 3. Mix of Units in Entergy

Table 4. Mix of Units in TVA

Table 5. Mix of Units in Southern 



\section{Introduction - EPRI Study on Wind Balancing}

\subsection{Project Overview}

Wind power development in the United States is outpacing previous estimates for many regions, particularly those with good wind resources. The pace of wind power deployment may soon outstrip regional capabilities to provide transmission and integration services to achieve the most economic power system operation. Conversely, regions such as the Southeastern United States do not have good wind resources and will have difficulty meeting proposed federal Renewable Portfolio Standards with local supply. There is a growing need to explore innovative solutions for collaborating between regions to achieve the least cost solution for meeting such a renewable energy mandate.

The Department of Energy funded the project "Integrating Midwest Wind Energy into Southeast Electricity Markets" to be led by EPRI in coordination with the main authorities for the regions: SPP, Entergy, TVA, Southern Company and OPC. EPRI utilized several subcontractors for the project including LCG, the developers of the model UPLAN. The study aims to evaluate the operating cost benefits of coordination of scheduling and balancing for Southwest Power Pool (SPP) wind transfers to Southeastern Electric Reliability Council (SERC) Balancing Authorities (BAs). The primary objective of this project is to analyze the benefits of regional cooperation for integrating mid-western wind energy into southeast electricity markets. Scenarios were defined, modeled and investigated to address production variability and uncertainty and the associated balancing of large quantities of wind power in SPP and delivery to energy markets in the southern regions of the SERC.

DOE funded Oak Ridge National Laboratory to provide additional support to the project, including a review of results and any side analysis that may provide additional insight. This report is a unit-by-unit analysis of changes in operations due to the different scenarios used in the overall study. It focuses on the change in capacity factors and the number of start-ups required for each unit since those criteria summarize key aspects of plant operations, how often are they called upon and how much do they operate.

The primary analysis of the overall project is based on security-constrained unit commitment (SCUC) and economic dispatch (SCED) simulations of the SPP-SERC regions as modeled for the year 2022. The SCUC/SCED models utilized for the project were developed through extensive consultation with the project utility partners, to ensure the various regions and operational practices are represented as best as possible in the model. SPP, Entergy, Oglethorpe Power Company (OPC), Southern Company, and the Tennessee Valley Authority (TVA) actively participated in the project providing input data for the models and review of simulation results and conclusions. While other SERC utility systems are modeled, the listed SERC utilities were explicitly included as active participants in the project due to the size of their load and relative proximity to SPP for importing wind energy.

\subsection{Report Structure and Relation to Previous Project Reports}

While the main report (EPRI 2011) summarizes the key results from the study, this report covers a sideanalysis that compared the unit-by-unit results for the different utilities under the different scenarios. It is an expansion of the information in the main report's appendices. The chapters provide the results for each of the main participants in the study: SPP, Entergy, TVA, and Southern regions (including both Southern Company and OPC.) Each chapter begins with a table of the number of units by technology type within the region and associated peak capacity. They then show figures for the capacity factors and number of starts for each technology type for each planning authority. 
LCG's Network Power Model (UPLAN) is an integrated electricity generation and transmission model developed to simulate both the behavior of market participants and the physical features of the electricity system. UPLAN is a full network model designed for electricity market simulation, replicating the engineering protocols and market procedures of an operator, and captures the commercial activities, such as bidding, trading, hedging, and contracting, of all players in a restructured power market. The model performs coordinated marginal (opportunity) cost-based energy and ancillary service procurement, congestion management, full-fledged contingency analysis with Security Constrained Unit Commitment (SCUC) and Security Constrained Economic Dispatch (SCED). Further detail on the model and the specifics of the cases simulated can be found in the main report or in interim reports provided by EPRI to DOE.

It should be noted that the High Wind Transfer SCUC/SCED models and associated simulation results presented in this report are to be used to compare different methods of balancing high penetrations of wind being moved from SPP to the relevant SERC areas. The model's purpose is not to give absolute answers on the operation of such systems with high amounts of wind, but rather to be used as a tool to compare strategies, based on certain input assumptions on wind, demand, unit parameters, reserve provisions, etc. Therefore, the absolute answers are meaningful only within the specific context of a particular study and can be extremely misleading if applied outside of that context.

\subsection{Scenarios}

One analysis simulated the addition of $14 \mathrm{GW}$ of wind within the SPP and SERC regions to represent a doubling of the current $7 \mathrm{GW}$ of wind capacity. Four high-wind cases were run that assumed $48 \mathrm{GW}$ of wind in the region to correspond to the amount needed to meet a 20\% Renewable Portfolio Standard for the SERC-SPP region as a whole. The variations on these cases were:

Scenario 1. SPP manages intra-hour variability for all wind (Base Case).

Scenario 2. Each region manages intra-hour variability for the wind assigned to their region.

Scenario 3. All regions are combined into a single super-region and intra-hour variability is managed jointly, with hurdle rates between regions.

Scenario 4. All regions are combined into a single super-region and intra-hour variability is managed jointly, without hurdle rates between regions.

A "Scenario 1 proxy" was also run that uses just the reserve requirements from the original $7 \mathrm{GW}$ wind case and assumes perfect forecasting of wind. This case was analyzed to evaluate the balancing costs that wind imposes on the system. Table 1 below presents key information about each of the scenarios presented in this report. More detail on these cases is available in the full report, DOE: Integrating Midwest Wind Energy into Southeast Electricity Markets (EPRI 2011).

Table 1. Scenarios parameters used in Study

\begin{tabular}{|c|c|c|c|c|}
\hline Scenario & Wind Amount & Variability Managed by & Hurdle rates & Notes \\
\hline Scenario 1 (Base) & $48 \mathrm{GW}$ & SPP & Standard & \\
\hline Scenario 2 & $48 \mathrm{GW}$ & $\begin{array}{l}\text { Each manages their } \\
\text { share of wind }\end{array}$ & Standard & \\
\hline Scenario 3 & $48 \mathrm{GW}$ & $\begin{array}{l}\text { Jointly by all regions } \\
\text { combined }\end{array}$ & Standard & \\
\hline Scenario 4 & $48 \mathrm{GW}$ & $\begin{array}{l}\text { Jointly by all regions } \\
\text { combined }\end{array}$ & None & \\
\hline Scenario 1 (proxy) & $48 \mathrm{GW}$ & SPP & Standard & $\begin{array}{l}\text { Lowered reserve } \\
\text { requirements and } \\
\text { perfect forecasting }\end{array}$ \\
\hline $14 \mathrm{GW}$ Unconstrained & $14 \mathrm{GW}$ & SPP & Standard & \\
\hline
\end{tabular}




\subsection{Generalized results}

Each chapter below details the generation mix and unit-level graphs of capacity factor and number of start-ups for each of the four balancing authority regions: SPP, Entergy, TVA, and Southern. The tables at the start of each chapter present the number of units and capacity by technology type as modeled in UPLAN. These present a picture of the mix of technologies so that the individual technology sections below in each chapter can be seen in perspective of their overall contribution.

For the graphs in the following sections, the X-axis shows the results (capacity factor or number of starts) for each power plant unit in the given region and technology in Scenario 1. This scenario is to represent a "base case" in which a large amount of wind is built but SPP is required to manage the intra-hour variability. The four other scenarios with $48 \mathrm{GW}$ of wind, plus the scenario with only $14 \mathrm{GW}$ of wind but otherwise unconstrained, are plotted along the y-axis. Consequently, each unit will have a single $\mathrm{x}$-value, but up to five y-values. Consequently, it would show up in the graph in a vertical column with different marker shapes and colors for the different scenarios. Each unit in the UPLAN model will have a separate marker along the $\mathrm{x}$ - and $\mathrm{y}$-axes, although two units with the same values in both Scenario 1 and another scenario will lie on top of each other.

A line labeled "Equal" is also on each graph that represents all points where the $\mathrm{x}$ - and $\mathrm{y}$-values are equal. If the values are the same in both scenarios then the point will lie along the "Equal" dashed line. If the values in the alternate scenarios are lower than Scenario 1 then the points will fall below the "Equal" line, while higher values in the other scenarios will be above the "Equal" line.

For example, Figure 1 shows the capacity factors for the gas and oil-fired steam units in Entergy. One unit had a capacity factor of $15 \%$ in Scenario 1 (the far right set of points in the graph). In Scenarios 2, 3, and 1 (proxy), the plant had about the same capacity factor so the points sit on top of each other on the "Equal" line. In Scenario 4, that plant operated slightly less and so had a capacity factor lower than the "Equal" line, while in the $14 \mathrm{GW}$ scenario, the plant operated more and had a capacity factor near $24 \%$; its point is well above the others.

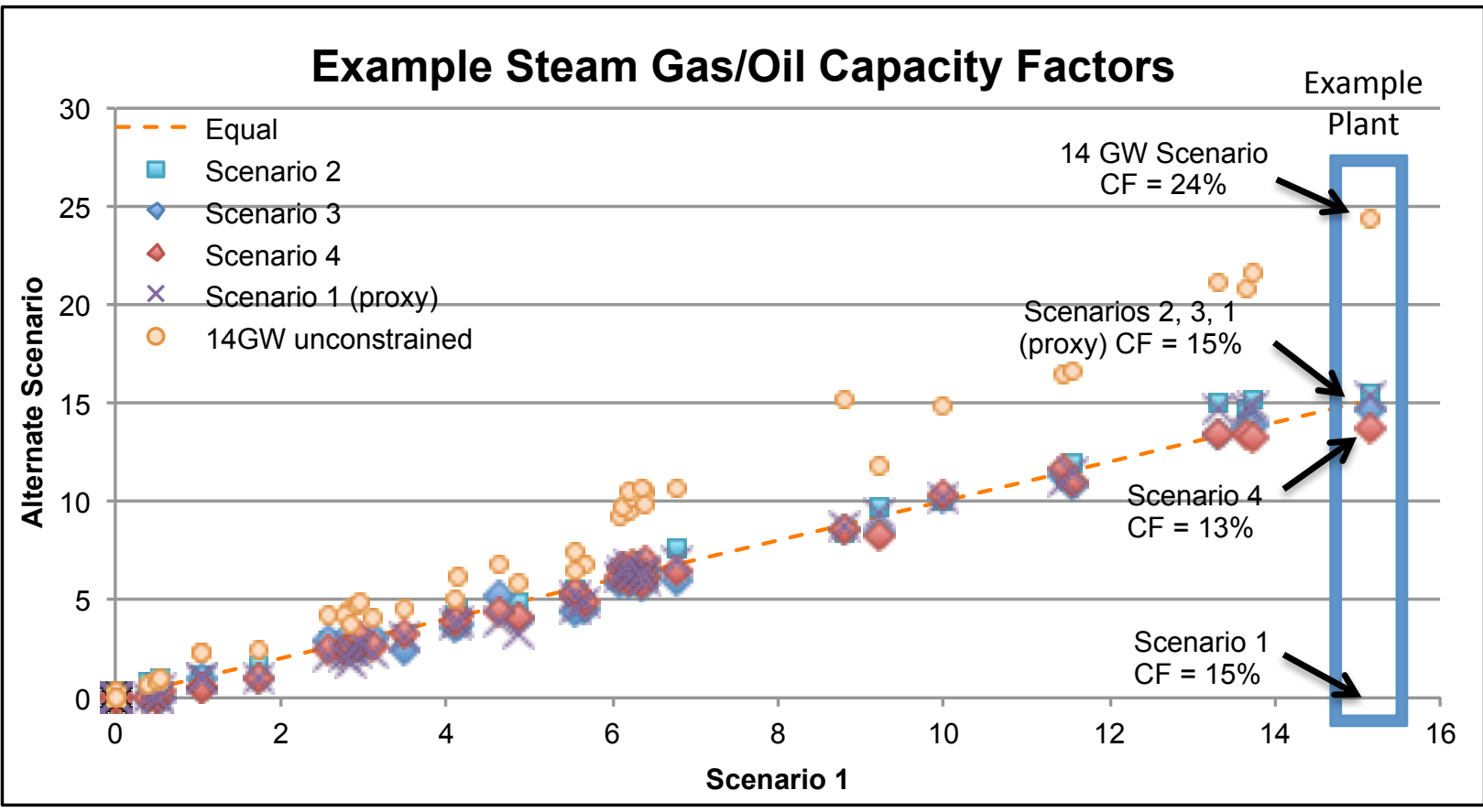

Figure 1. Entergy Gas/Oil-fired Steam Plant Capacity Factors 
Unit-Level Changes from Increased SPP Wind Study 


\section{SPP}

In the scenario with just $14 \mathrm{GW}$ of wind capacity, SPP has a diverse spread of power technologies. According to Table 2, 31\% of their capacity mix is coal-fired and $41 \%$ from gas (with a small share of this possibly oil.) Even with the smaller wind expansion to $14 \mathrm{GW}, 17 \%$ of the region's capacity mix is expected to come from wind. There are only three nuclear units in the region, one in Kansas and two in Nebraska.

In the $48 \mathrm{GW}$ wind scenarios (Scenarios 1-4 and Scenario 1 (proxy)), most of the added wind capacity is built in the SPP region, with capacity rising from $14 \mathrm{GW}$ to $46 \mathrm{GW}$. This raises the percentage of capacity mix from wind to $40 \%$, lowering the percentages from other technologies accordingly.

Table 2. Mix of Units in SPP

\begin{tabular}{|c|c|c|c|c|}
\hline & $\begin{array}{c}\text { Number of } \\
\text { Units }\end{array}$ & Capacity (MW) & $\begin{array}{c}\text { Capacity Mix } \\
\text { with } 14 \mathrm{GW} \text { wind }\end{array}$ & $\begin{array}{c}\text { Capacity Mix } \\
\text { with } 48 \mathrm{GW} \text { wind }\end{array}$ \\
\hline Combine Cycle & 79 & 11,394 & $14 \%$ & $10 \%$ \\
\hline Steam Coal & 93 & 25,605 & $31 \%$ & $23 \%$ \\
\hline Steam Gas/Oil & 137 & 13,097 & $16 \%$ & $12 \%$ \\
\hline Gas Turbine & 176 & 10,111 & $12 \%$ & $9 \%$ \\
\hline Nuclear & 3 & 2,468 & $3 \%$ & $2 \%$ \\
\hline Hydro & 88 & 2,796 & $3 \%$ & $2 \%$ \\
\hline Wind (14 GW / 48 GW Scenarios) & $72 / 150$ & $14,388 / 45,536$ & $17 \%$ & $40 \%$ \\
\hline Other & 182 & 2,473 & $3 \%$ & $2 \%$ \\
\hline Total & $830 / 908$ & $82,333 / 113,481$ & $100 \%$ & $100 \%$ \\
\hline
\end{tabular}




\subsection{Combined Cycle Plants}

With only $14 \mathrm{GW}$ of wind, the combined cycle plants are use more in the $14 \mathrm{GW}$ unconstrained scenario, resulting generally in higher capacity factors (above the "Equal" line.) With the $48 \mathrm{GW}$ of wind in Scenarios 2-4, the capacity factors are lower than in Scenario 1. This is because Scenario 1 requires all balancing of wind in SPP and this is done through increased use of combined cycle capacity (along with combustion turbine capacity described below.)

Combined cycle plants have both lower capacity factors and increased number of start-ups. While normally one would think that reduced production would mean fewer start-ups, it depends on how the plants are operated. Rather than being kept running at partial capacity, the plants are shut down during off-hours and restarted the next day, thereby increasing the number of starts.

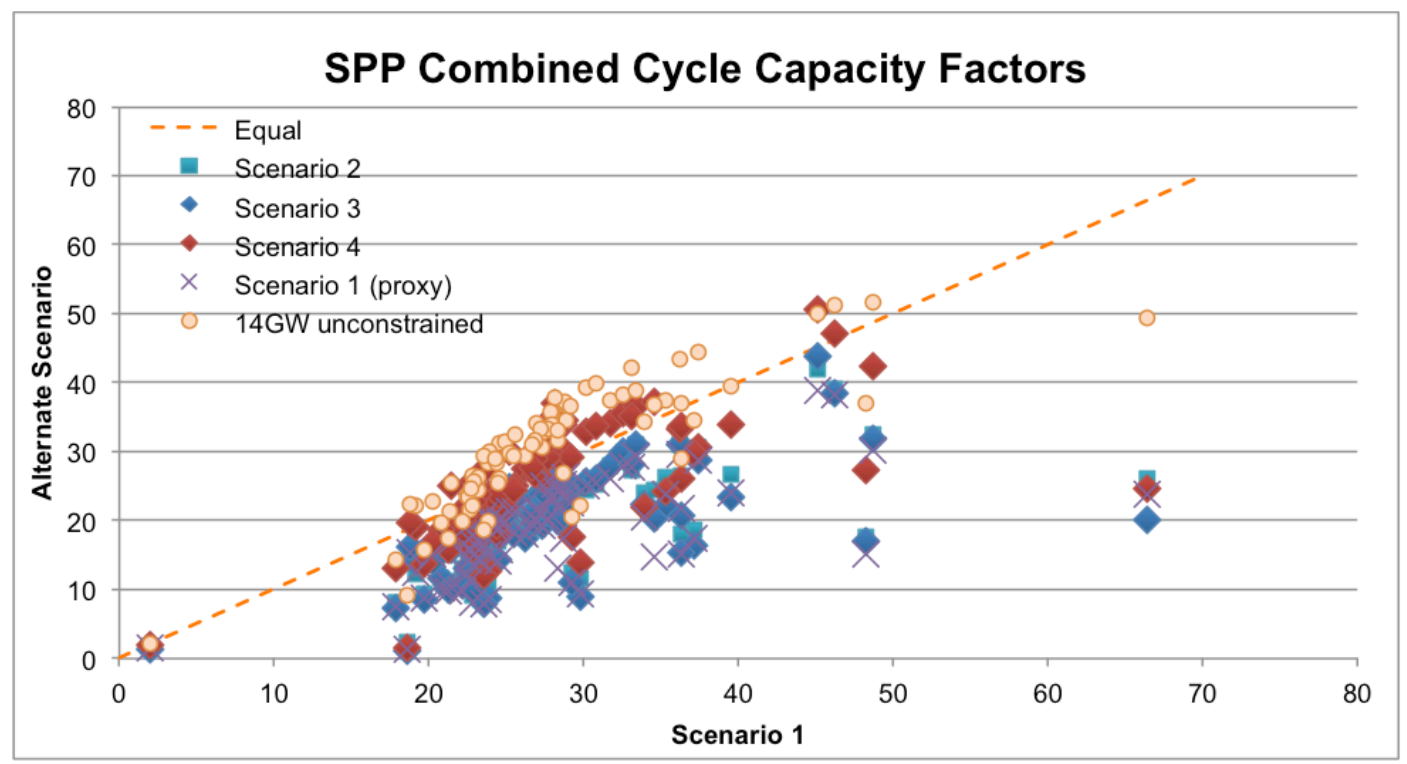

Figure 2. SPP Combined Cycle Capacity Factors

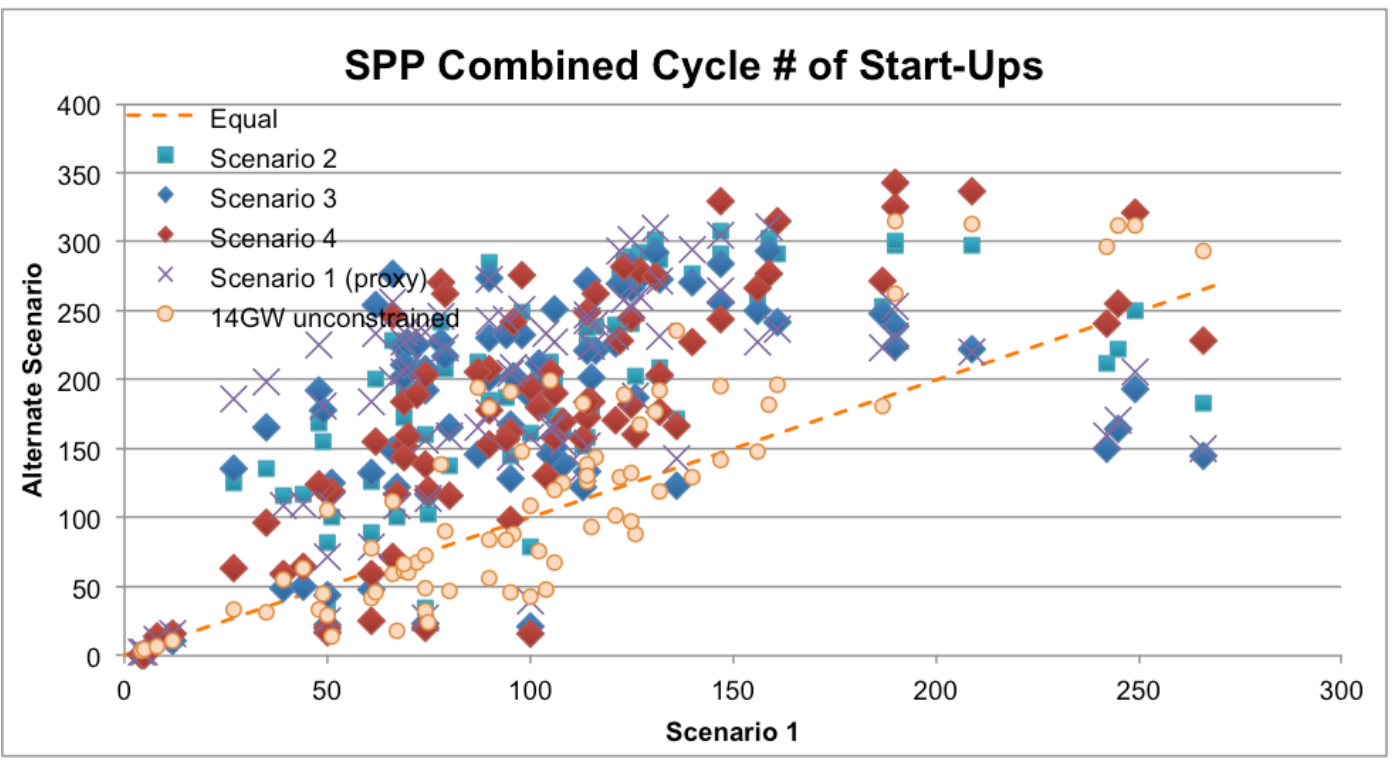

Figure 3. SPP Combined Cycle \# of Start-Ups 


\subsection{Coal-fired Steam Plants}

Most of the coal units have increased capacity factors in the $14 \mathrm{GW}$ and alternate $48 \mathrm{GW}$ wind scenarios as compared to Scenario 1. Balancing operations could be performed by flexible units in other regions, allowing more of the low cost coal plants to be used as base load. There is an exception for a few of the least efficient coal plants that have the lowest capacity factors; these reduce their operation with the sharing of balancing operations.

Many of the coal plants have less than ten start-ups over the year while a few have closer to 35 . The latter are likely less efficient, more expensive, and so shut down during common times of low demands such as weekends.

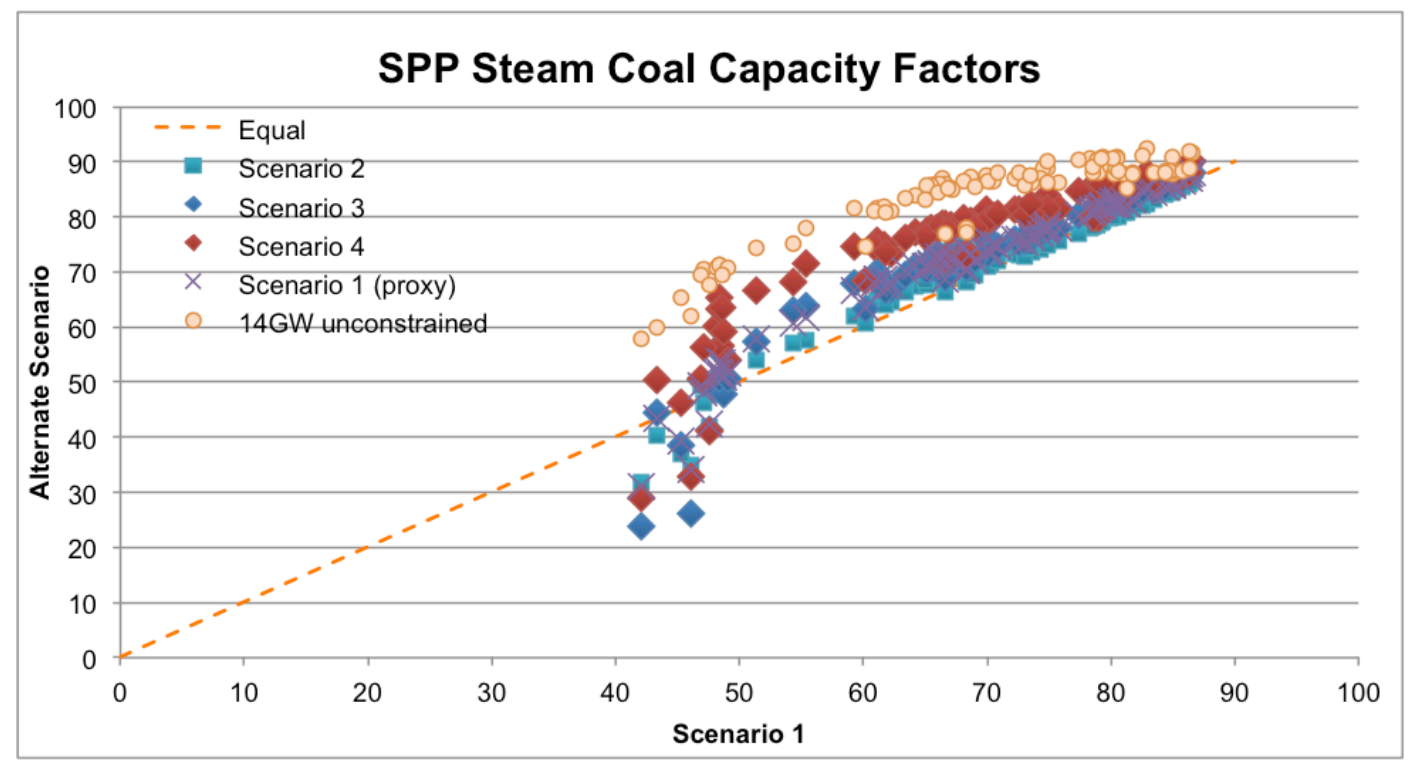

Figure 4. SPP Coal-fired Steam Plant Capacity Factors

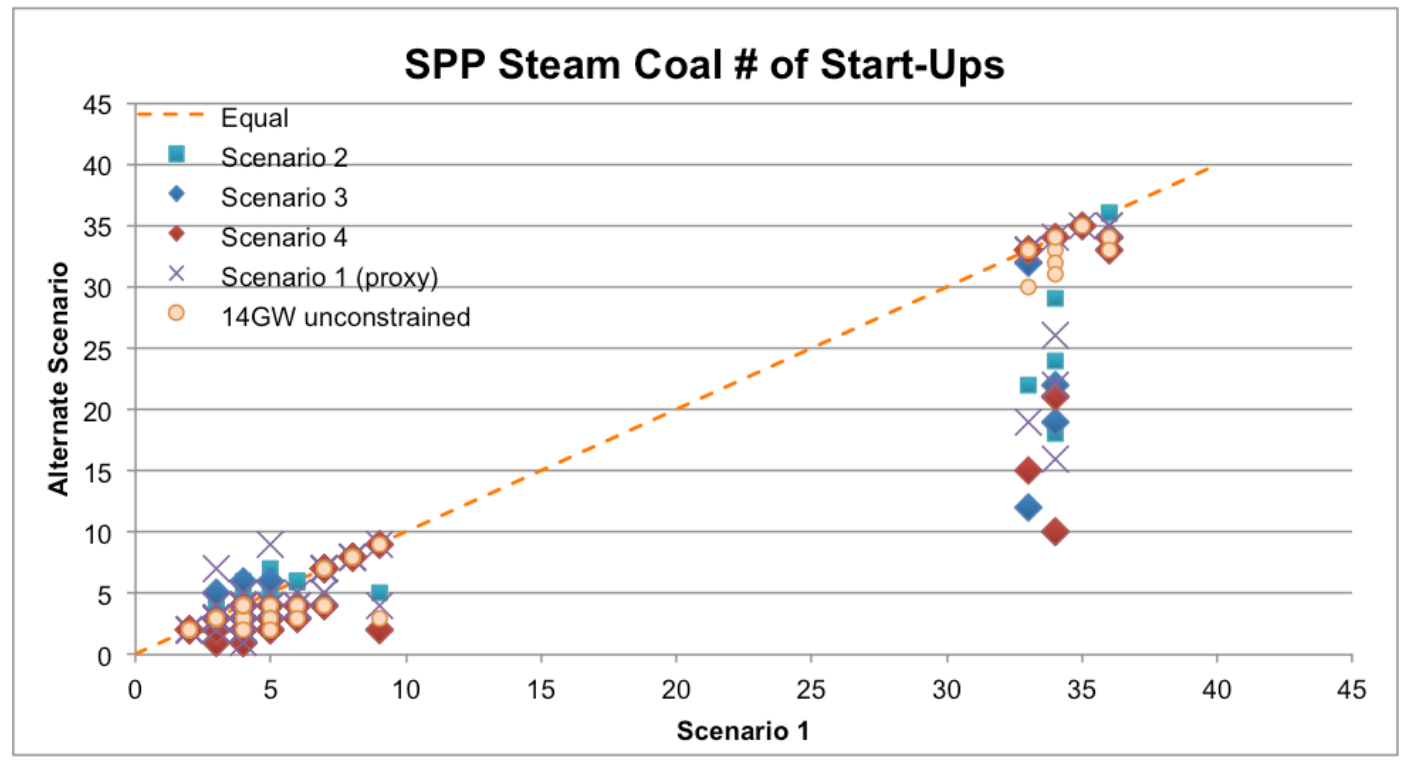

Figure 5. SPP Coal-fired Steam Plant \# of Start-Ups 


\subsection{Gas/Oil-fired Steam Plants}

The gas/oil steam plants are rarely used, with capacity factors below 1\%. Many of the plants are essentially shut down with the extra wind capacity, with capacity factors at zero. This applies mostly to those with shared balancing between regions. Start-ups for the most part are less than 50 for Scenario 1 and less than 20 for the other scenarios.

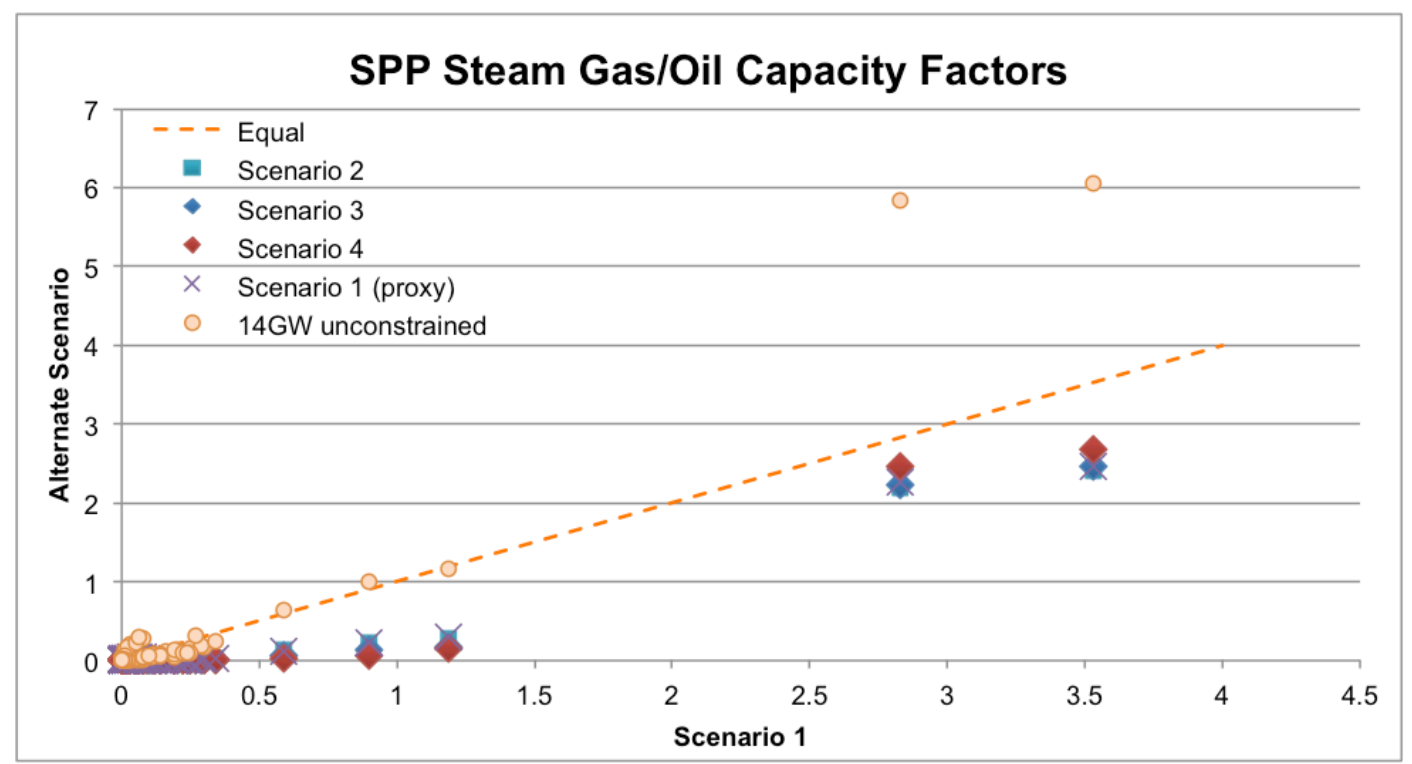

Figure 6. SPP Gas/Oil-fired Steam Plant Capacity Factors

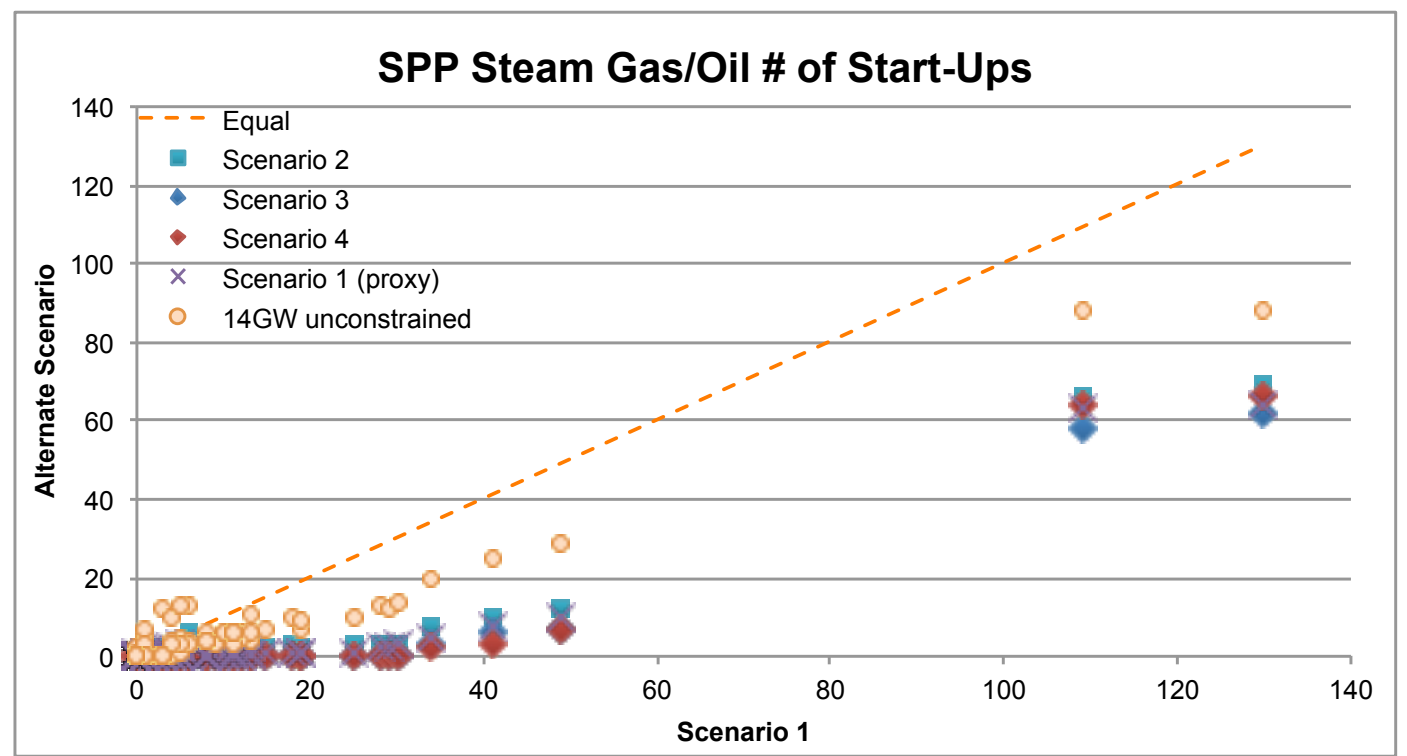

Figure 7. SPP Gas/Oil-fired Steam Plant \# of Start-Ups 


\subsection{Gas Turbines}

Gas turbines are used for balancing and peaking operations. As such, they have low capacity factors below $16 \%$ and many start-ups. One gas turbine reports a high capacity factor out of the UPLAN model; it appears to be an independent industrial facility so may have lowered costs of operation. All of the alternate scenarios have many fewer start-ups than Scenario 1. The latter relies on gas turbines for most of the balancing of the added wind in the region, which creates more variability on their operation.

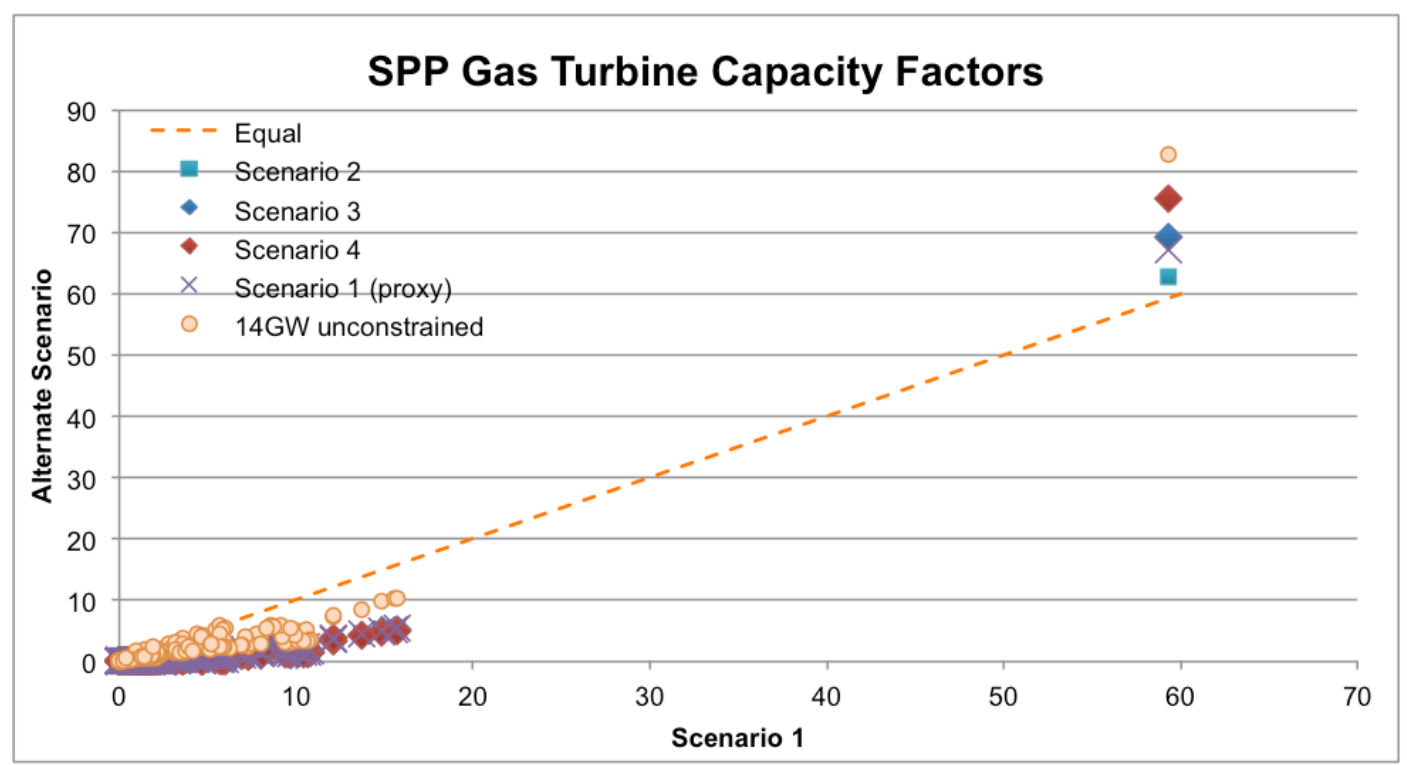

Figure 8. SPP Gas Turbine Capacity Factors

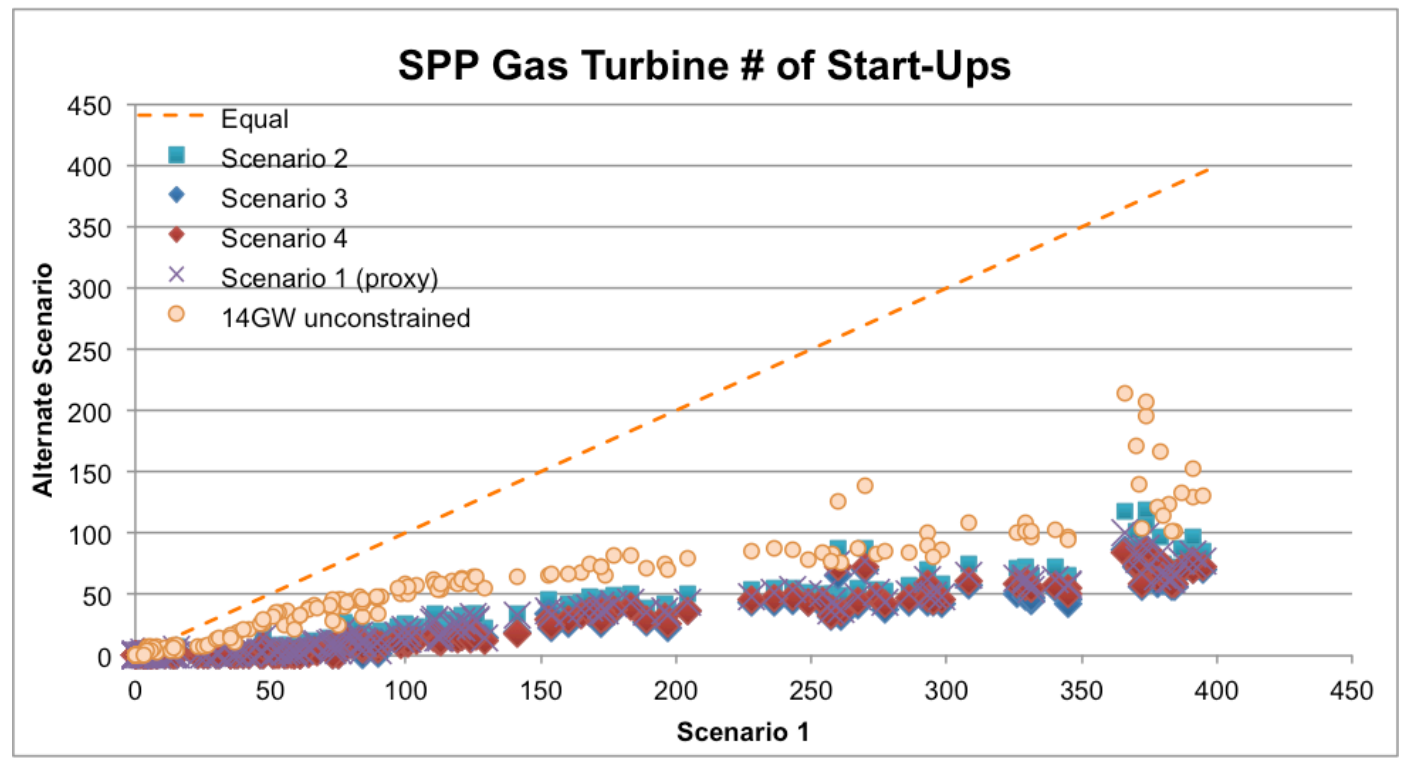

Figure 9. SPP Gas Turbine \# of Start-Ups 


\subsection{Nuclear and Hydro}

The three nuclear plants have high capacity factors and only one or two start-ups during the year. Most hydro plants show no start-ups during the year but have a variety of capacity factors. This is likely due to the method that UPLAN uses to model hydro plants. A few of the hydro plants do show frequent start-ups but most are probably required to have at least a minimum flow of water and consequent generation at al times. UPLAN is capable of simulating different types of generators such as thermal, hydro, wind and renewable, cogeneration and many other technologies. An in-line hydro scheduler dispatches hydro, pumped storage and CAES units daily and hourly to maximize net income.

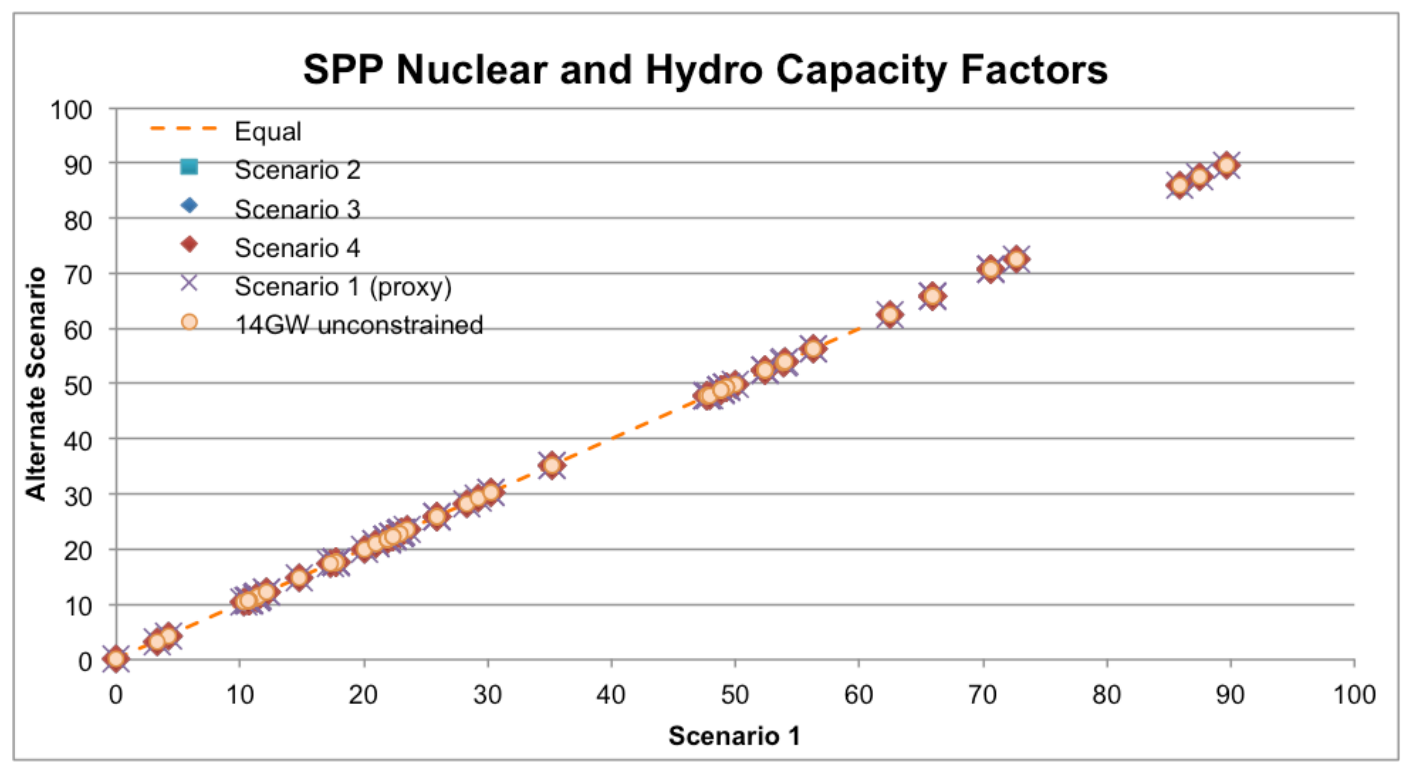

Figure 10. SPP Nuclear and Hydro Capacity Factors

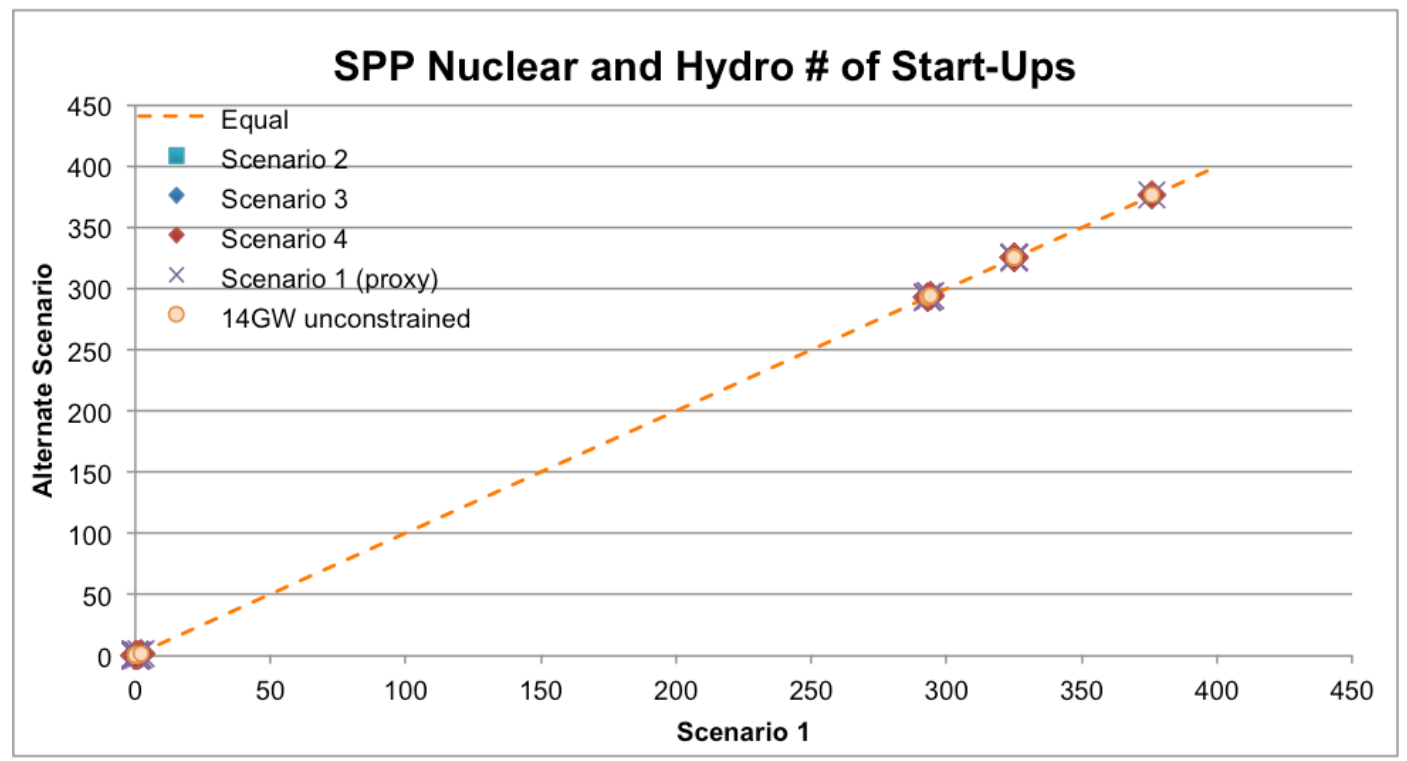

Figure 11. SPP Nuclear and Hydro \# of Start-Ups 


\subsection{Wind}

Different wind plant expansions are defined for the $14 \mathrm{GW}$ and $48 \mathrm{GW}$ scenarios and so the specific plants have different names. This means the $14 \mathrm{GW}$ plants cannot be graphed in comparison to their Scenario 1 values. In the other scenarios, the capacity factors are not much impacted by the scenario the plants are used in, so all fall along the "Equal" line. The variation in capacity factor is due to different wind resources available at the different sites. The number of start-ups are slightly affected..

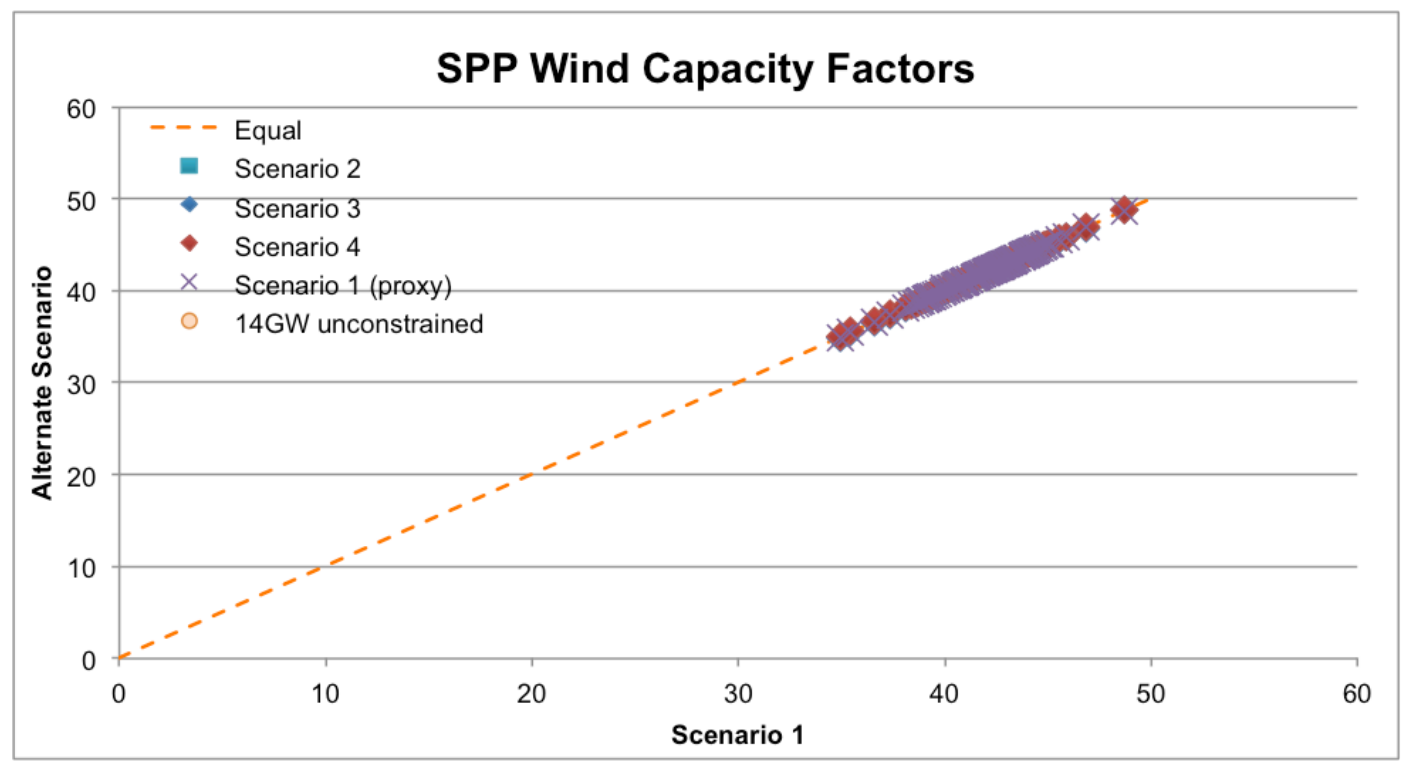

Figure 12. SPP Wind Capacity Factors

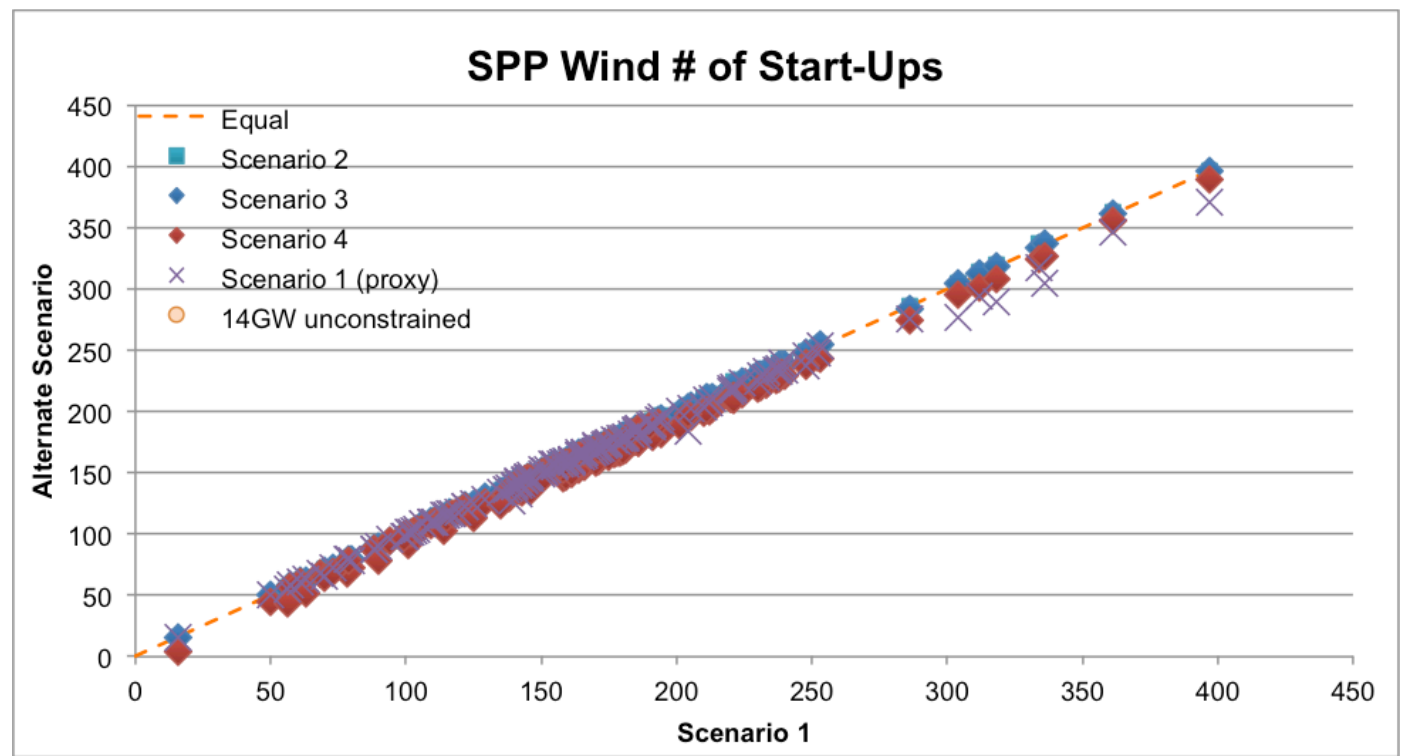

Figure 13. SPP Wind \# of Start-Ups 


\subsection{Other}

"Other" plants include internal combustion engines and distributed generation across the region. They are generally small in size. Most run only sporadically; only 14 of the 182 plants have a capacity factor greater than $2.5 \%$ in Scenario 1 . The category also includes advanced technologies such as fluidized bed coal-fired plants, advanced combustion turbines, and biomass plants. The plants with the large variation in capacity factors are these coal, natural gas, wood waste, and municipal waste plants. These provide the bulk of the generation from this segment. The three units with high start-ups are gas-fired turbines at Anadarko and so are used as intermediate to peaking capacity, with capacity factors a little over $20 \%$.

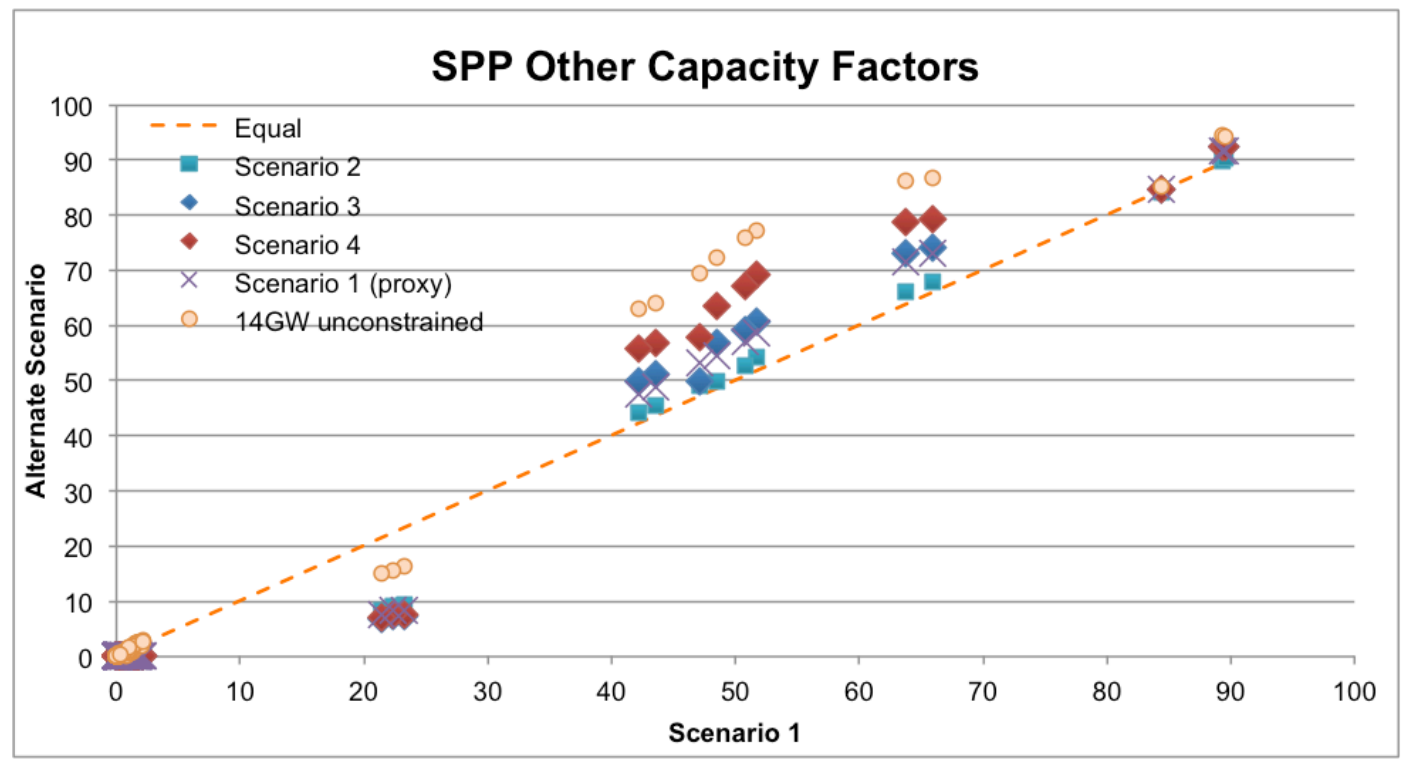

Figure 14. SPP Other Capacity Factors

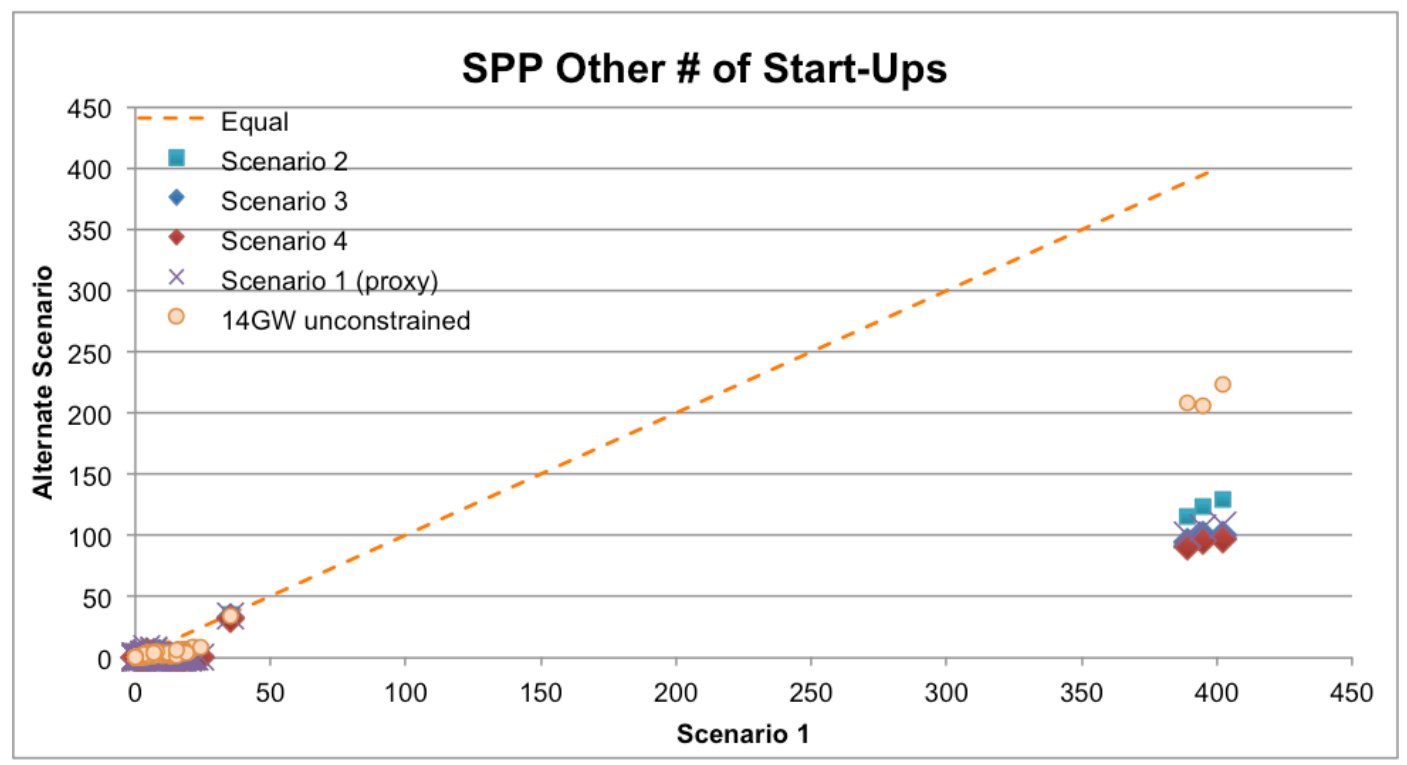

Figure 15. SPP Other \# of Start-Ups 


\section{Entergy}

In the $14 \mathrm{GW}$ scenario, Entergy's main capacity mix is provided by gas-fired plants at $74 \%$, with $31 \%$ from combined cycle, $35 \%$ from gas(or oil)-fired steam, and $8 \%$ from gas turbines. There is $14 \%$ from nuclear and $11 \%$ from coal (Table 3). Even in the $48 \mathrm{GW}$ scenarios, the mix does not change much since only $693 \mathrm{MW}$ of wind (2\%) is added to the fleet.

Table 3. Mix of Units in Entergy

\begin{tabular}{|c|c|c|c|c|}
\hline & $\begin{array}{c}\text { Number of } \\
\text { Units }\end{array}$ & Capacity (MW) & $\begin{array}{c}\text { Capacity Mix } \\
\text { with } 14 \mathrm{GW} \\
\text { wind }\end{array}$ & $\begin{array}{c}\text { Capacity Mix } \\
\text { with } 48 \mathrm{GW} \\
\text { wind }\end{array}$ \\
\hline Combine Cycle & 90 & 11,883 & $31 \%$ & $30 \%$ \\
\hline Steam Coal & 12 & 4,251 & $11 \%$ & $11 \%$ \\
\hline Steam Gas/Oil & 95 & 13,440 & $35 \%$ & $34 \%$ \\
\hline Gas Turbine & 61 & 2,996 & $8 \%$ & $8 \%$ \\
\hline Nuclear & 5 & 5,458 & $14 \%$ & $14 \%$ \\
\hline Hydro & 12 & 698 & $2 \%$ & $2 \%$ \\
\hline Wind (14 GW / 50 GW Scenarios) & $0 / 3$ & $0 / 693$ & $0 \%$ & $2 \%$ \\
\hline Other & 13 & 159 & $0 \%$ & $0 \%$ \\
\hline Total & $288 / 291$ & $38,885 / 39,578$ & $100 \%$ & $100 \%$ \\
\hline
\end{tabular}




\subsection{Combined Cycle Plants}

Combined Cycle plants in Entergy are called upon much more in the $14 \mathrm{GW}$ wind scenario than the 48 GW scenarios. The wind production from SPP is used to reduce combined cycle generation as the marginal producer much of the time. The scenarios with balancing shifting to Entergy and the other regions requires the combined cycle plants to operate a bit more than Scenario 1 where all balancing is done by SPP.

With the increased usage in the $14 \mathrm{GW}$ scenario, the combined cycle plants generally do not have as many start-ups. A few show an increase from around 150 start-ups to 200 start-ups. These plants also see increased capacity factors from around $15 \%$ to $30 \%$ or so. So the start-ups translate into increased calls upon their production rather than just increased, shorter periods. It's likely these are generally seeing shut-downs at night-time and calls for increased output during higher usage days.

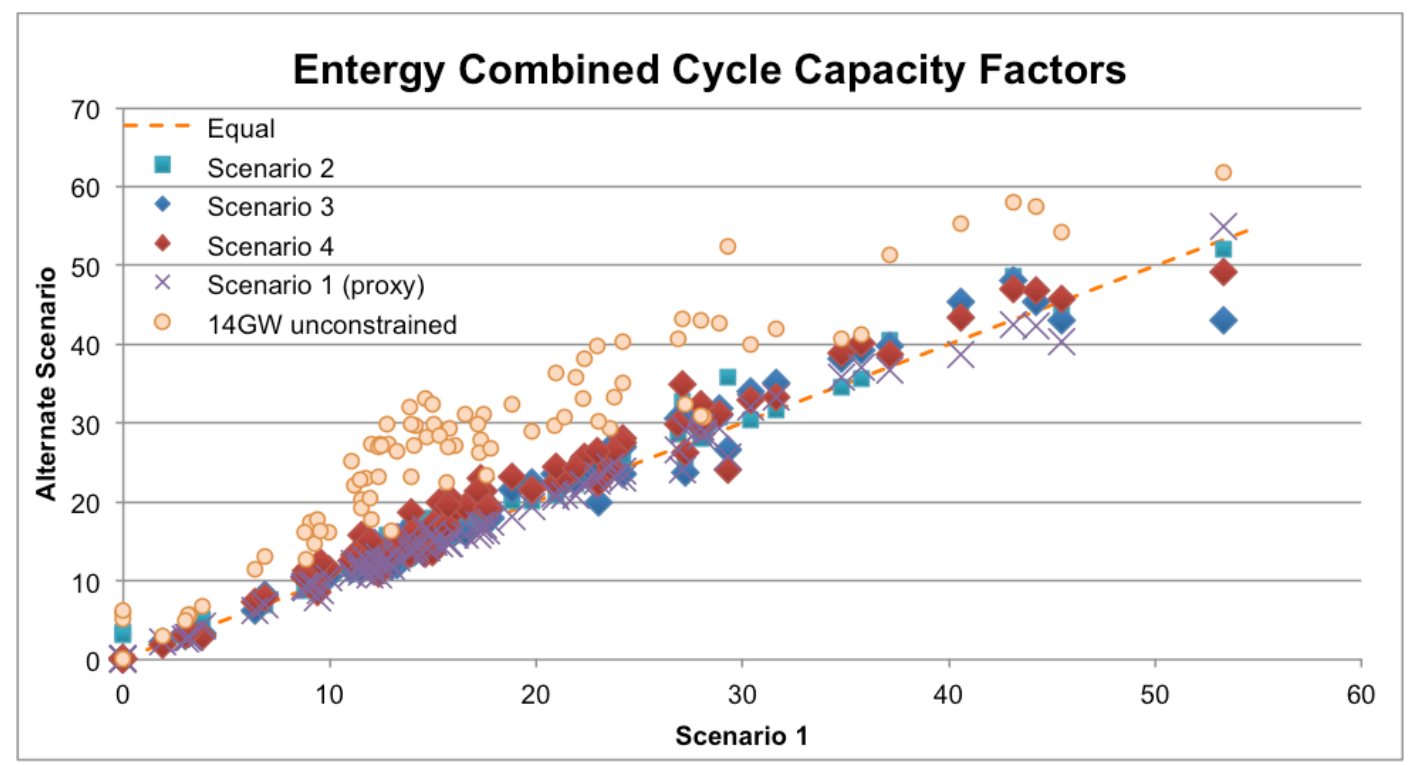

Figure 16. Entergy Combined Cycle Capacity Factors

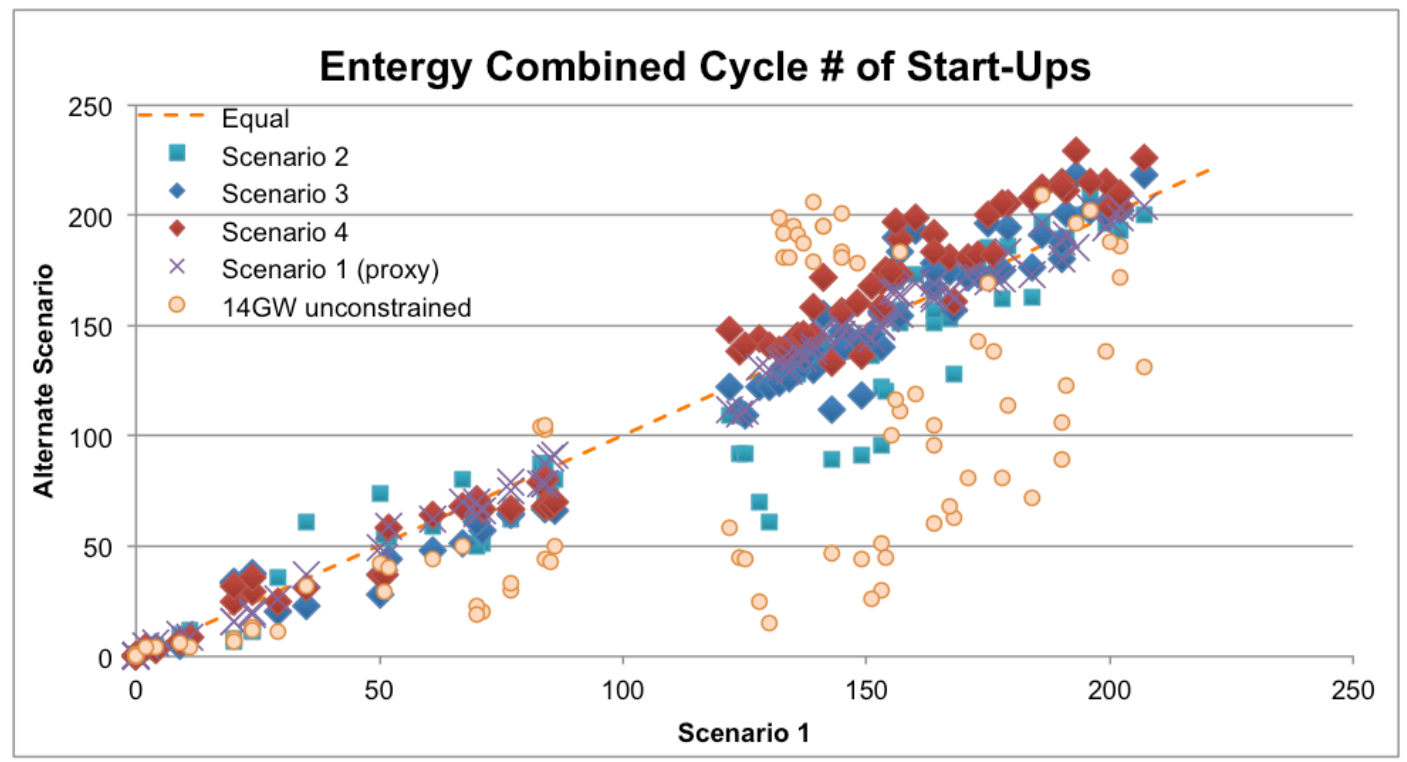

Figure 17. Entergy Combined Cycle \# of Start-Ups 


\subsection{Coal-fired Steam Plants}

The number of coal plants in the Entergy region are limited. Most are running at baseload levels throughout the year though it appears that three units are run seasonally. Their capacity factors are lower, but the number of start-ups is still very few.

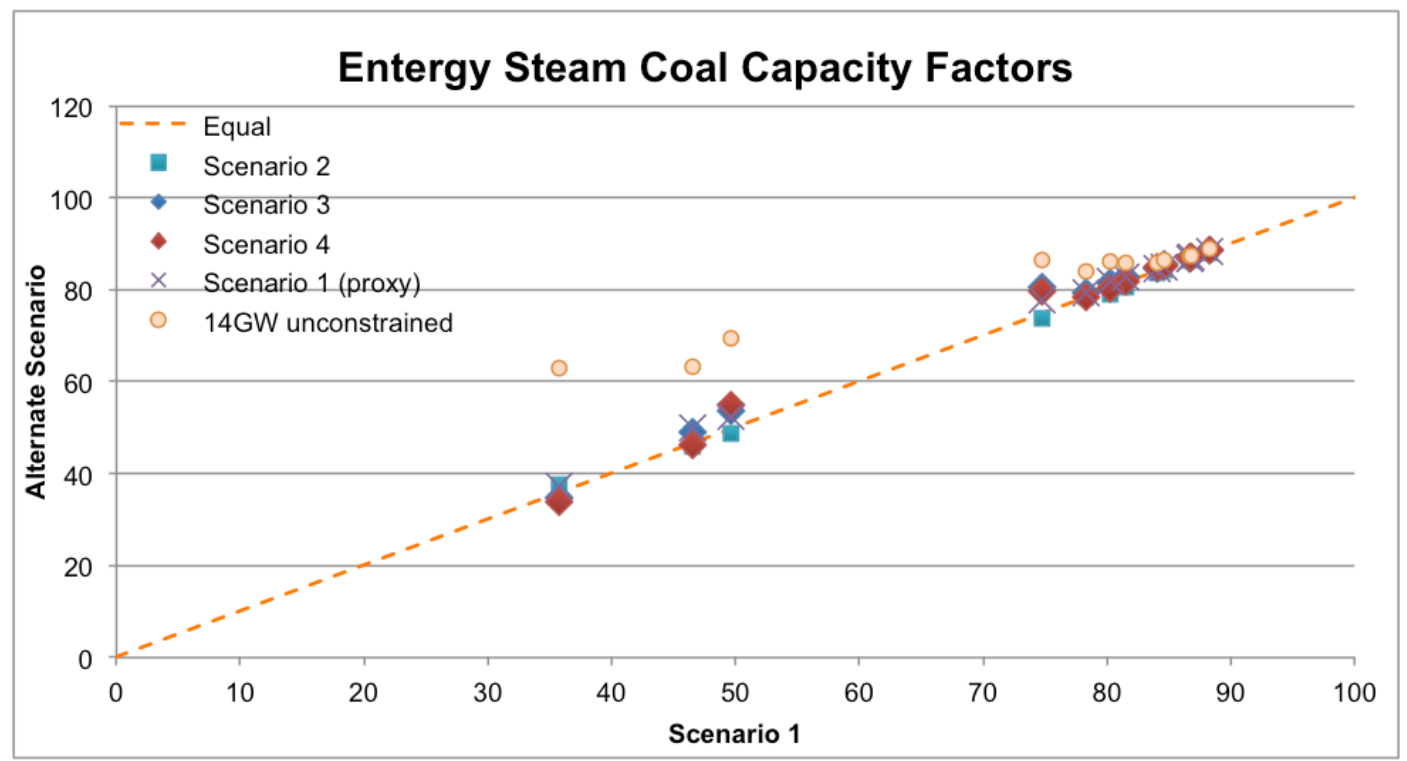

Figure 18. Entergy Coal-fired Steam Plant Capacity Factors

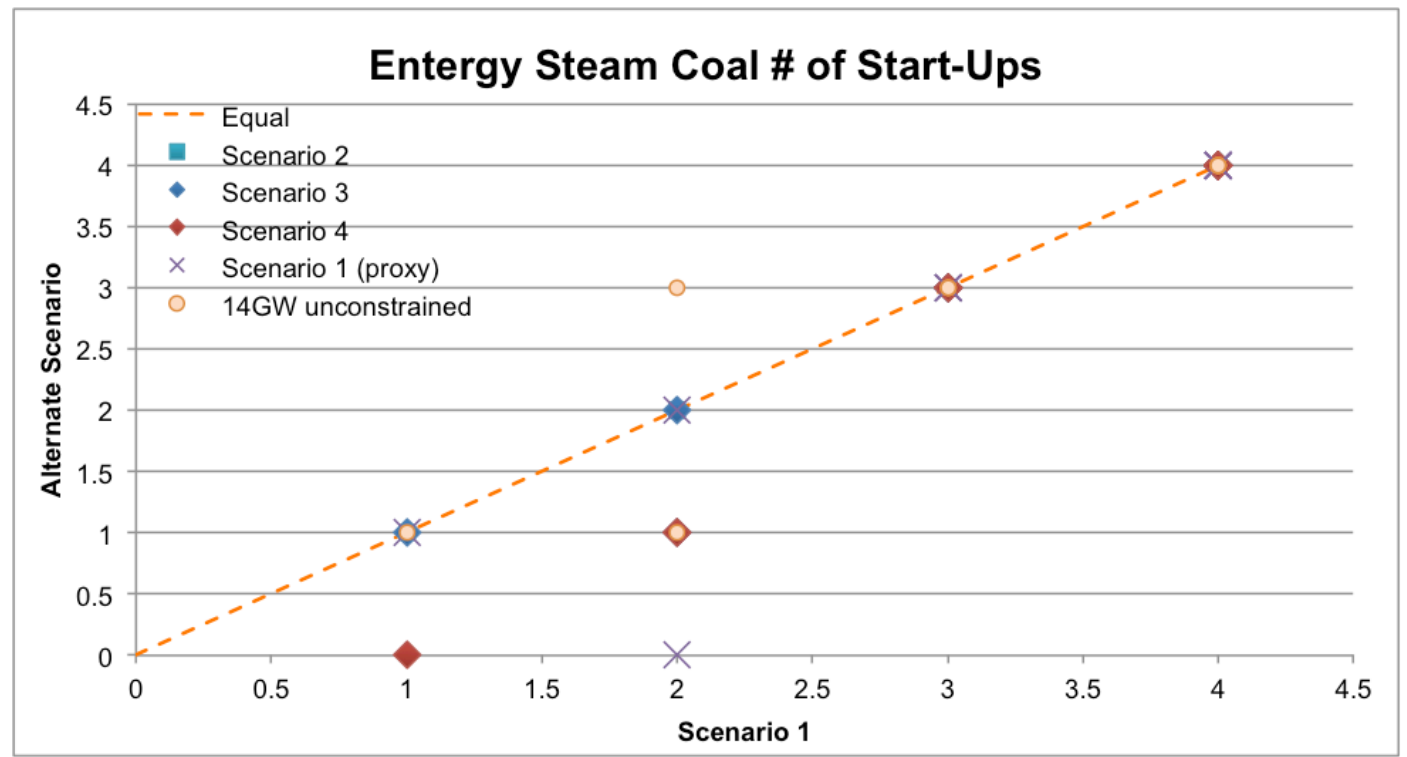

Figure 19. Entergy Coal-fired Steam Plant \# of Start-Ups 


\subsection{Gas/Oil-fired Steam Plants}

While these units make a large fraction of the total Entergy capacity mix, they all operate with a capacity factor less than $16 \%$, and so provide limited generation. However, they are not daily peaking plants, as evidenced by the few number of start ups. Rther, once called upon, they remain up for some time. This is likely due to the nature of the technology, requiring some time for initial start-up.

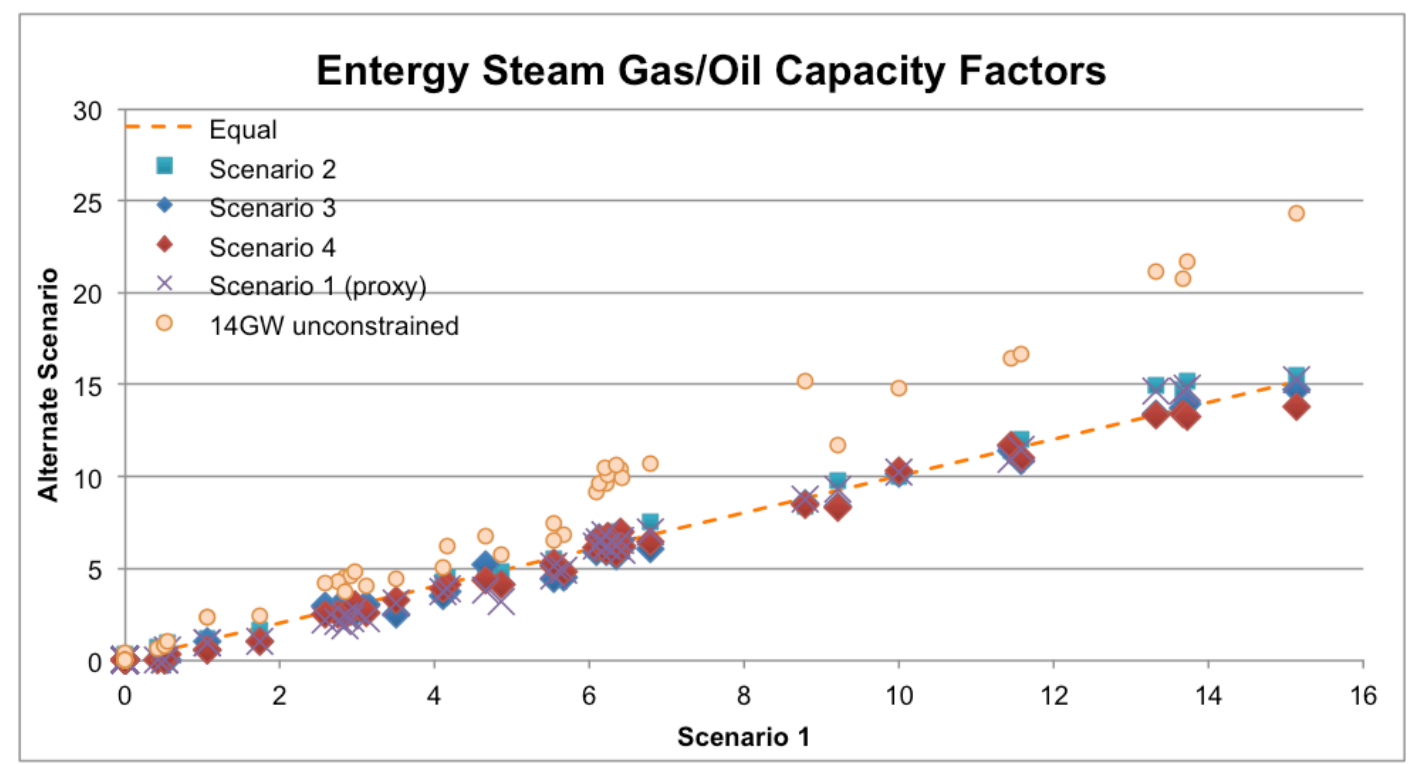

Figure 20. Entergy Gas/Oil-fired Steam Plant Capacity Factors

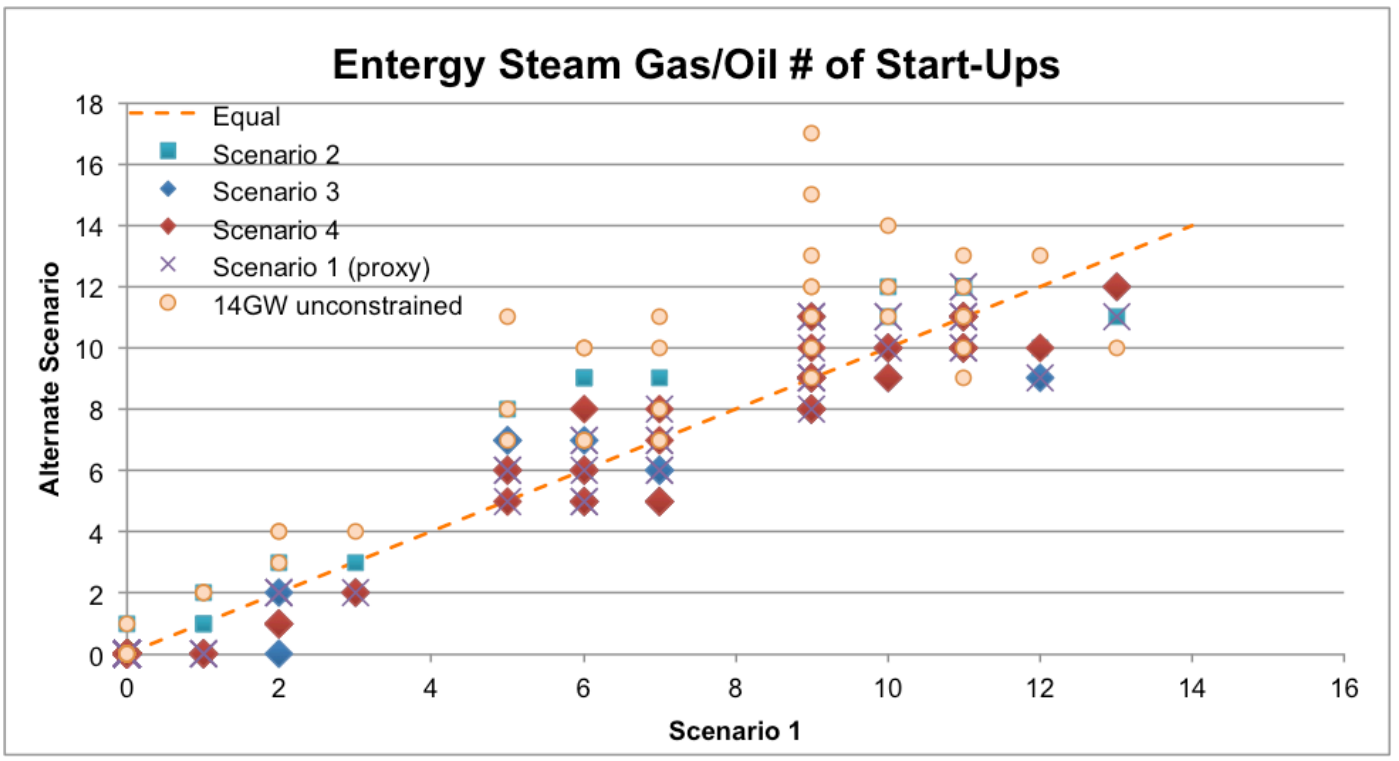

Figure 21. Entergy Gas/Oil-fired Steam Plant \# of Start-Ups 


\subsection{Gas Turbines}

Gas turbines are used as peaking plants in the Entergy system, with low capacity factors and frequent start-ups. They are called upon more frequently in the $14 \mathrm{GW}$ scenario.

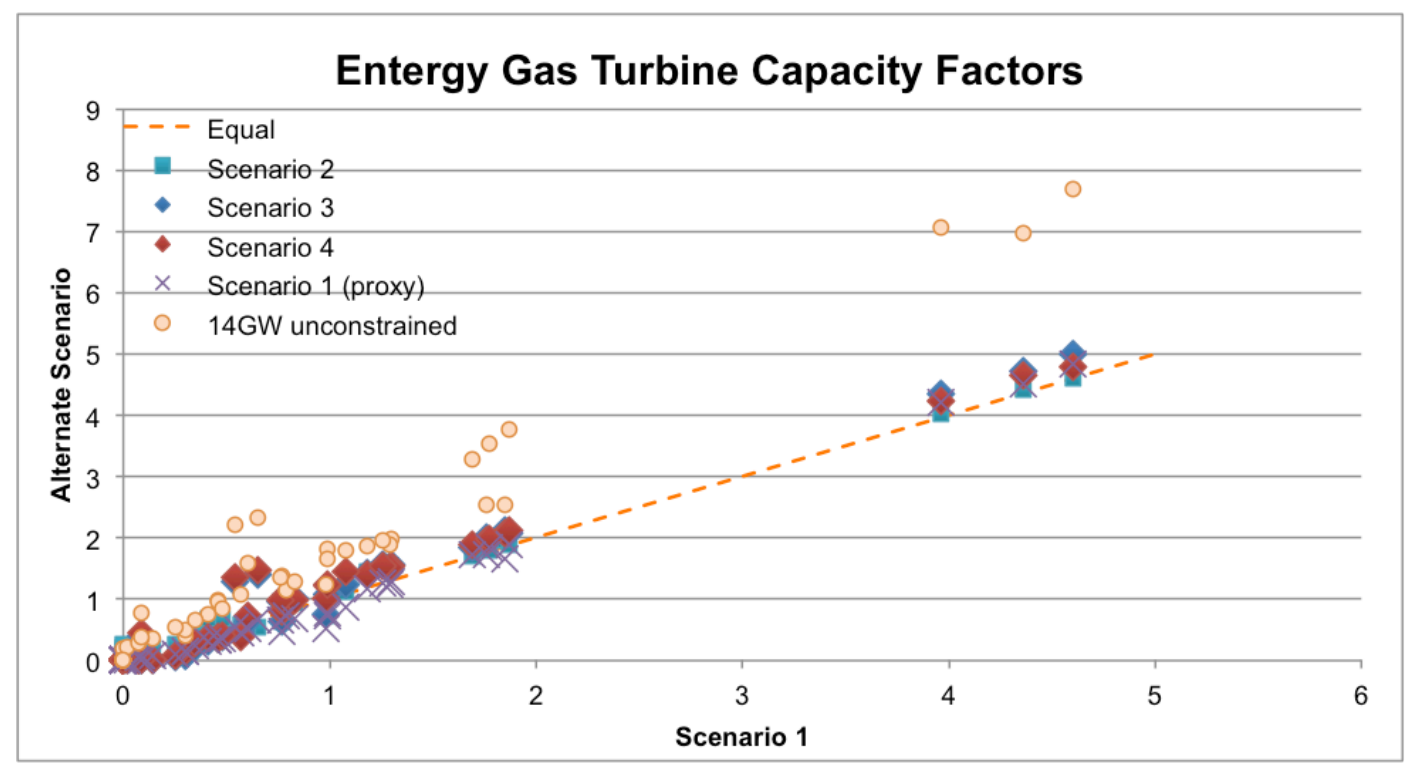

Figure 22. Entergy Gas Turbine Capacity Factors

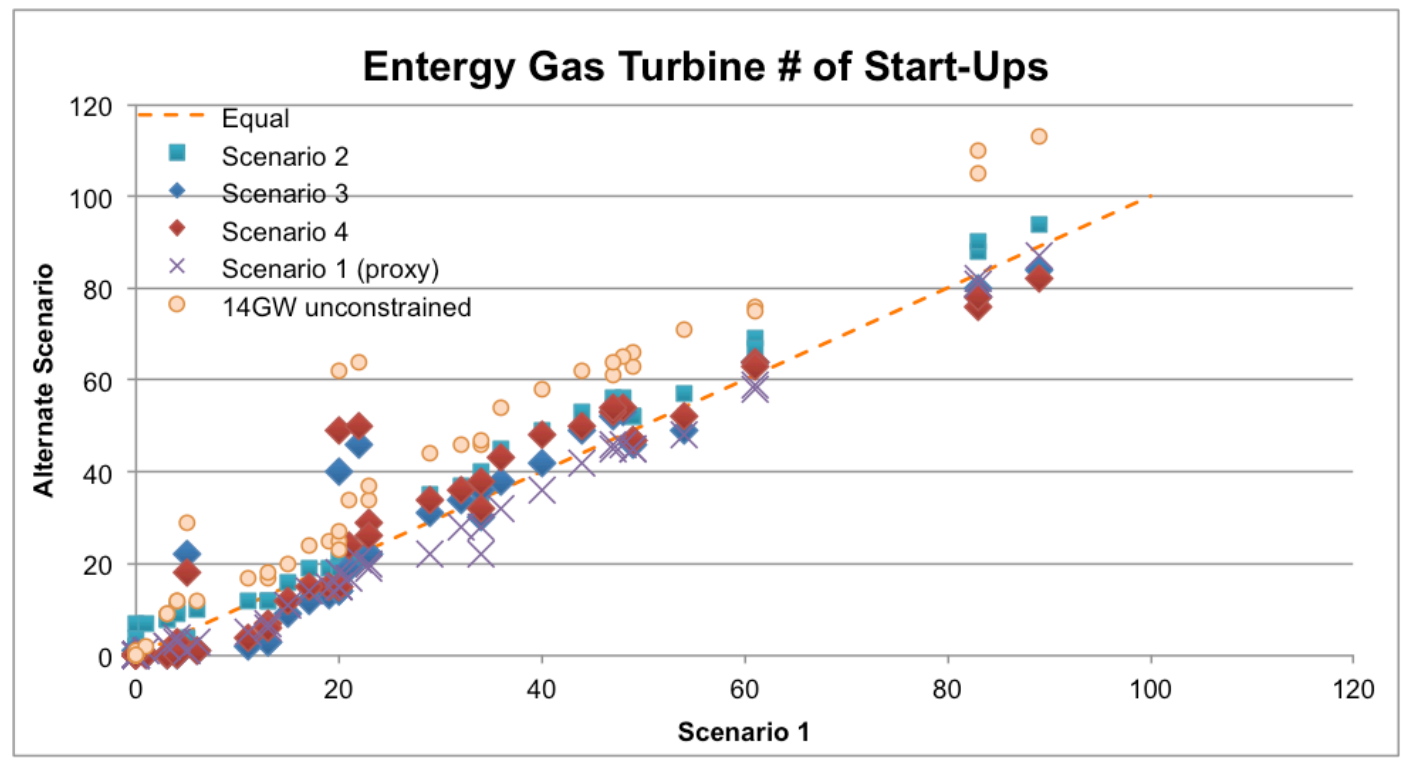

Figure 23. Entergy Gas Turbine \# of Start-Ups 


\subsection{Nuclear and Hydro}

Nuclear plants are operated at baseload while the hydro plants are operated as available. Most hydro plants show no start-ups during the year but have a variety of capacity factors. They likely need to run continuously at some level for water quality purposes. UPLAN is capable of simulating different types of generators such as thermal, hydro, wind and renewable, cogeneration and many other technologies. An inline hydro scheduler dispatches hydro, pumped storage and CAES units daily and hourly to maximize net income.

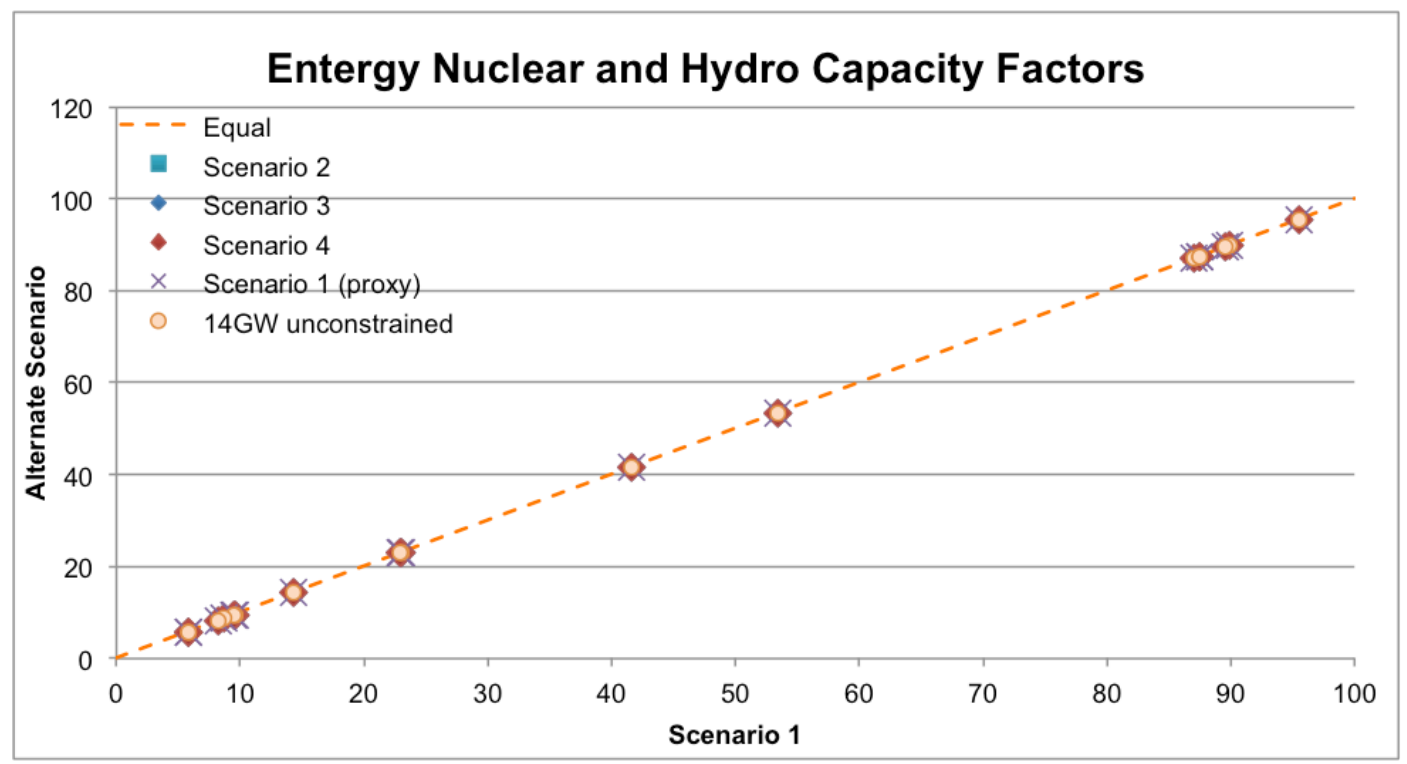

Figure 24. Entergy Nuclear and Hydro Capacity Factors

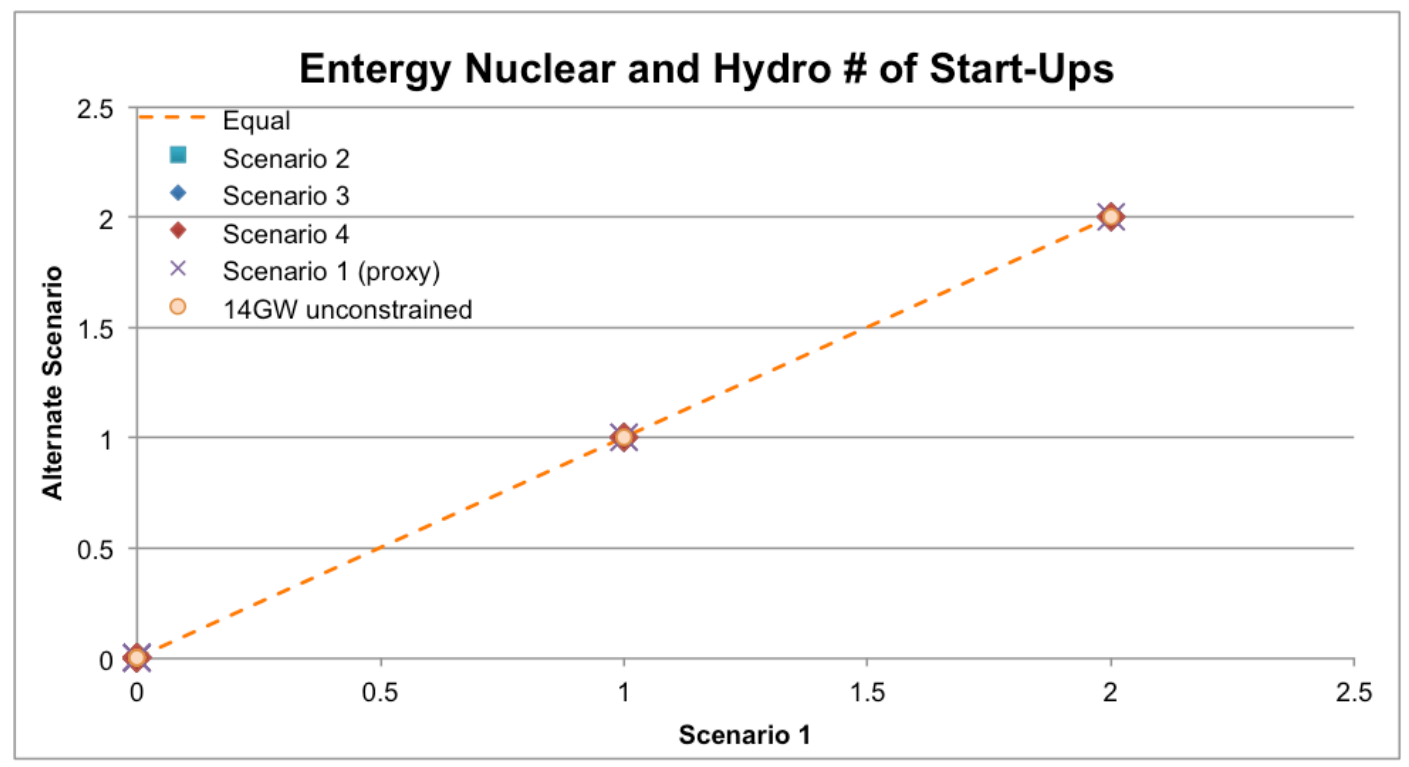

Figure 25. Entergy Nuclear and Hydro \# of Start-Ups 


\subsection{Wind}

The three wind plants in the Entergy region are added as part of the increase in capacity to $48 \mathrm{GW}$. These three report capacity factors of $69 \%$ rather than the more typical $40 \%-45 \%$, although it is not clear the rationale. Being of relatively little capacity, they should have small impact on the overall results.

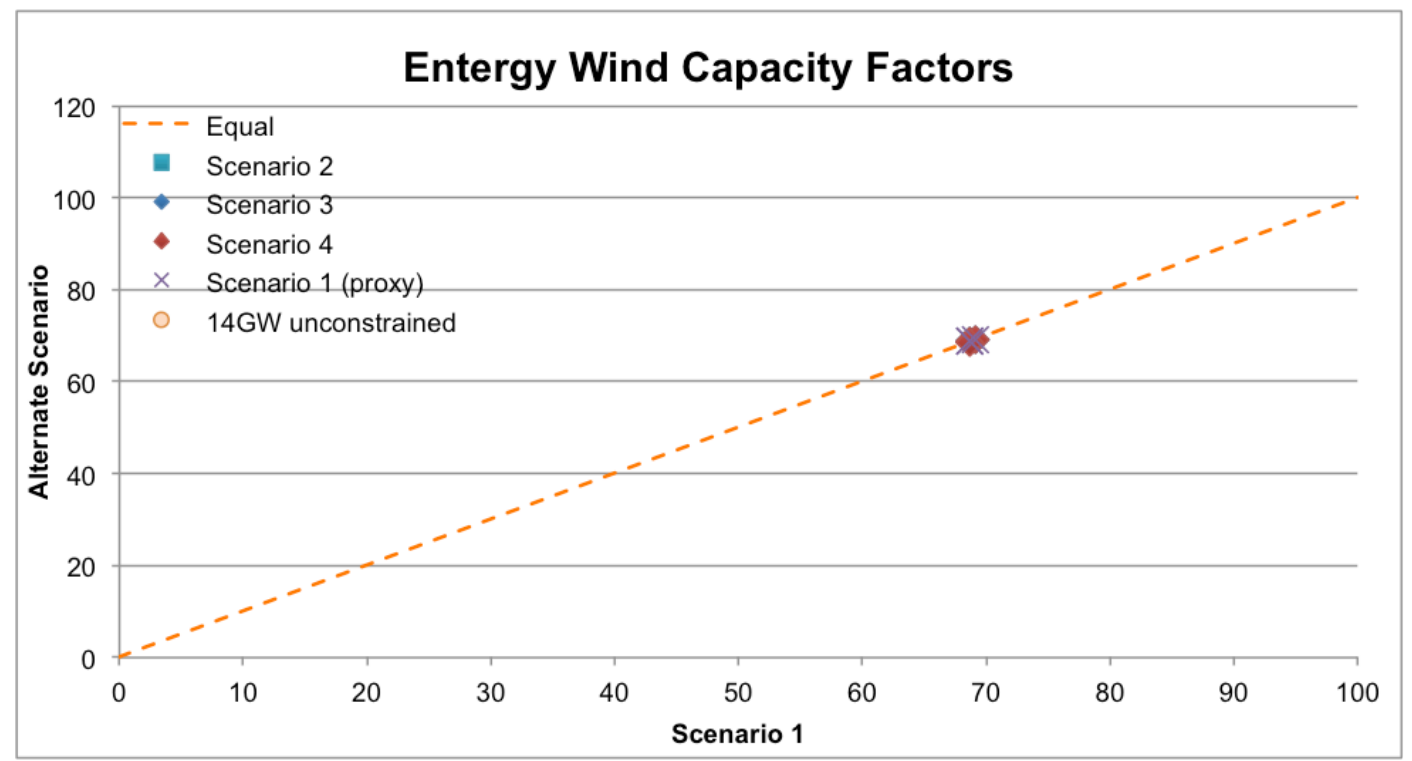

Figure 26. Entergy Wind Capacity Factors

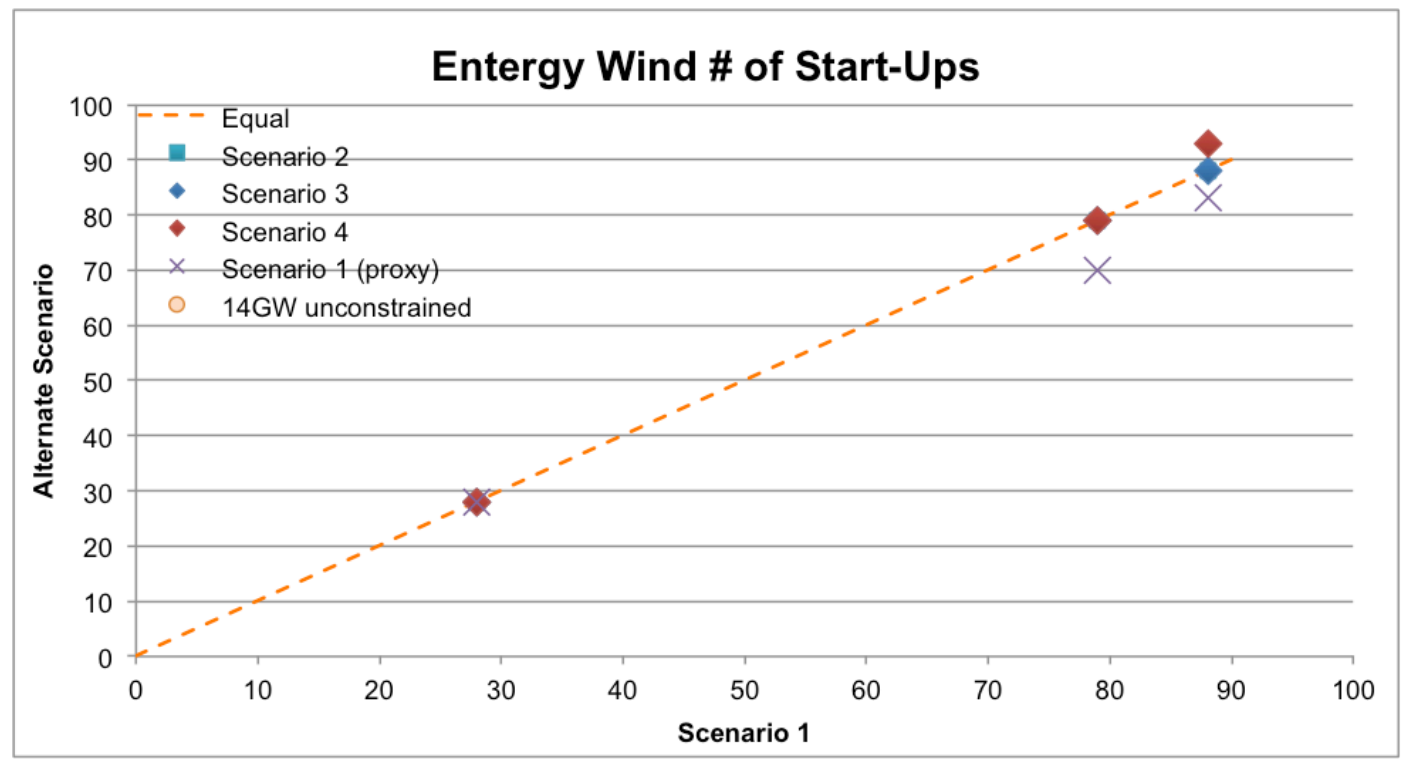

Figure 27. Entergy Wind \# of Start-Ups 


\subsection{Other}

"Other" plants include internal combustion engines and distributed cogeneration across the region. Some sources utilize biomass such as landfill gas, wastewater treatment biogas, or wood scrap.

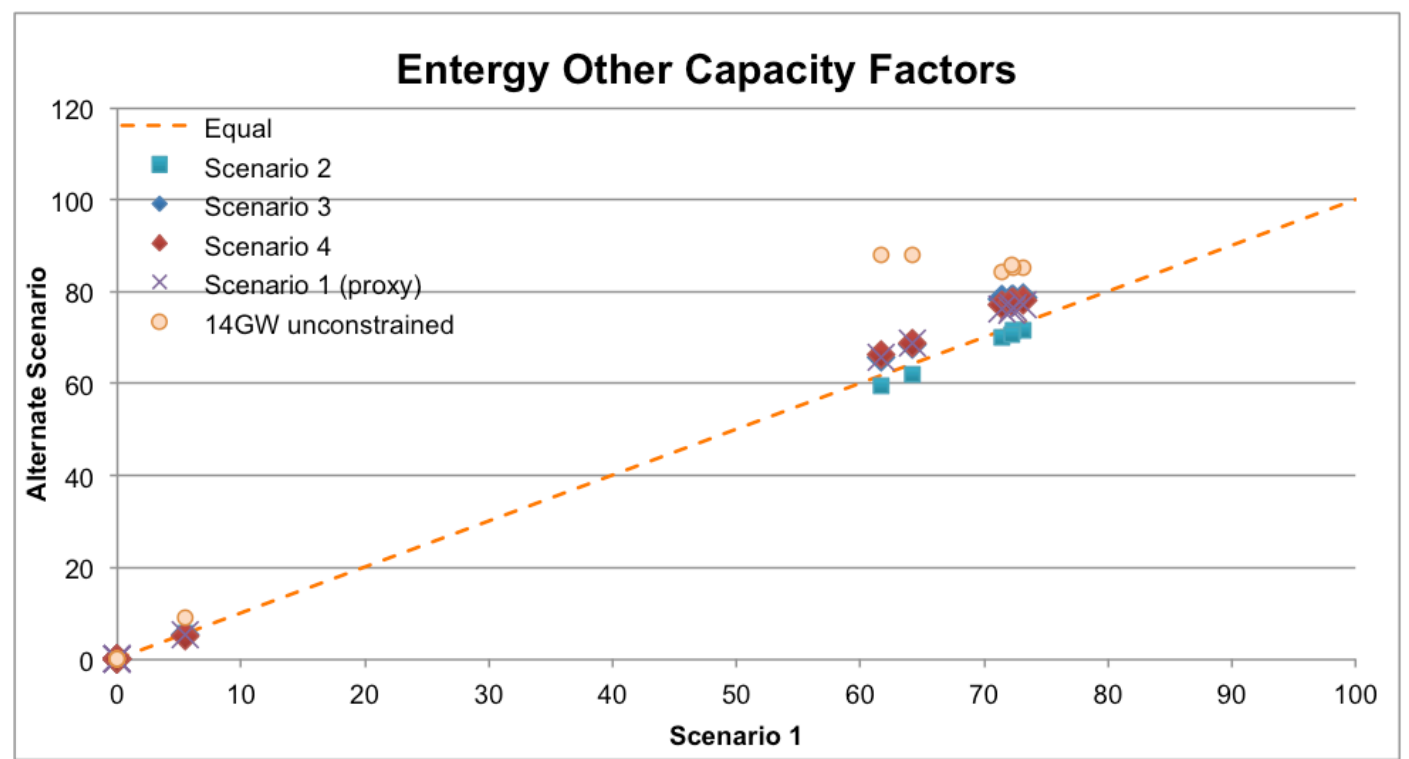

Figure 28. Entergy Other Capacity Factors

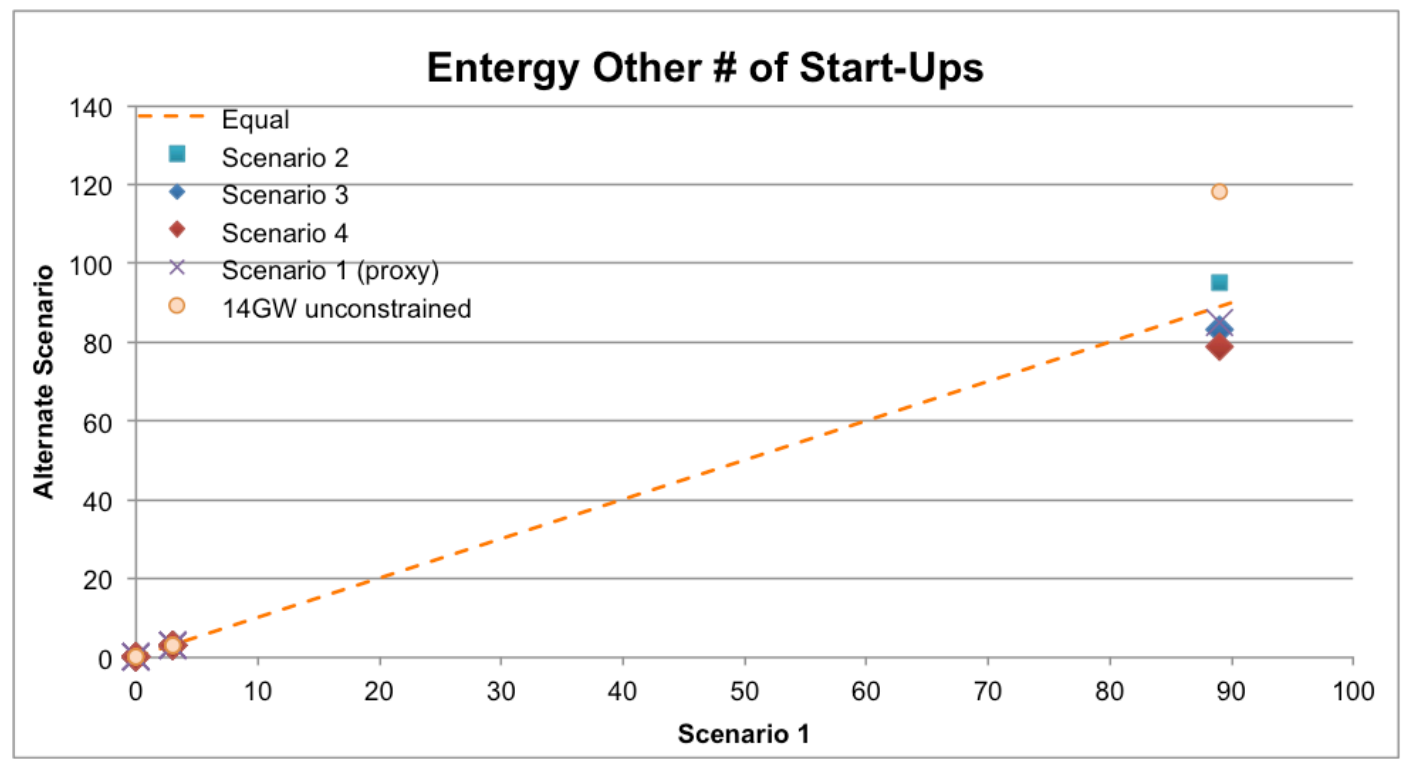

Figure 29. Entergy Other \# of Start-Ups 


\section{TVA}

TVA has the same capacity mix in both the $14 \mathrm{GW}$ and $48 \mathrm{GW}$ scenarios because no new wind is added in its territory. TVA's main capacity mix is provided by coal-fired plants at $34 \%$, followed by $29 \%$ from combined cycle, gas(or oil)-fired steam, and gas turbines. Nuclear power provides $21 \%$ of the capacity mix while Hydro provides $15 \%$. Wind capacity is small with just the $29 \mathrm{MW}$ currently located in the region.

Table 4. Mix of Units in TVA

\begin{tabular}{|l|r|r|r|}
\hline & Number of Units & \multicolumn{1}{c|}{$\begin{array}{c}\text { Capacity } \\
\text { (MW) }\end{array}$} & $\begin{array}{c}\text { Capacity Mix with } \\
\text { 14 or 48 GW wind }\end{array}$ \\
\hline Combined Cycle & 36 & 6,252 & $14 \%$ \\
\hline Steam Coal & 64 & 15,029 & $34 \%$ \\
\hline Steam Gas/Oil & 7 & 239 & $1 \%$ \\
\hline Gas Turbine & 93 & 6,433 & $21 \%$ \\
\hline Nuclear & 8 & 9,245 & $15 \%$ \\
\hline Hydro & 150 & 6,832 & $0 \%$ \\
\hline Wind & 1 & 29 & $2 \%$ \\
\hline Other & 10 & 687 & $100 \%$ \\
\hline Total & 369 & 44,746 & \\
\hline
\end{tabular}




\subsection{Combined Cycle Plants}

TVA's combined cycle plants see increased use in the $14 \mathrm{GW}$ scenario and also in the scenario 2 that has balancing conducted by each region for the wind allocated to them. Because combined cycle plants are more flexible than coal plants, there is a shift in generation from coal to combined cycle. On the other hand, when balancing is conducted for the region as a whole in scenarios 3 and 4, then TVA combined cycle plants are used less. Combined cycle plants in other regions are more economic and so used for the balancing activity.

Start-ups generally decline with the lower capacity factors. In addition, many of the plants with higher capacity factors in alternate scenarios have few start-ups. This may represent that plants are kept in operation over multiple days rather than nightly shutdowns.

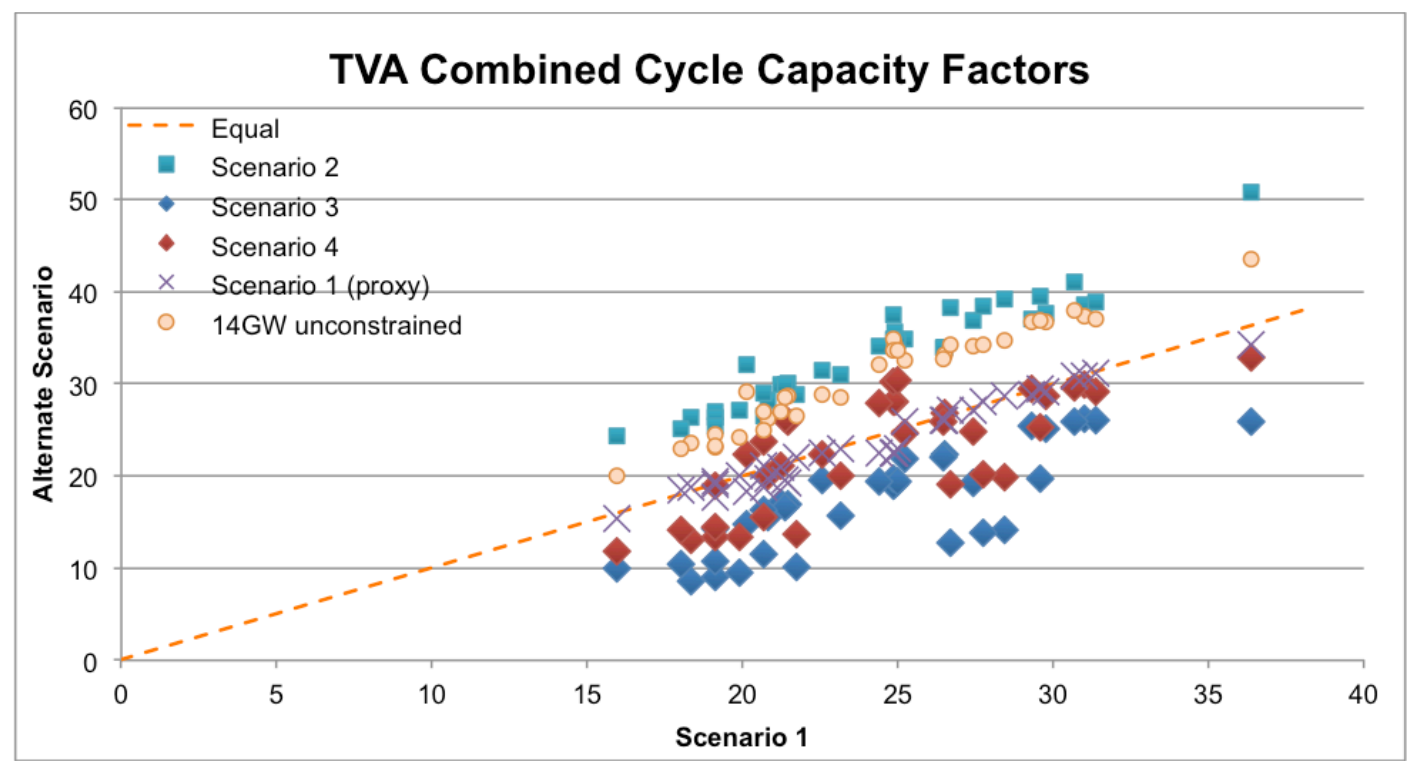

Figure 30. TVA Combined Cycle Capacity Factors

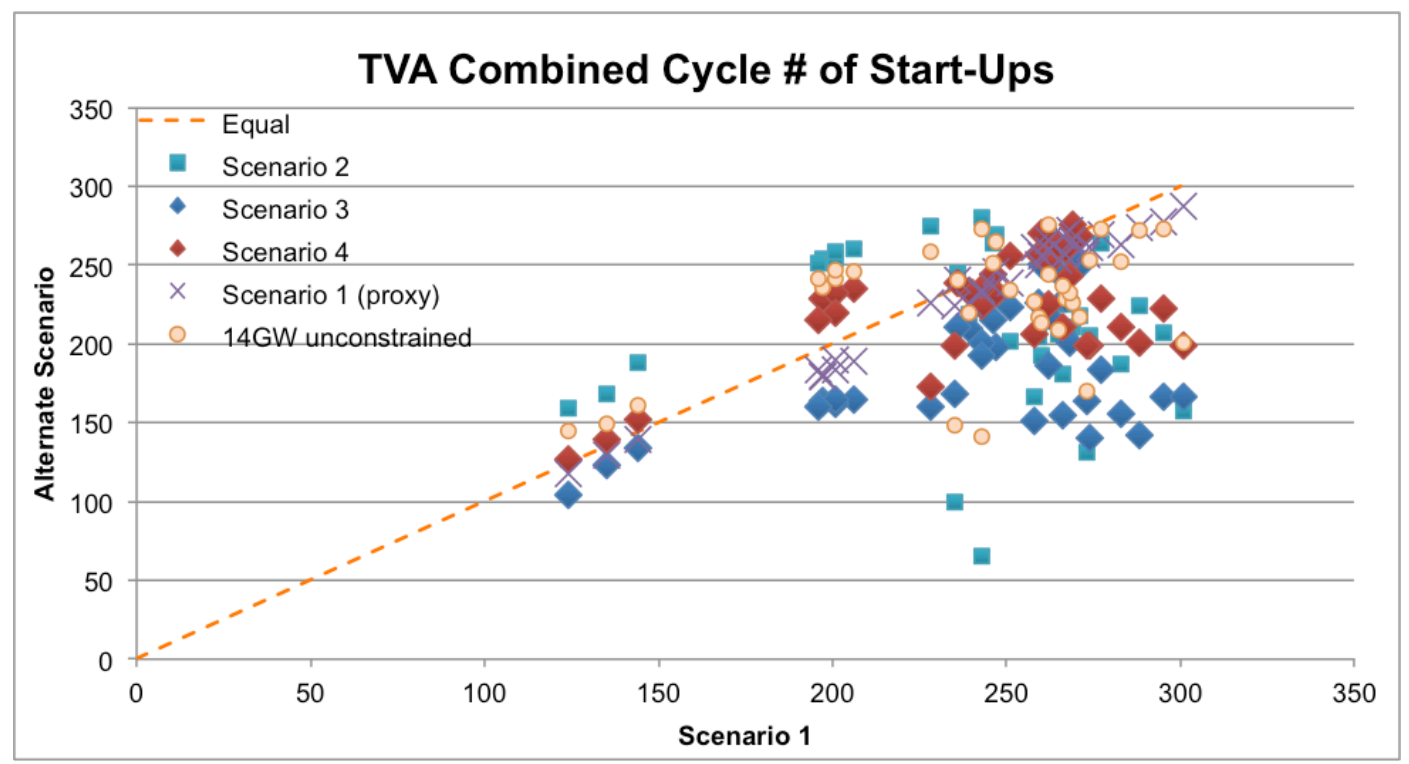

Figure 31. TVA Combined Cycle \# of Start-Ups 


\subsection{Coal-fired Steam Plants}

Except for some independent power plants, TVA's plants run at $50 \%$ or higher capacity factors. These are used for baseload operations with some shutdowns for the less efficient during low periods. All plants have less than 25 start-ups through the year.

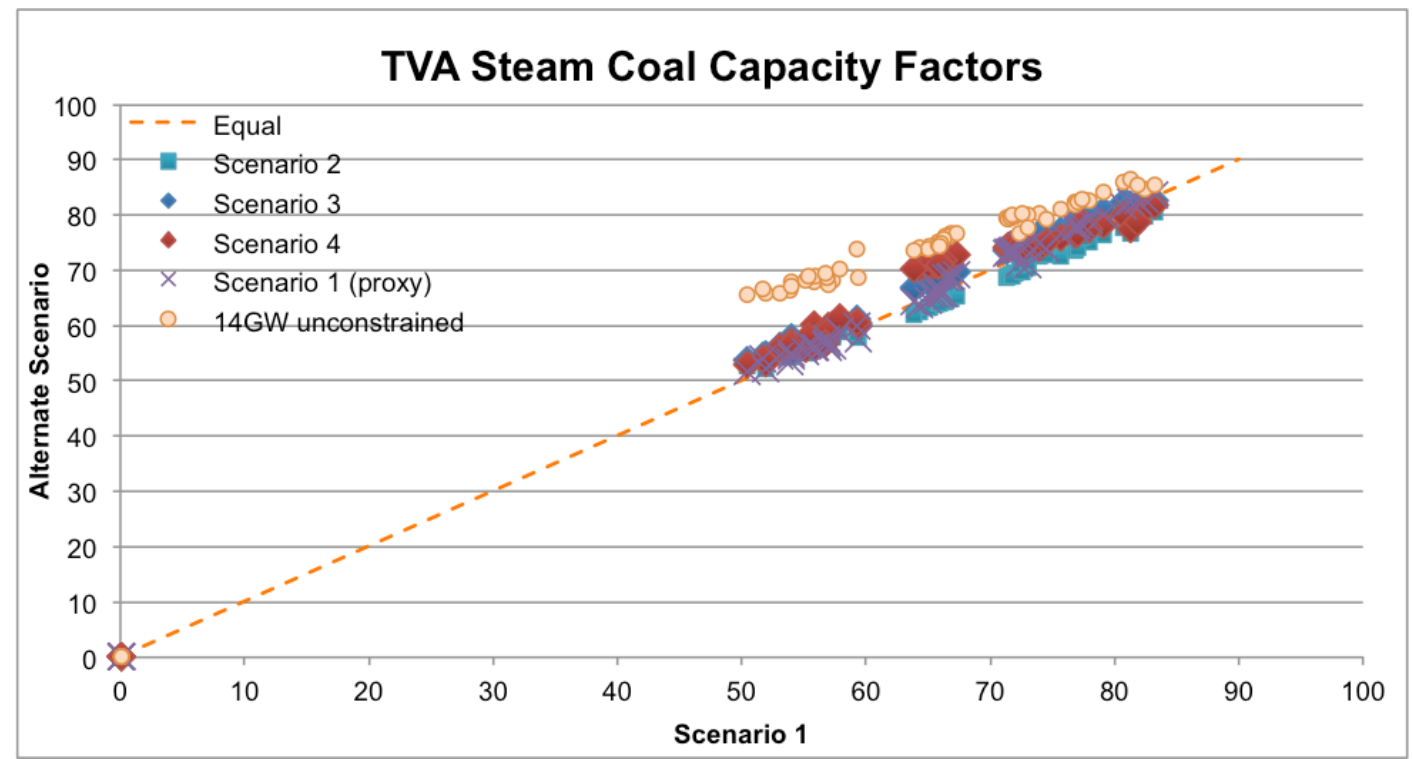

Figure 32. TVA Coal-fired Steam Plant Capacity Factors

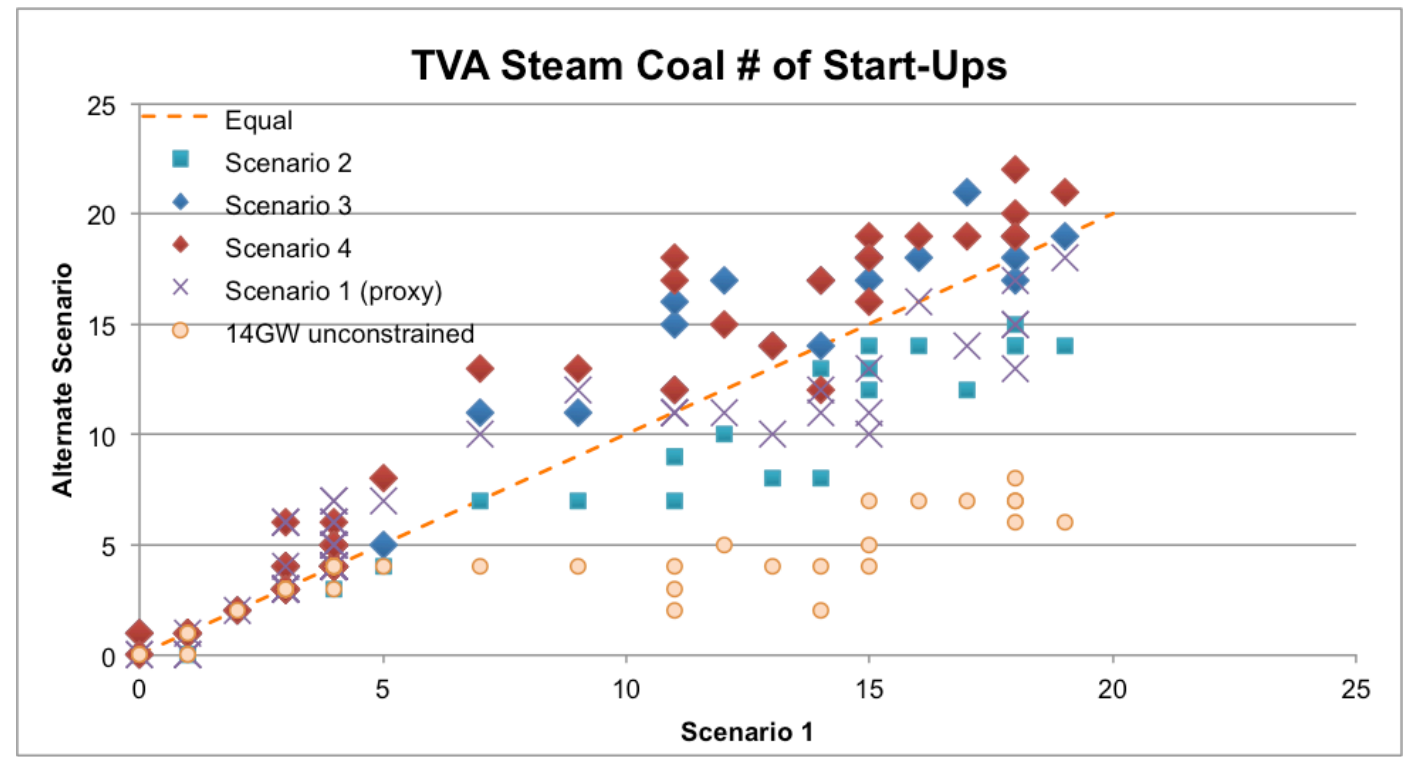

Figure 33. TVA Coal-fired Steam Plant \# of Start-Ups

\subsection{Gas/Oil-fired Steam Plants}

All seven units in TVA do not operate. 


\subsection{Gas Turbines}

TVA's gas turbines have low capacity factors as peakers, but see wide variation depending on the scenario. The $14 \mathrm{GW}$ scenario results in some increase, as would be expected because of less overall capacity in the system. Scenario 2 has the largest increase since TVA's turbines are used for balancing the wind power that is assigned to TVA. Scenarios 3 and 4 shows a marked reduction in capacity factor and startups since the unified balancing allows more efficient plants (such as SPP coal plants and Entergy gas plants) to be used more.

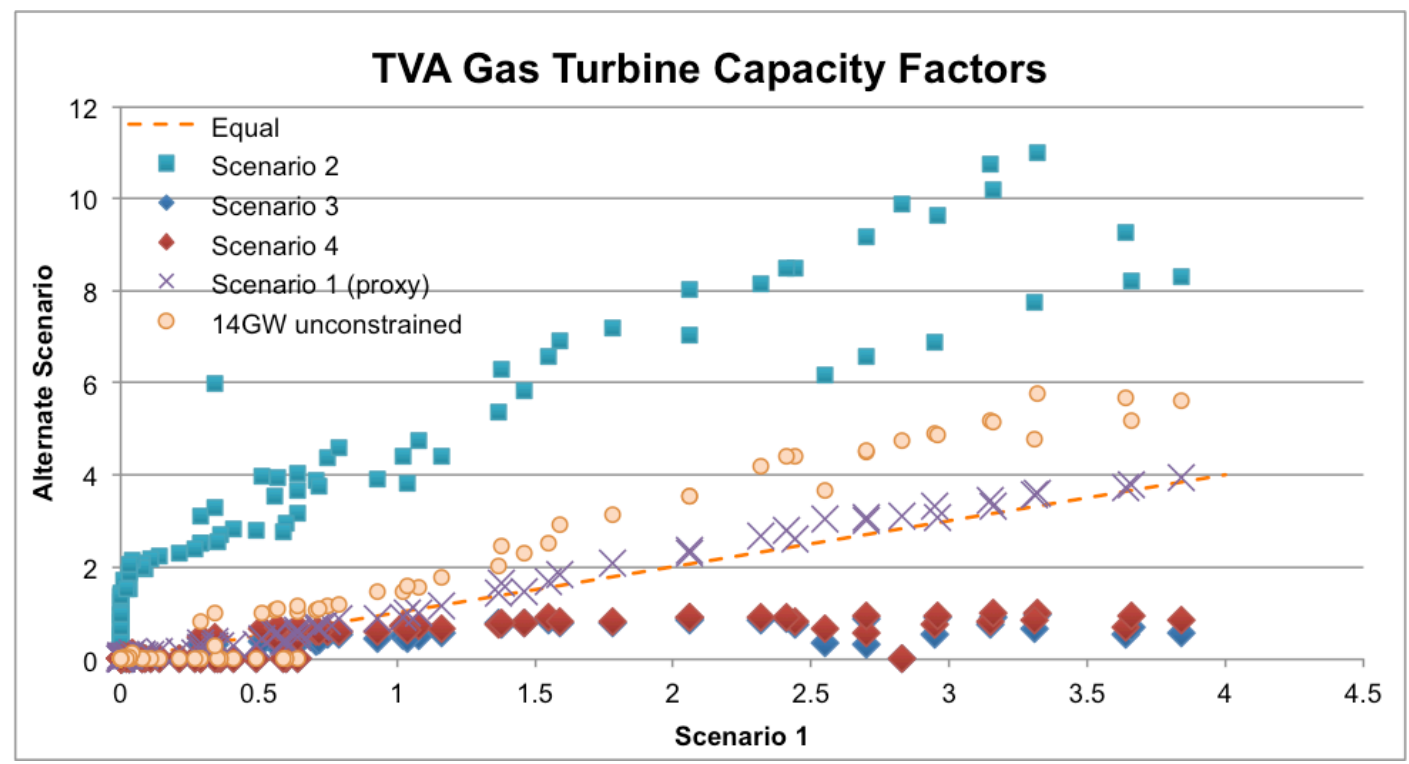

Figure 34. TVA Gas Turbine Capacity Factors

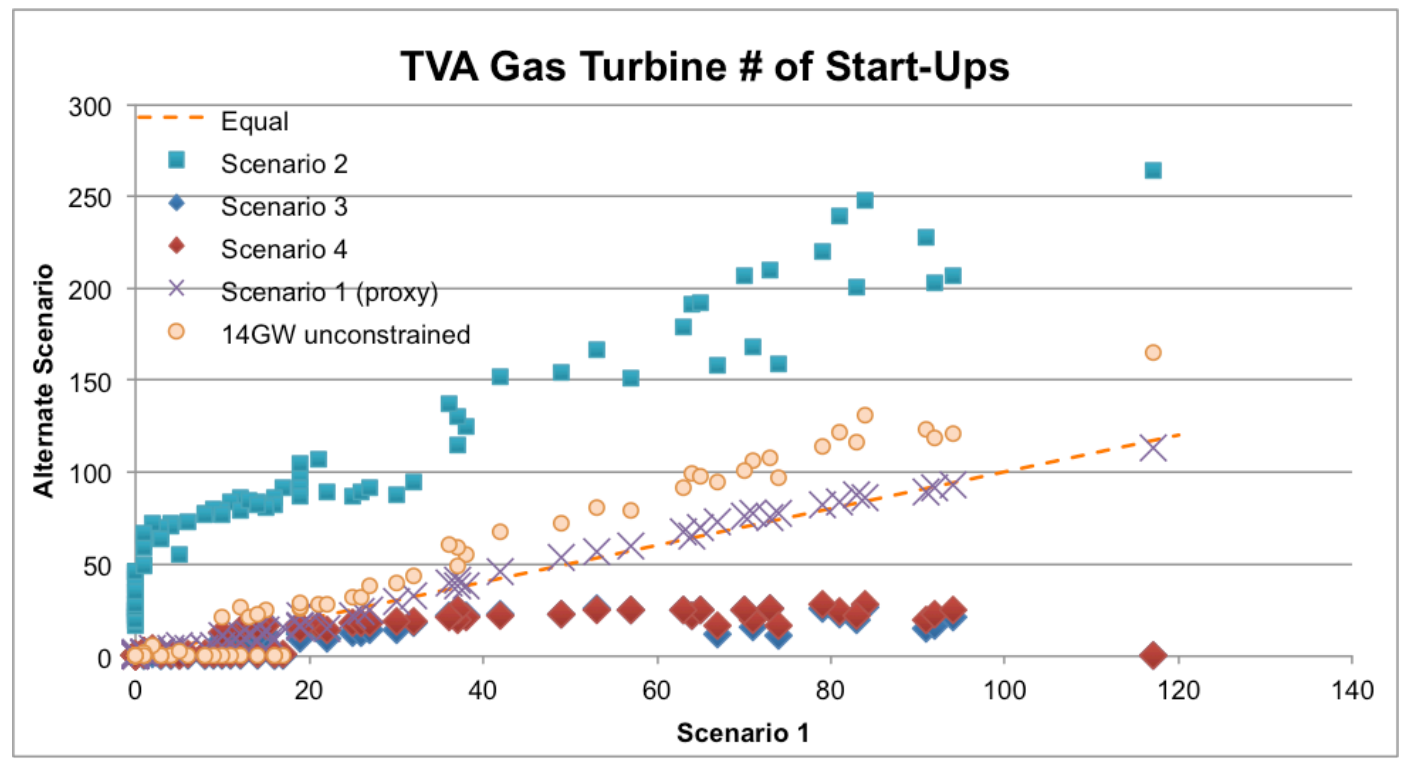

Figure 35. TVA Gas Turbine \# of Start-Ups 


\subsection{Nuclear and Hydro}

All of TVA's 8 nuclear units operate at baseload capacity factors while the 150 hydro units operate the same in all scenarios, as defined by their input generation schedules. Raccoon Mountain and Hiwassee unit 2 has high numbers of start-ups while others are listed at two or less. They likely need to run continuously at some level for water quality purposes. UPLAN is capable of simulating different types of generators such as thermal, hydro, wind and renewable, cogeneration and many other technologies. An inline hydro scheduler dispatches hydro, pumped storage and CAES units daily and hourly to maximize net income.

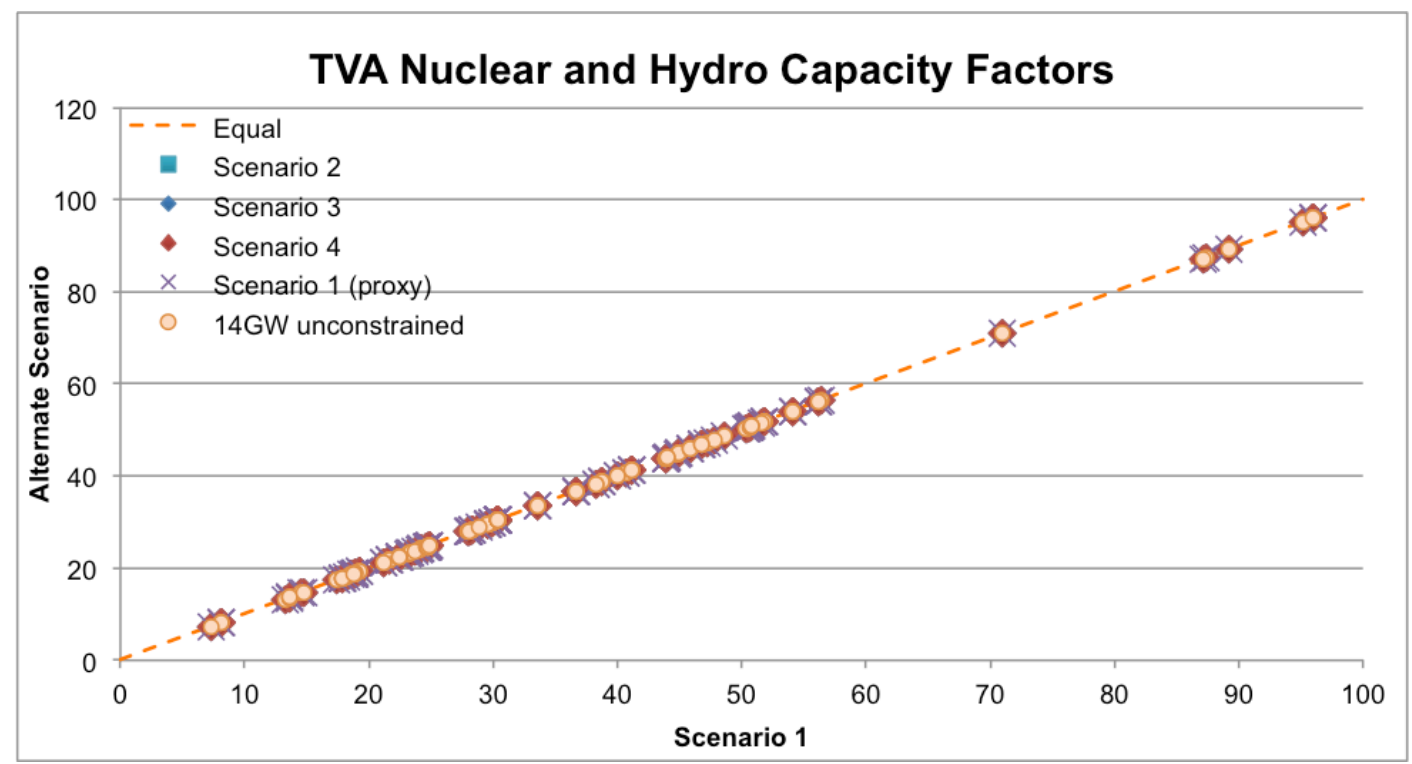

Figure 36. TVA Nuclear and Hydro Capacity Factors

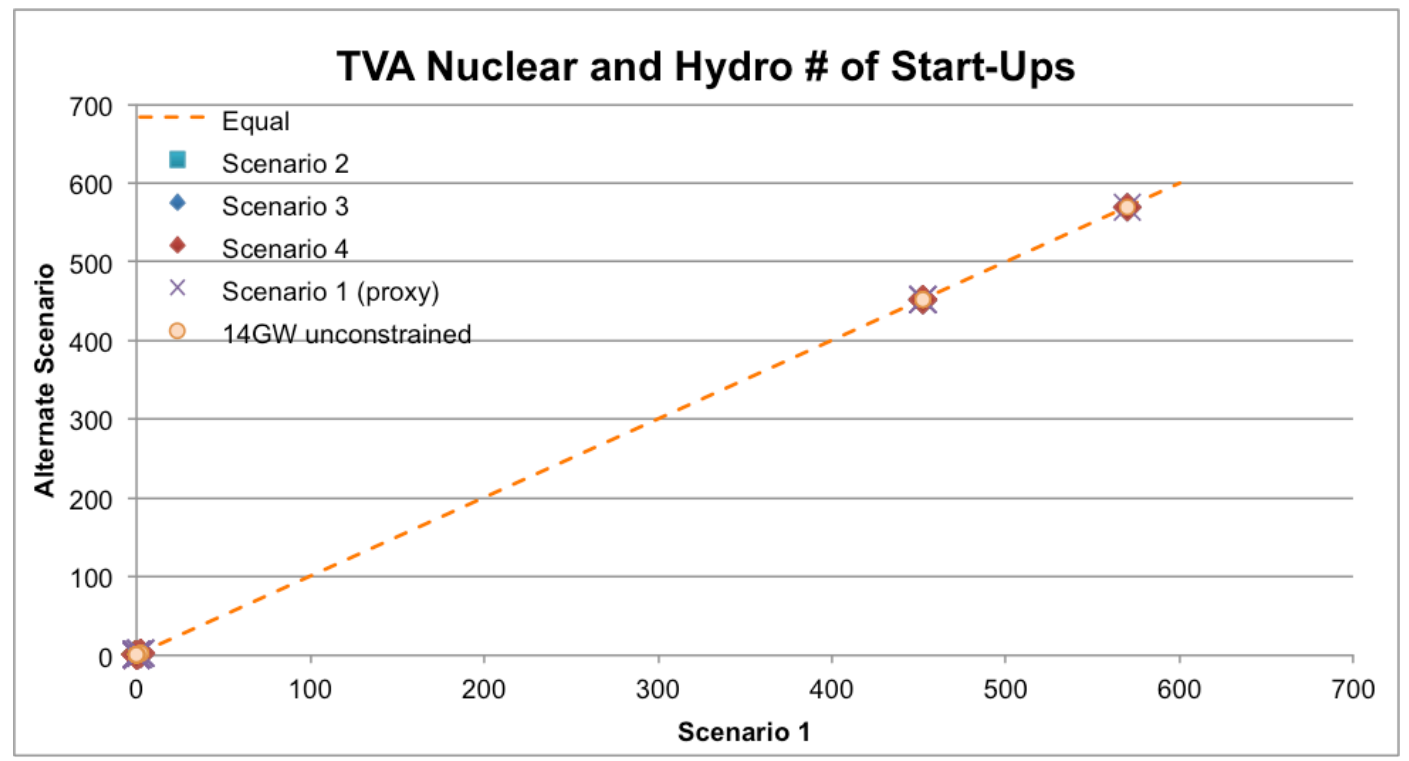

Figure 37. TVA Nuclear and Hydro \# of Start-Ups 


\subsection{Wind}

The only wind plant in TVA territory is the $29 \mathrm{MW}$ Buffalo Mountain site, which is modeled at a capacity factor of $41 \%$ and two start-ups throughout the year. This capacity factor is high compared to how much these units are currently operating.

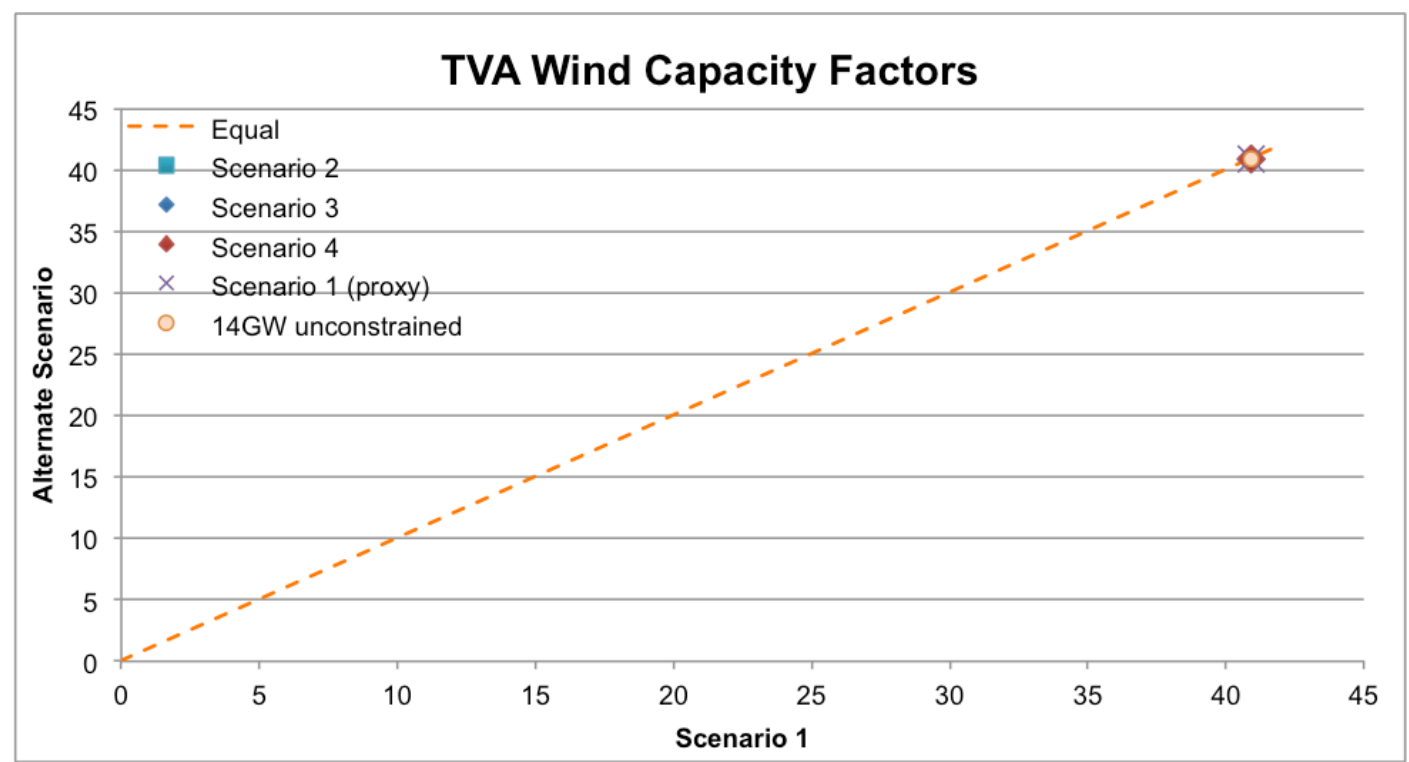

Figure 38. TVA Wind Capacity Factors

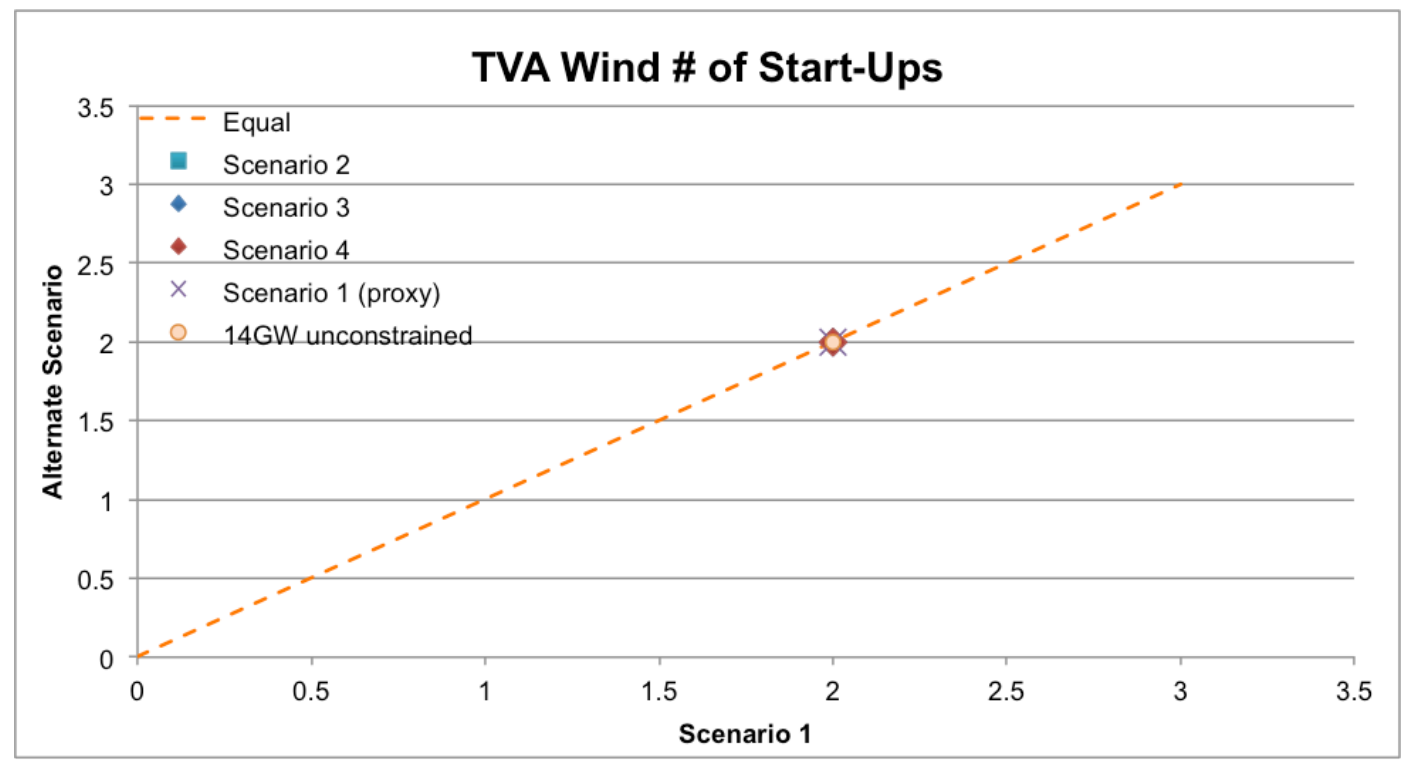

Figure 39. TVA Wind \# of Start-Ups 


\subsection{Other}

TVA's "Other" category refers to a mixture of internal combustion, cogeneration, landfill gas, and other technologies. Two thirds of the capacity in it comes from the Red Hills fluidized bed lignite plant. Three of the "other" plants operate at base load conditions while others are peakers that rarely if ever operate.

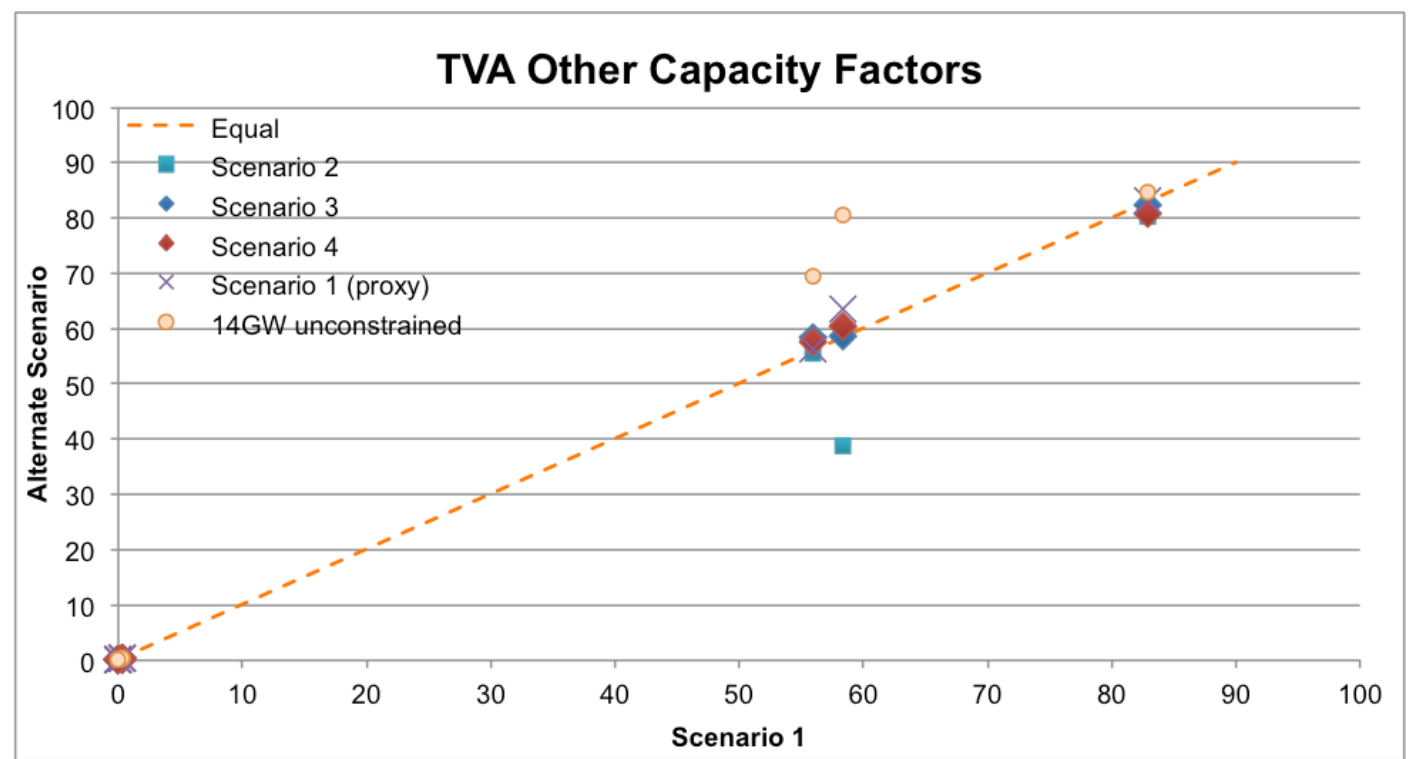

Figure 40. TVA Other Capacity Factors

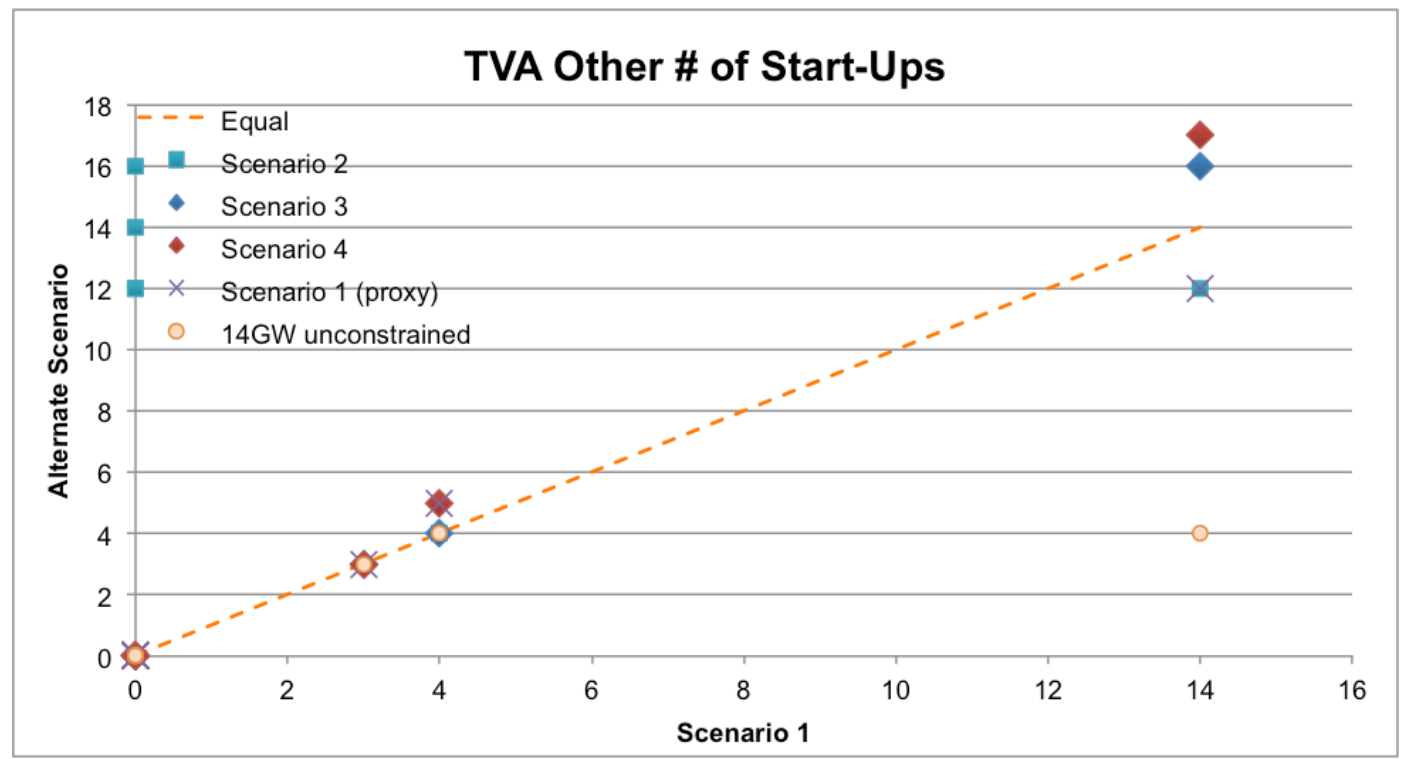

Figure 41. TVA Other \# of Start-Ups 


\section{Southern}

The Southern Co. planning authority territory has the same capacity mix in both the $14 \mathrm{GW}$ and $48 \mathrm{GW}$ scenarios because no new wind is added in its territory. Southern's main capacity mix is provided by gas (33\% combined cycle, $19 \%$ gas turbine, and $2 \%$ steam) followed by coal-fired plants at $26 \%$. Nuclear power provides $11 \%$ of capacity while Hydro provides $7 \%$. There is no wind capacity in the region.

Table 5. Mix of Units in Southern

\begin{tabular}{|l|r|r|r|}
\hline & $\begin{array}{c}\text { Number of } \\
\text { Units }\end{array}$ & $\begin{array}{c}\text { Capacity } \\
\text { (MW) }\end{array}$ & $\begin{array}{c}\text { Capacity Mix with } \\
\mathbf{1 4} \text { or 48 GW wind }\end{array}$ \\
\hline CC & 98 & 23,499 & $33 \%$ \\
\hline Steam Coal & 43 & 18,640 & $26 \%$ \\
\hline Steam Gas/Oil & 54 & 1,758 & $2 \%$ \\
\hline GT & 144 & 13,654 & $19 \%$ \\
\hline Nuclear & 8 & 7,998 & $7 \%$ \\
\hline Hydro & 61 & 4,769 & $0 \%$ \\
\hline Wind & 0 & 0 & $2 \%$ \\
\hline Other & 58 & 1,673 & $100 \%$ \\
\hline Total & 466 & 71,992 & \\
\hline
\end{tabular}




\subsection{Combined Cycle Plants}

All of Southern's combined cycle plants see increased activity in the 14 GW scenario because of the extra generation needed. In Scenario 2 the need for increased balancing in the Southern region increases the use of combined cycle. Meanwhile, Scenarios 3 and 4 show decreased use as more cost-effective resources are used to provide generation, either within Southern territory or other regions.

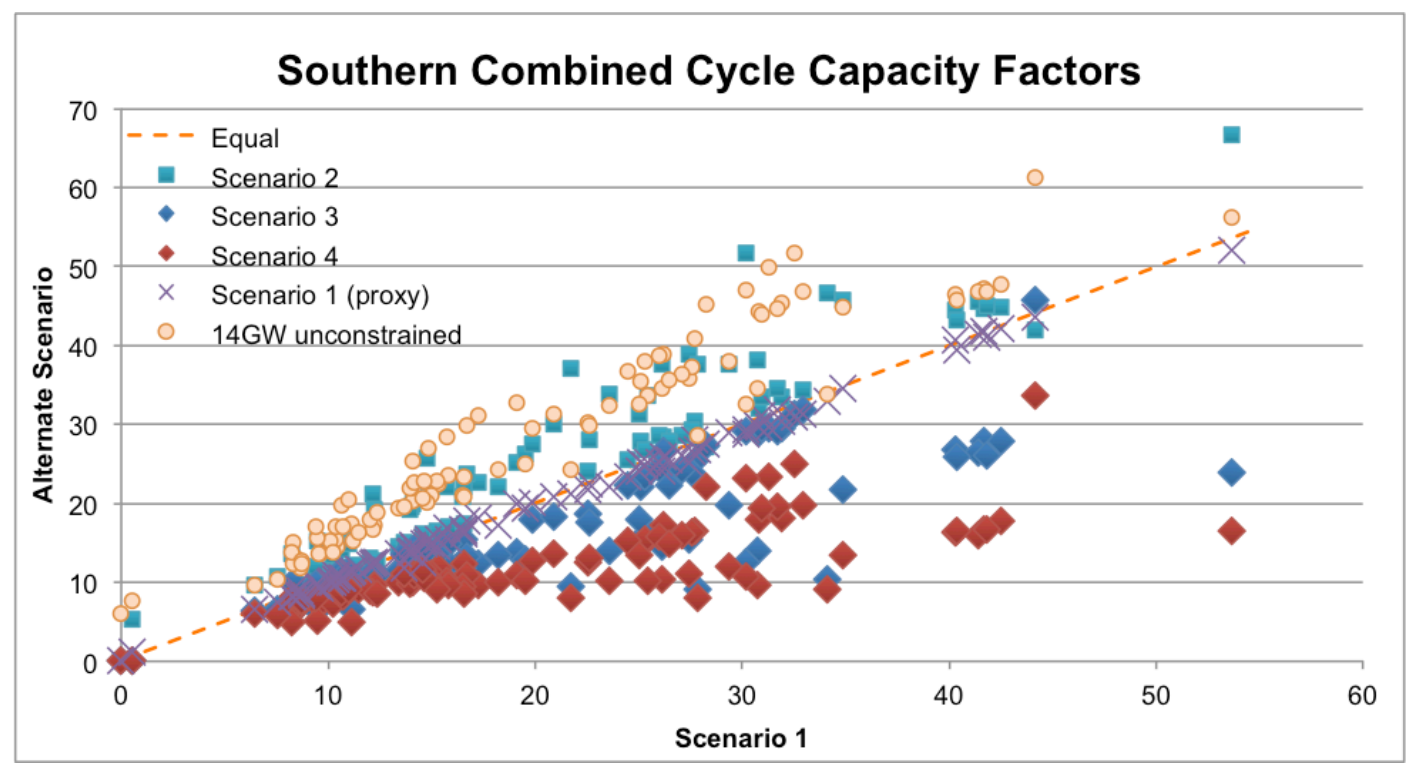

Figure 42. Southern Combined Cycle Capacity Factors

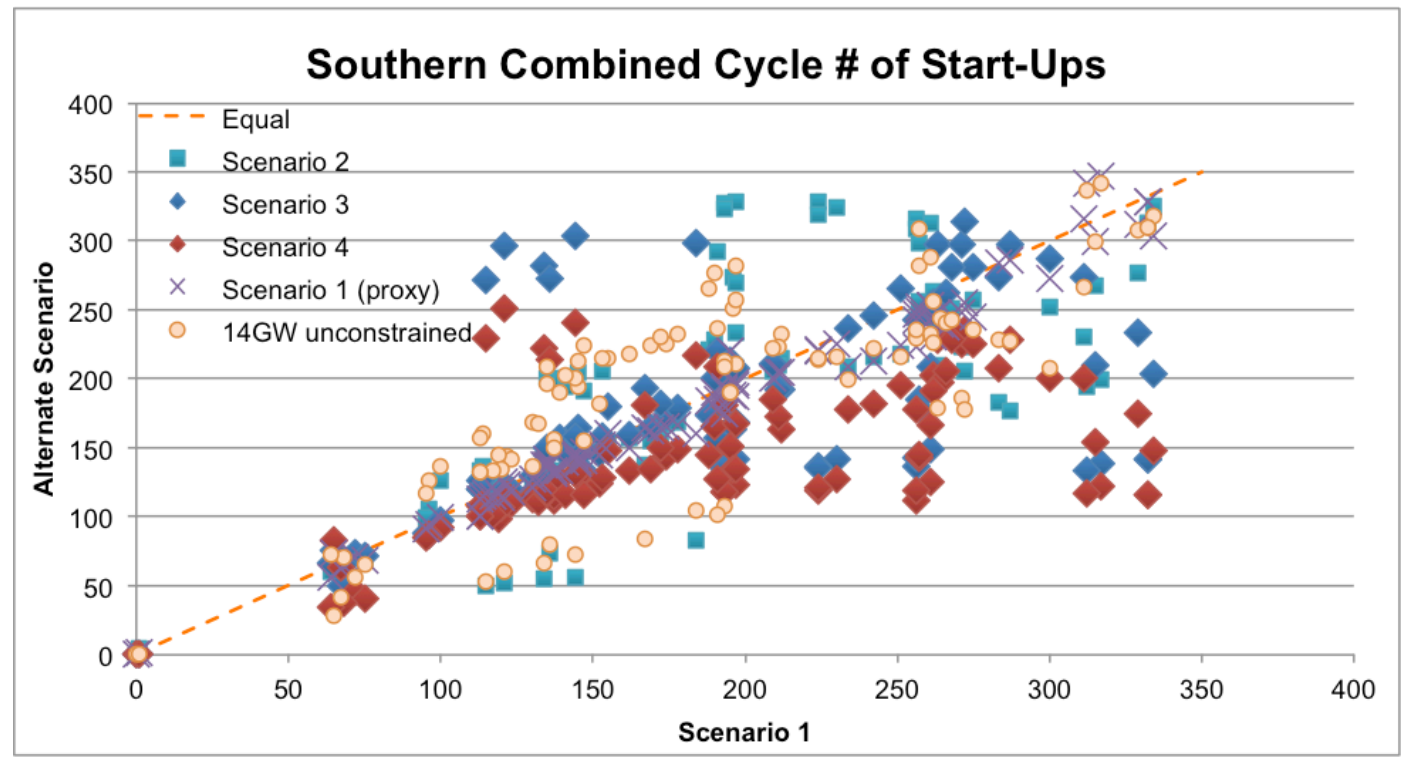

Figure 43. Southern Combined Cycle \# of Start-Ups 


\subsection{Coal-fired Steam Plants}

Most of the coal plants have high, baseload level capacity factors, but a few coal plants have very low capacity factors. They have higher numbers of start-ups, reflecting that they are used as occasional peaking plants due to the cost and efficiency. There are slight variations in plant capacity factors between scenarios, while start-ups varies more frequently, at least for those peaking plants with low capacity factors.

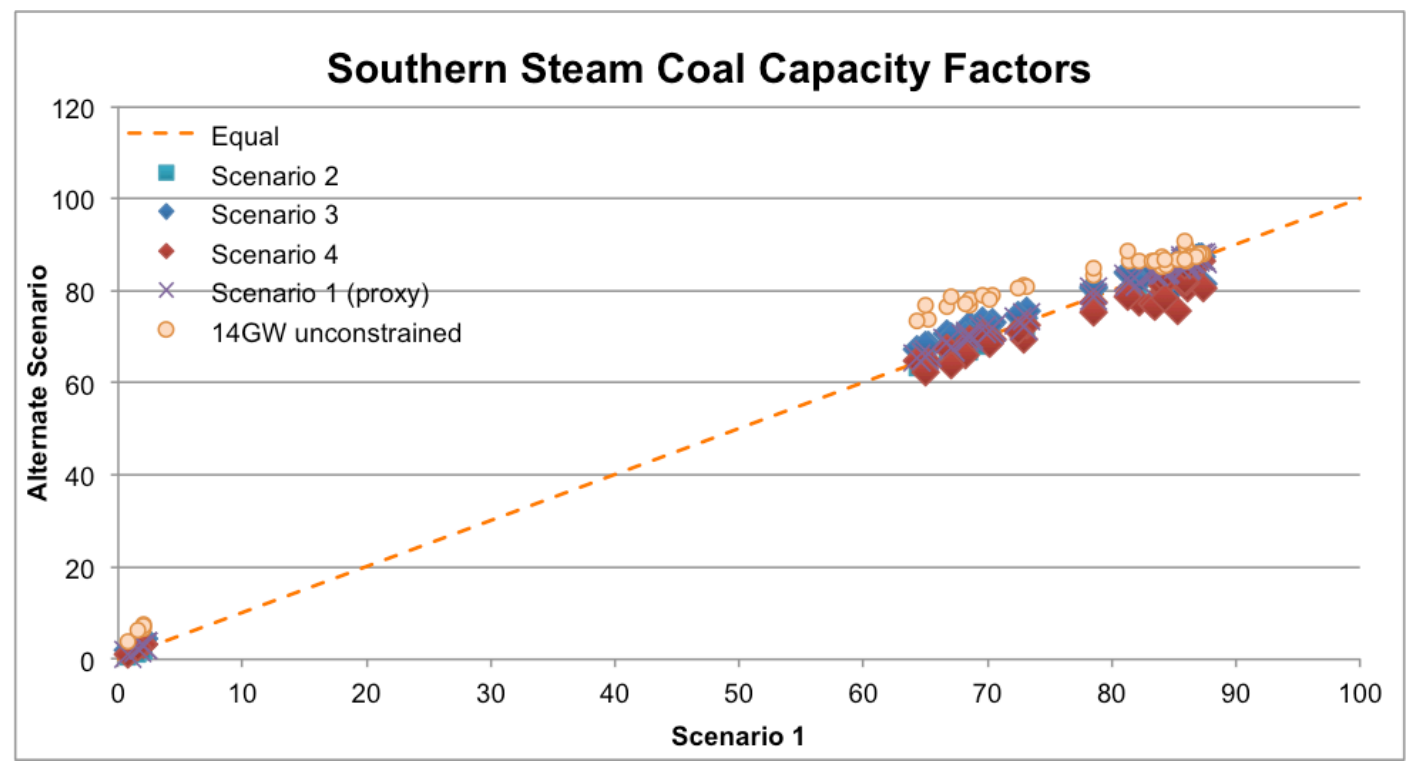

Figure 44. Southern Coal-fired Steam Plant Capacity Factors

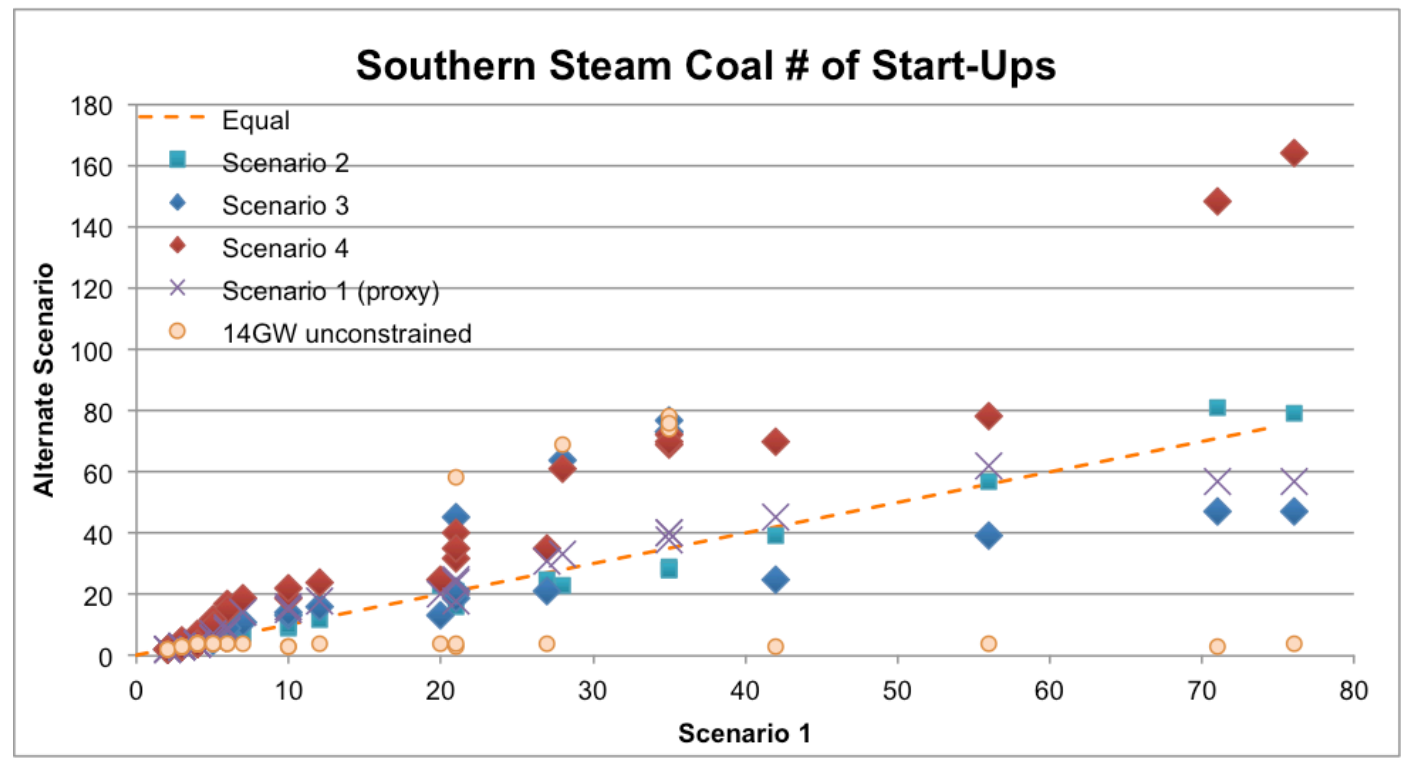

Figure 45. Southern Coal-fired Steam Plant \# of Start-Ups 


\subsection{Gas/Oil-fired Steam Plants}

One gas/oil-fired plant has a capacity factor over $10 \%$ and over 120 start-ups in the $14 \mathrm{GW}$ scenario, but these drop to zero in the $48 \mathrm{GW}$ scenarios. None of the other plants had capacity factors over $0.15 \%$ and are not called upon more than five times over the year.

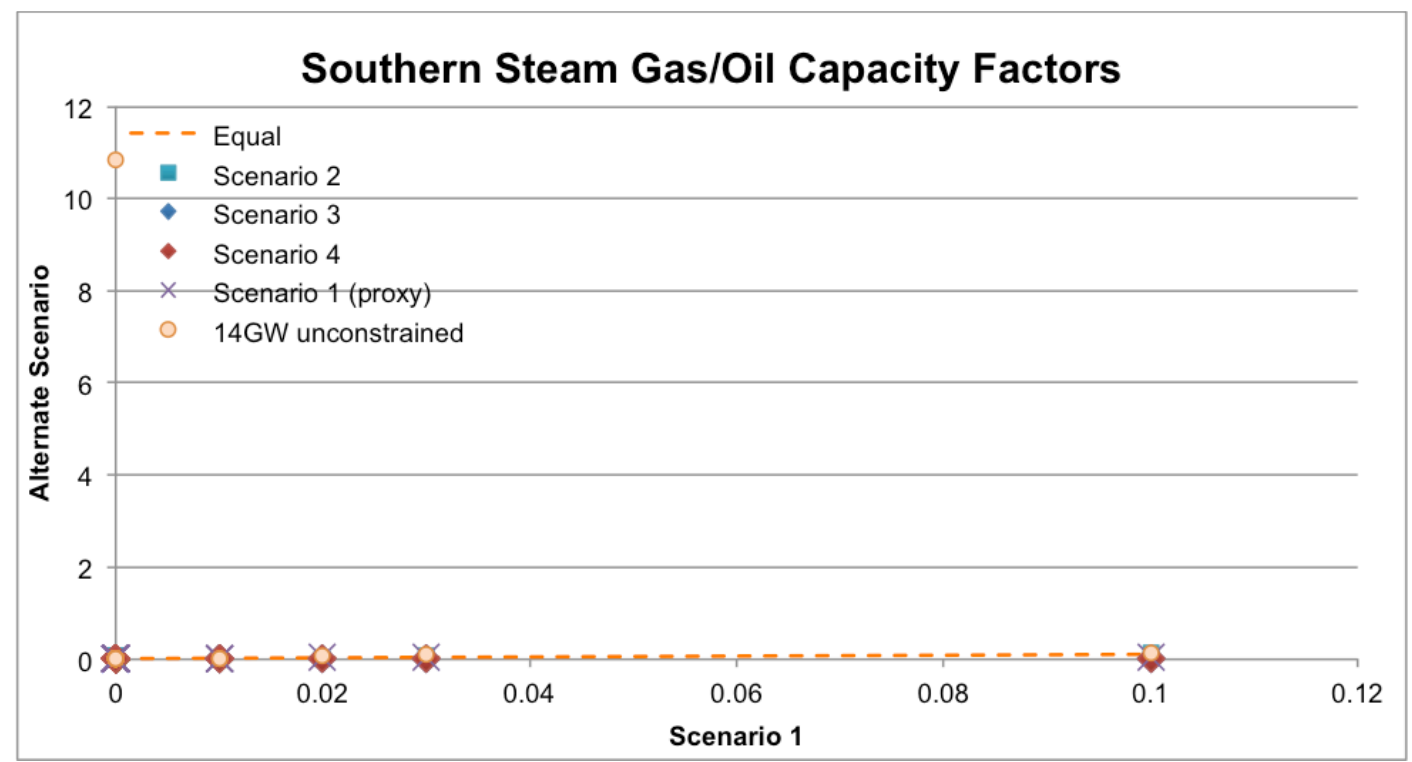

Figure 46. Southern Gas/Oil-fired Steam Plant Capacity Factors

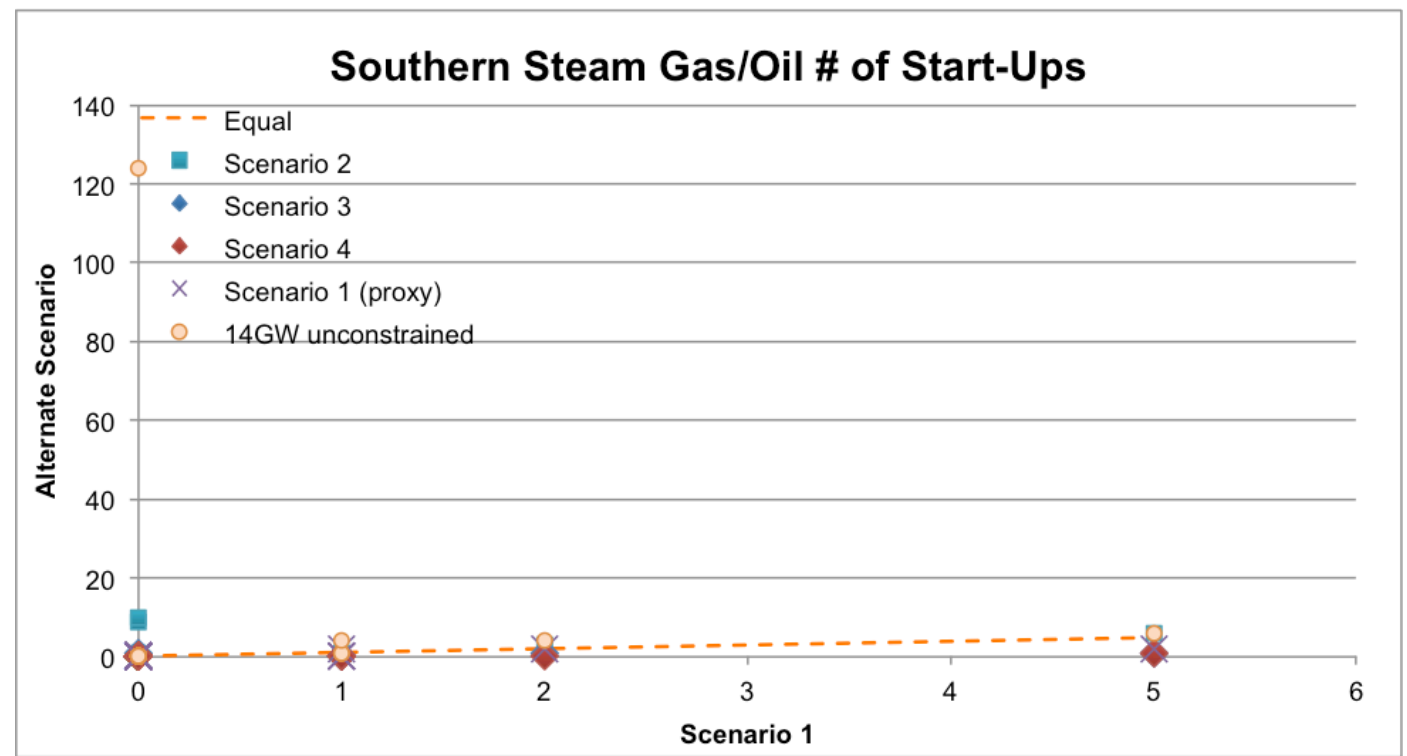

Figure 47. Southern Gas/Oil-fired Steam Plant \# of Start-Ups 


\subsection{Gas-Fired Turbines}

Southern's gas turbines have low capacity factors since they operate as peakers. The $14 \mathrm{GW}$ scenario results in some increase, as would be expected because of less overall capacity in the system. There are two turbines (along the left axis) that see no operation in Scenario 1 but have capacity factors of $24 \%$ and $28 \%$ in the $14 \mathrm{GW}$ scenario. These two Hartwell Energy plants are owned by Oglethorpe Power Corp, but it is otherwise unclear why these two plants are significantly more used in that scenario. Scenarios 3 and 4 show a reduction in capacity factor and startups since the unified balancing allows more efficient plants (such as SPP coal plants and Entergy gas plants) to be used more.

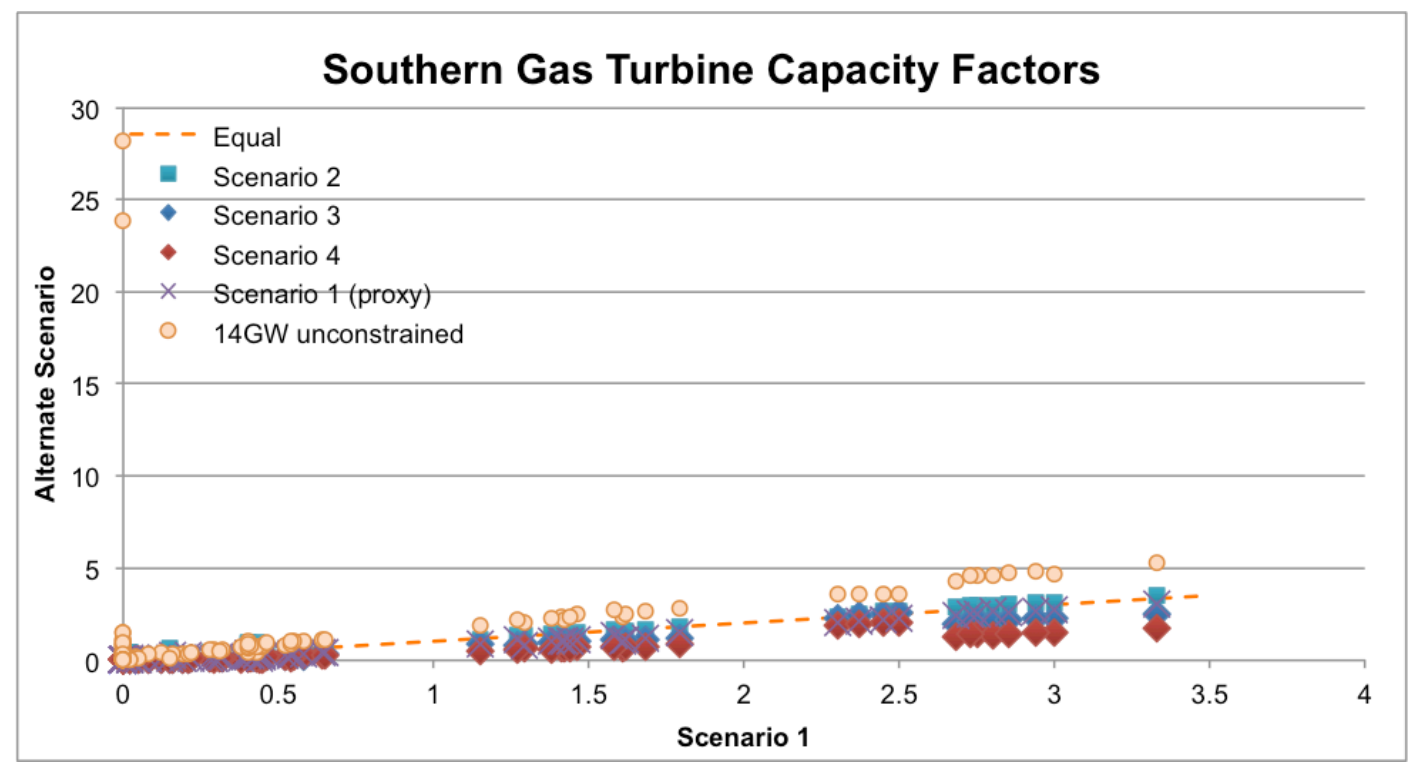

Figure 48. Southern Gas Turbine Capacity Factors

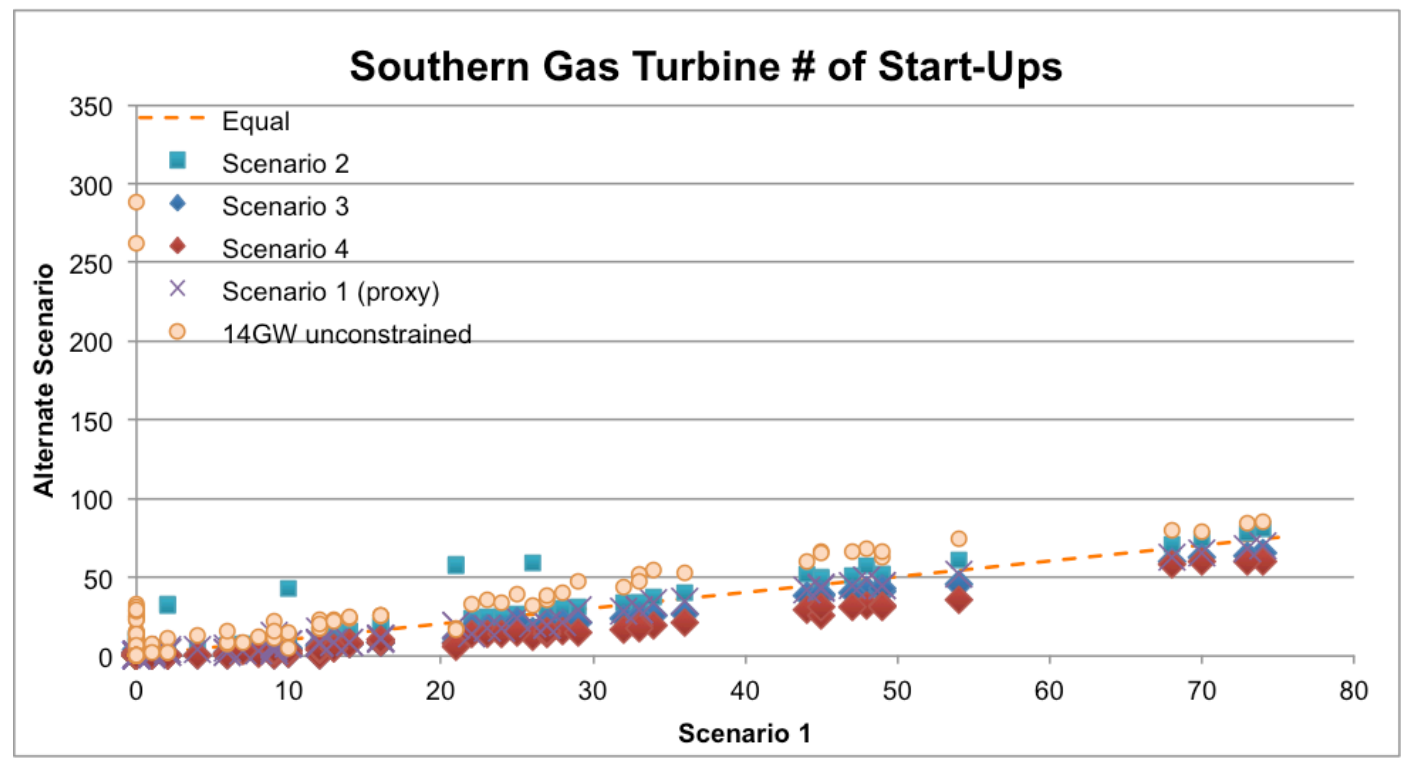

Figure 49. Southern Gas Turbine \# of Start-Ups 


\subsection{Nuclear and Hydro}

All of Southern's 8 nuclear units operate at baseload capacity factors while the 61 hydro units operate the same in all scenarios, as defined by their input generation schedules. Some of the units at Carters, Rochy Mountain, and Wallace Dam, have high numbers of start-ups while all others are listed at two or less.

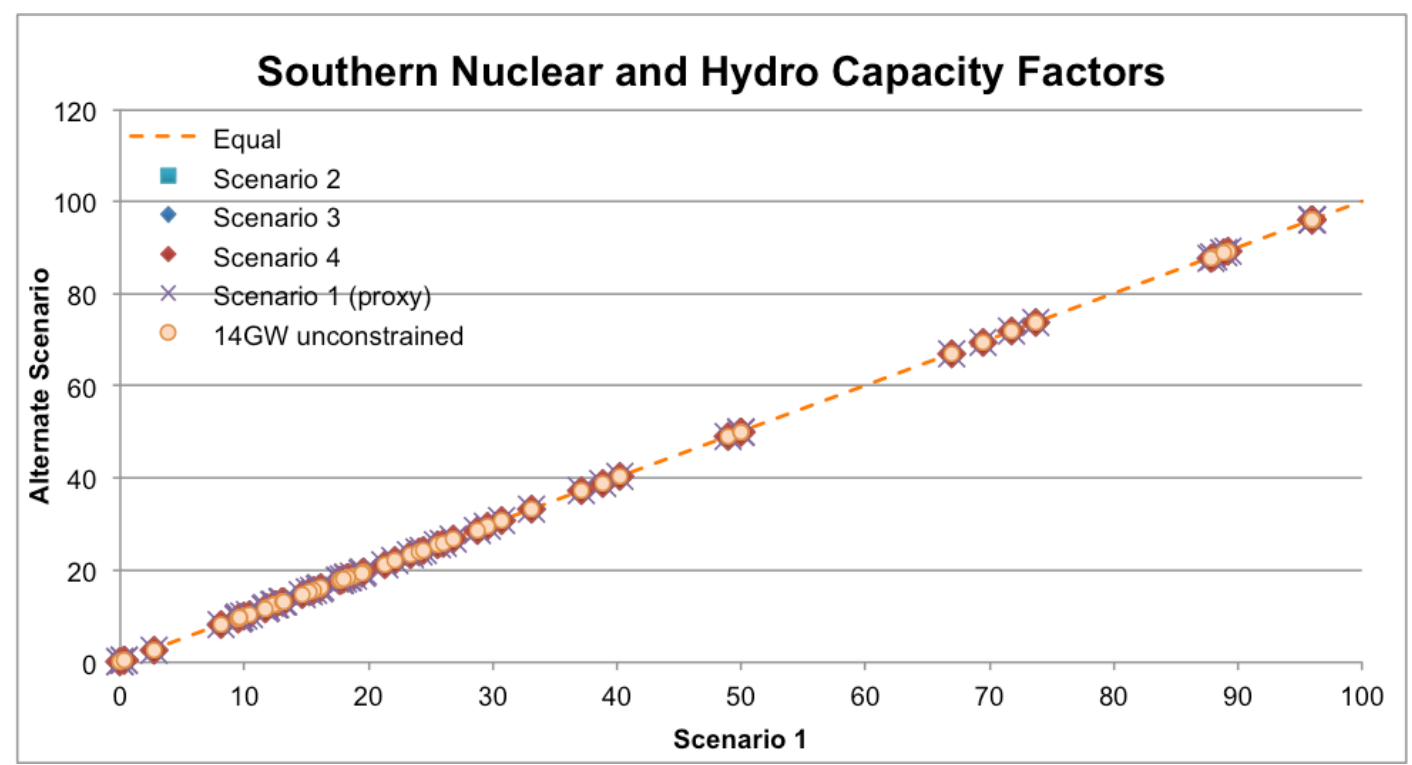

Figure 50. Southern Nuclear and Hydro Capacity Factors

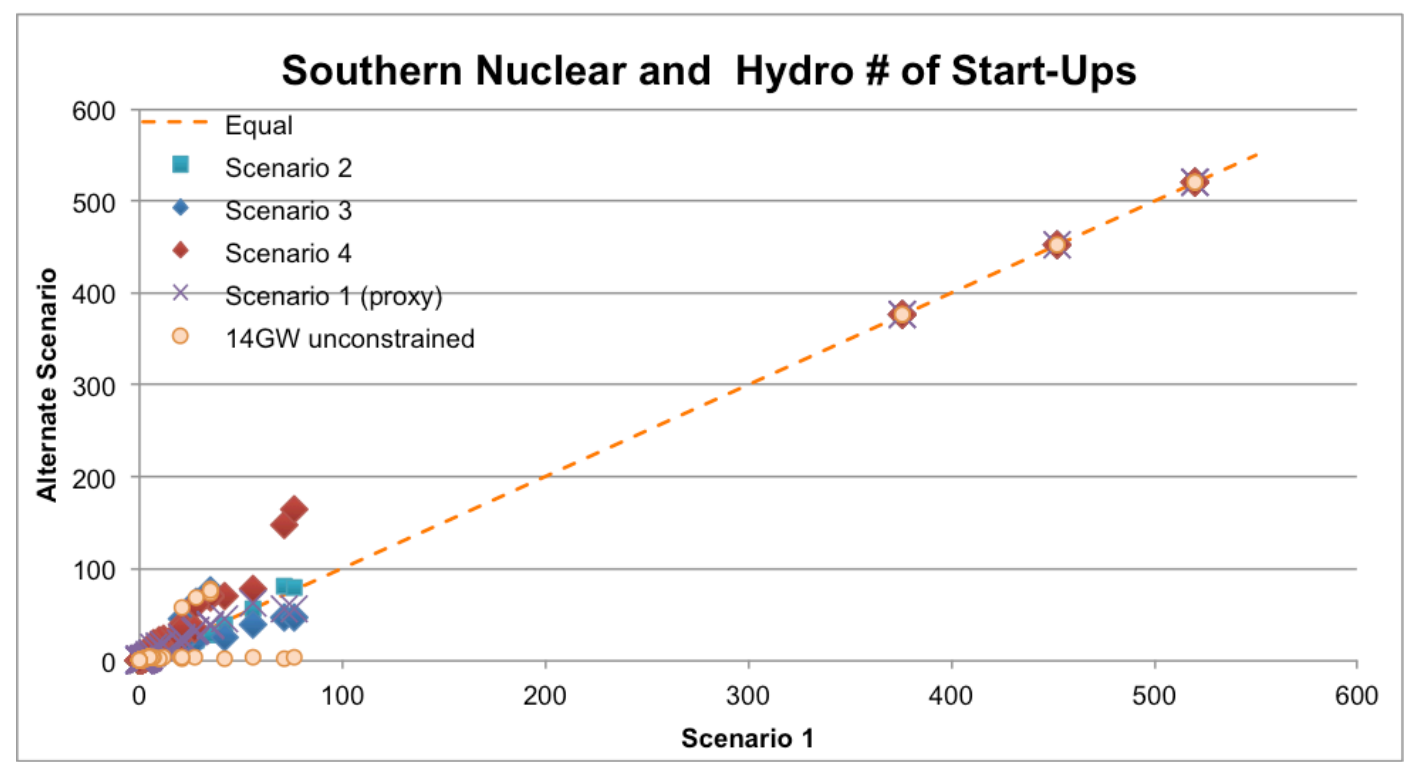

Figure 51. Southern Nuclear and Hydro \# of Start-Ups 


\subsection{Wind}

None

\subsection{Other}

Southern's "Other" category refers to a mixture of internal combustion, cogeneration, landfill gas, municipal solid waste, wood products, combustion turbines, and other technologies. One third of the capacity is from the Kemper County IGCC, while another third is from the Hawk Road gas-fired combustion turbines owned by Oglethorpe Power Corp. The Kemper plant and several of the cogeneration facilities operate at baseload levels, while most of the other plants operate only as peaking plants or not at all.

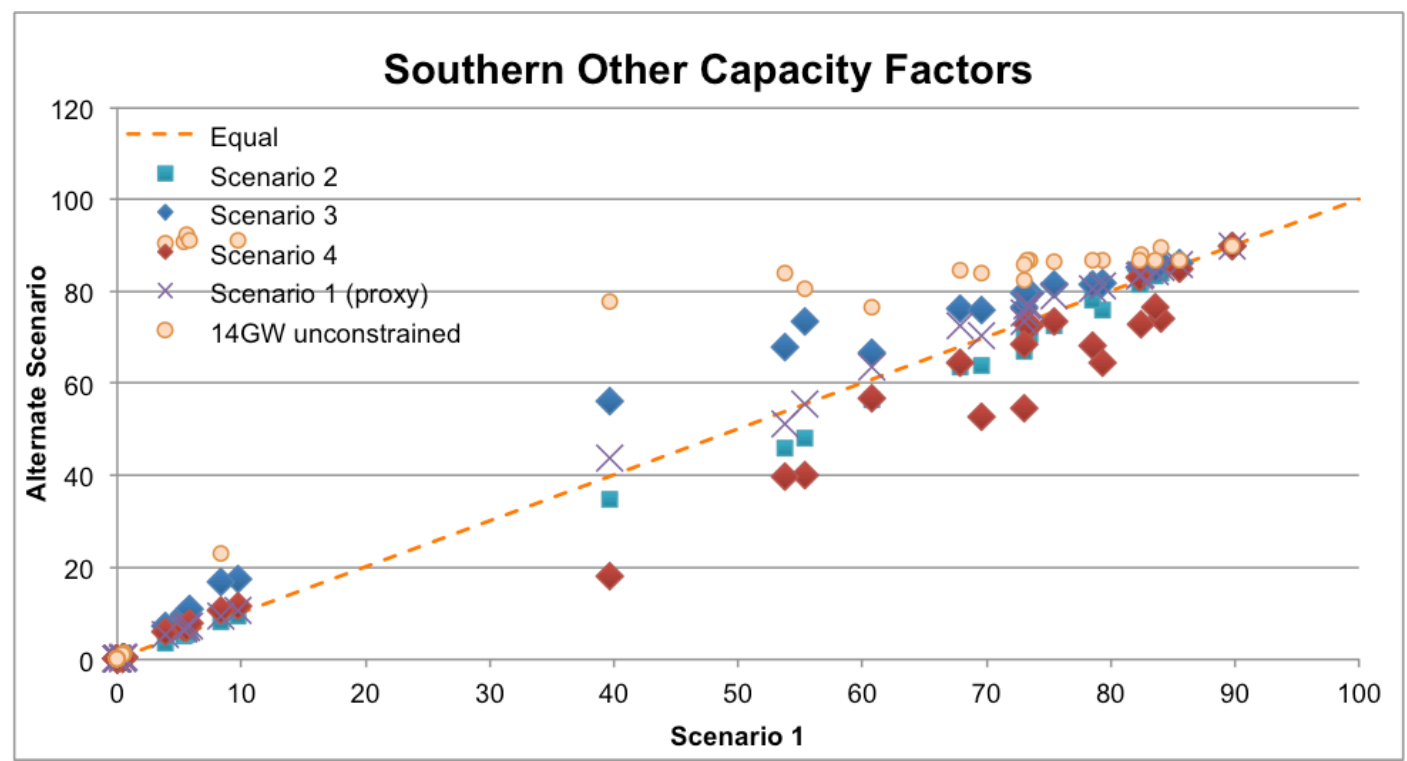

Figure 52. Southern Other Capacity Factors

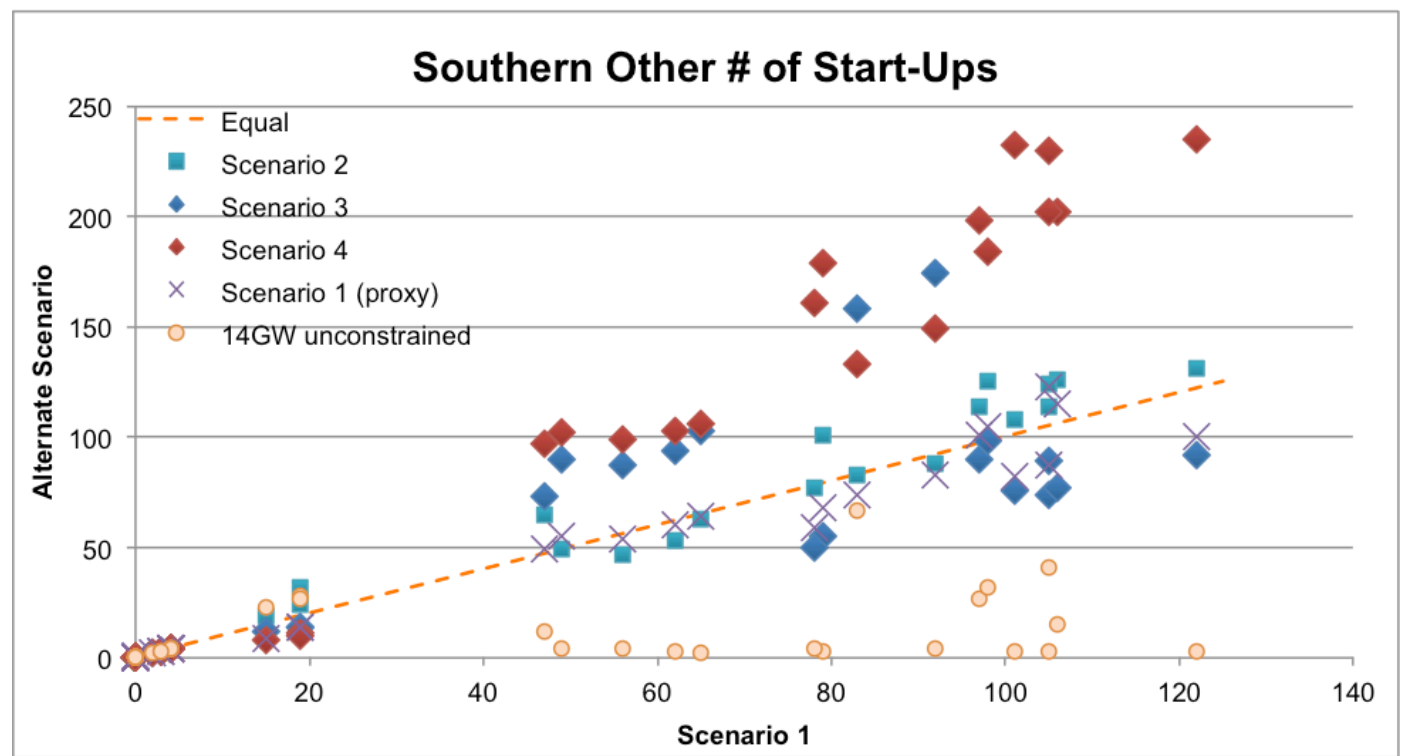

Figure 53. Southern Other \# of Start-Ups 


\section{Summary}

The figures above show that while general trends can be found by examining the operation of plant types as a whole, the actual modeling gives an idea of the broad envelope that individual plants may operate in. For some technologies, the different scenarios have little impact on the operations of individual plants in a region, but other technologies could show wide variations.

Capacity factors change the most for those technologies that are frequently used for significant generation but can be on the margin. As other supplies increase they are called upon less often. For example, TVA coal plant (Figure 32) that have a high capacity factor in Scenario 1 show a small increase when wind capacity is reduced in the $14 \mathrm{GW}$ scenario, while those coal plants with a lower capacity factor (and are likely on the margin more often) have a larger increase.

Another key factor is the flexibility of the technology; combined cycle plants are called upon more when they are needed for balancing purposes than coal plants that cannot provide balancing as easily. For example, SPP's combined cycle capacity factors (Figure 2) decline while its coal capacity (Figure 4) sees an increase in capacity factor as the balancing requirement shifts from SPP to the other regions in Scenarios 2, 3, and 4. With less balancing needed, the region's lower cost coal plants can provide more of the demand.

Peaking plants show similar changes in the number of start-ups parameter as in the change in their capacity. With different requirements for balancing, the peakers are called upon more or less frequently, with a consequent similar change in the total amount of energy from them. This can be seen in comparing the combustion turbine capacity factors and start-ups for any of the four regions. For example, TVA's CT capacity factors (Figure 34) and start-ups (Figure 35) have very similar shapes, with a proportionately large increase in Scenario 2 compared to Scenario 1. The turbines are used for balancing TVA's share of the wind capacity out of SPP in Scenario 2.

Overall, the regions' combined cycle plants had the most variations between the scenarios. As the marginal or swing supply for much of the time, changes in a region's balancing requirements or overall generation were most reflected in this technology. This is reflected in the amount of spread between scenarios for the different regions. The points for the combined cycle plants are generally much more scattered than for other technologies. 


\section{Reference}

EPRI 2011, DOE: Integrating Midwest Wind Energy into Southeast Electricity Markets: Final Report, DE-EE0001377, Electric Power Research Institute, October. 